TA7 W34h

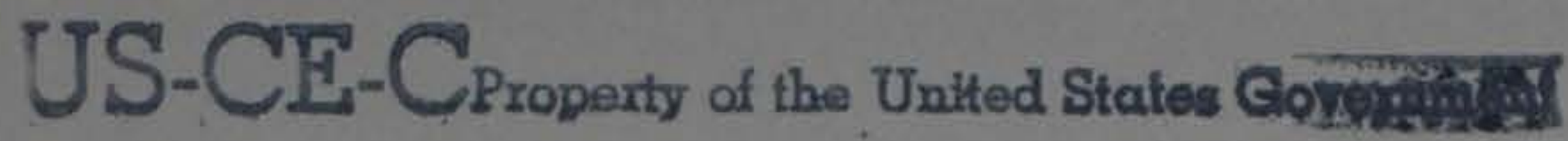
no. SL-8 $2-9$ $\cos \cdot 3$

\title{
ini:i:
}

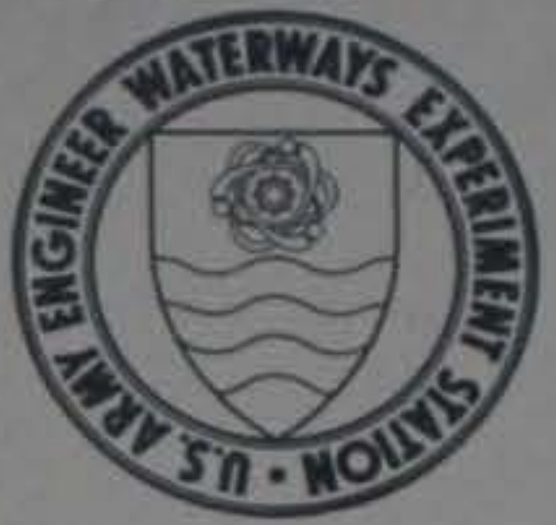

MISCELLANEOUS PAPER SL-82-9

\section{THERMAL STUDIES OF HEMSS CYLINDRICAL TEST BEDS CONTAINING SRI-RMG-2C4 GROUT}

\author{
by \\ Anthony A. Bombich \\ Structures Laboratory \\ U. S. Army Engineer Waterways Experiment Station \\ P. O. Box 631, Vicksburg, Miss. 39180
}

July 1982

Final Report

Approved For Public Release; Distribution Unlimited

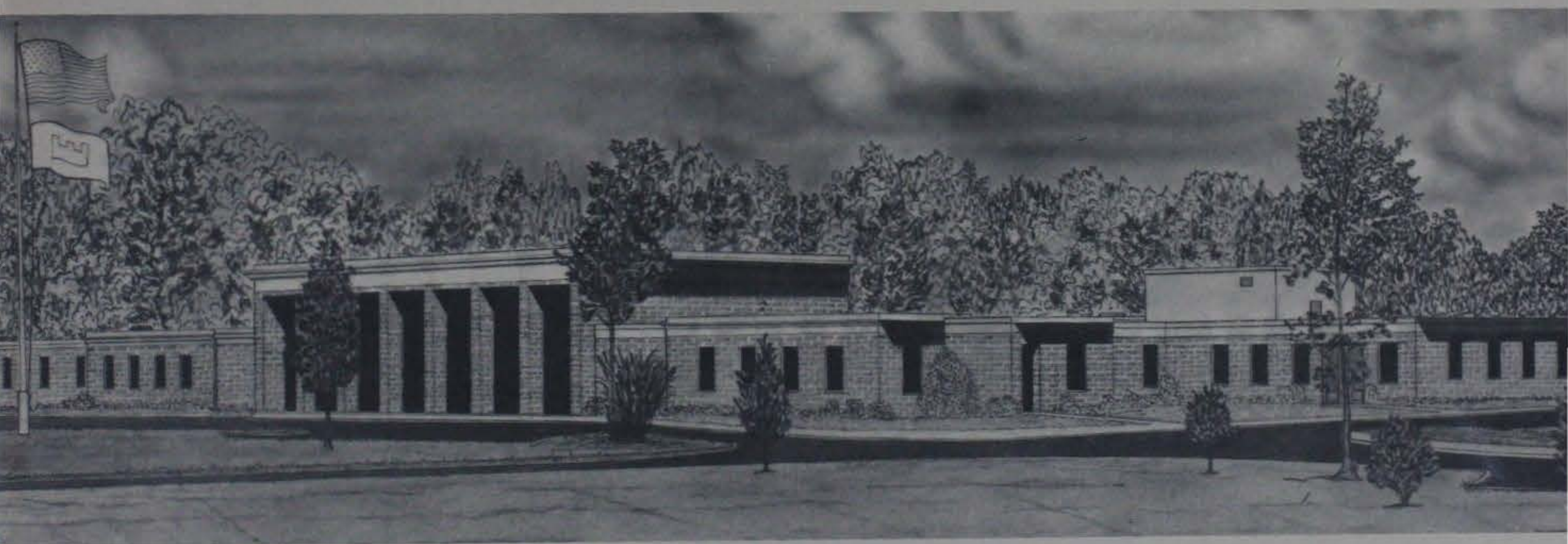

Prepared for Defense Nuclear Agency

Washington, D. C. 20305

Under DNA SUbtask J34HAXSX311

TECHNICAL INFORMATION CENTER

US ARMY ENGINEER WATERWAYS EXPERIMENT STATION VICKSBURG, MISSISSIPPI 
Unclassified

SECURITY CLASSIFICATION OF THIS PAGE (When Date Entered)

\begin{tabular}{|c|c|}
\hline REPORT DOCUMENTATION PAGE & $\begin{array}{c}\text { READ INSTRUCTIONS } \\
\text { BEFORE COMPLETING FORM }\end{array}$ \\
\hline $\begin{array}{l}\text { 1. REPORT NUMBER } \\
\text { Miscellaneous Paper SL-82-9 }\end{array}$ & 3. RECIPIENT'S CATALOG NUMBER \\
\hline \multirow{2}{*}{$\begin{array}{l}\text { 4. TITLE (and Subttie) } \\
\text { THERMAL STUDIES OF HEMSS CYLINDRICAL TEST BEDS } \\
\text { CONTAINING SRI-RMG-2C4 GROUT }\end{array}$} & $\begin{array}{l}\text { 5. TYPE OF REPORT \& PERIOD COVERED } \\
\text { Final report }\end{array}$ \\
\hline & 6. PERFORMING ORG. REPORT NUMBER \\
\hline $\begin{array}{l}\text { 7. AUTHOR(o) } \\
\text { Anthony A. Bombich }\end{array}$ & 8. CONTRACT OR GRANT NUMBER(a) \\
\hline $\begin{array}{l}\text { 9. PERFORMING ORGANIZATION NAME AND ADDRESS } \\
\text { U. S. Army Engineer Waterways Experiment Station } \\
\text { Structures Laboratory } \\
\text { P. O. Box } 631 \text {, Vicksburg, Miss. } 39180\end{array}$ & $\begin{array}{l}\text { 10. PROGRAM ELEMENT, PROJECT, TASK } \\
\text { AREA \& WORK UNIT NUMBERS } \\
\text { DNA Subtask } \\
\text { J34HAXSX } 311\end{array}$ \\
\hline \multirow{2}{*}{$\begin{array}{l}\text { 11. CONTROLLING OFFICE NAME AND ADDRESS } \\
\text { Defense Nuclear Agency } \\
\text { Washington, D. C. } 20305\end{array}$} & $\begin{array}{l}\text { 12. REPORT DATE } \\
\text { July } 1982\end{array}$ \\
\hline & $\begin{array}{l}\text { 13. NUMBER OF PAGES } \\
55\end{array}$ \\
\hline \multirow[t]{2}{*}{ 14. MONITORING AGENCY NAME \& ADDRESS(If different from Controlling Offico) } & $\begin{array}{l}\text { 15. SECURITY CLASS. (of this roport) } \\
\text { Unclassified }\end{array}$ \\
\hline & $\begin{array}{l}\text { 15a. DECLASSIFICATION/DOWNGRADING } \\
\text { SCHEDULE }\end{array}$ \\
\hline
\end{tabular}

Approved for public release; distribution unlimited.

17. DISTRIBUTION STATEMENT (of the abstract ontered in Block 20, if different from Report)

18. SUPPLEMENTARY NOTES

Available from National Technical Information Service, 5285 Port Royal Road, Springfield, Va. 22151.

This is CTIAC Report No. 56.

19. KEY WORDS (Continuo on reverse side if nocessary and idontify by block number)

Computer programs

Nuclear explosions

Cylinders

Thermal properties.

Grouts

20. ABSTAACT (Continue an roveres sich it necosaly and tdentify by block number)

Large cylindrical test beds $2.13 \mathrm{~m}$ ( $7 \mathrm{ft}$ ) in diameter and cast from SRIRMG-2C4 grout were used by Merritt CASES, Inc., and Physics International Company to investigate the simulation of nuclear test effects on deep-based structures in the "High-Explosive Model Structure Simulation (HEMSS) Program." $2 \mathrm{C} 4$ grout was used in the test beds and reached temperatures in excess of $108^{\circ} \mathrm{C}$ $\left(226^{\circ} \mathrm{F}\right)$ in HEMSS No. 1 and 2 cylinders. Although the grout properties were wel1 documented, the effects of heat of hydration on the grout

(Continued) 


\section{ABSTRACT (Continued)}

when cast in large volumes were unknown.

Thermal studies of the HEMSS cylinders were conducted at the U. S. Army Engineer Waterways Experiment Station (WES) based upon computer simulations. These studies were conducted to determine the thermal response of 2C4 grout placed in mass. The computer simulations were conducted in four groups. Group I runs were conducted to duplicate the thermal histories in the HEMSS No. 1 cylinder, including the establishment of thermal properties. Group II computer runs were made to evaluate several temperature control measures which could be employed on future HEMSS test beds to reduce internal temperature and potential excessive thermal stress or strain. Measures recommended included reducing placement temperature and ventilating the $0.3048-\mathrm{m}(1-\mathrm{ft})$ hole at the axis of the cylinders. Group III runs predicted temperatures in the HEMSS No. 3 cylinder while evaluating the effects of the diurnal ambient temperature cycle and the several attainable placement temperatures. Group IV runs included postcasting temperature and thermal stress-strain evaluation of the 2.13-m (7-ft) diameter HEMSS No. 3 cylinder as well as the same analysis on potential $3.66-$ and 6.10-m (12- and 20-ft) diameter cylinders.

The study showed that the finite-element method temperature simulation program in use at WES could predict temperature distribution in the HEMSS cylinders as a function of time after casting. Temperature in the 2.13-m (7-ft) diameter cylinders could only be effectively controlled by lowering the placement temperature of the grout. Simulations of $3.66-$ and $6.10-m(12-$ and $20-f t)$ diameter cylinders indicated increasing peak temperature and thermal strains as cylinder diameter increased. With conditions similar to those of the HEMSS No. 3 cylinder, a $6.10-\mathrm{m}(20-\mathrm{ft})$ diameter cylinder is predicted to reach a peak temperature of $116^{\circ} \mathrm{C}\left(240^{\circ} \mathrm{F}\right)$. It is recommended that additional work be done to document the properties of $2 \mathrm{C} 4$ grout when cured at temperatures at or near $100^{\circ} \mathrm{C}\left(212^{\circ} \mathrm{F}\right)$. 


\section{Preface}

This study was conducted in the Structures Laboratory (SL) of the U. S. Army Engineer Waterways Experiment Station (WES) under the sponsorship of the Defense Nuclear Agency as part of the FY 1978 Nuclear Weapons Effects Program, Subtask J34HAXSX311, "Underground Structures."

The study was conducted under the general supervision of $\mathrm{Mr}$. Bryant Mather, Chief, SL, and Mrs. Katharine Mather, former Chief, Engineering Sciences Division, and under the direct supervision of Mr. Billy R. Sullivan, former Chief, Engineering Physics Branch. Mr. Anthony A. Bombich was project leader and prepared this report.

Funds for publication of the report were provided from those made available for operation of the Concrete Technology Information Analysis Center (CTIAC). This is CTIAC Report No. 56.

Commander and Director of WES when this report was published was COL Tilford C. Cree1, CE. Technical Director was Mr. F. R. Brown. 


\section{Contents}

Page

Preface

Conversion Factors, Non-SI to SI (Metric)

Units of Measurement

Introduction

Temperature Calculations

Group I temperature runs . . . . . . . . . . . . . 8

Group II temperature runs . . . . . . . . . . . . . 9

Group III temperature runs . . . . . . . . . . . . . 10

Group IV temperature runs . . . . . . . . . . . . 12

Thermal Stress-Strain Simulations . . . . . . . . . . . . 15

2.13-m (7-ft) cylinder . . . . . . . . . . . . . . 17

3.66- and 6.10-m (12- and 20-ft) cylinders . . . . . . 18

Conclusions and Recommendations . . . . . . . . . . . . . 19

References .. . . . . . . . . . . . . . . . . . 24

Table 1

Figures 1-23 
Non-SI units of measurement used in this report can be converted to SI (metric) units as follows:

\begin{tabular}{|c|c|c|}
\hline Multiply & By & To Obtain \\
\hline $\begin{array}{l}\text { British thermal unit } \\
\text { (International table) } \cdot \text { feet } \\
\text { per hour } \text { · square foot } \\
\text { degree Fahrenheit }\end{array}$ & 1.730735 & $\begin{array}{l}\text { watts per metre } \\
\text { Kelvin }\end{array}$ \\
\hline $\begin{array}{l}\text { British thermal units } \\
\text { (International table) per } \\
\text { pound (mass) } \cdot \text { degree } \\
\text { Fahrenheit }\end{array}$ & 4186.8 & $\begin{array}{l}\text { joules per } \\
\text { kilogram } \cdot \text { Kelvin }\end{array}$ \\
\hline $\begin{array}{l}\text { calories (International table) } \\
\text { per gram }\end{array}$ & 4186.8 & joules per kilogram \\
\hline cubic feet per minute & 0.0004719474 & $\begin{array}{l}\text { cubic metres per } \\
\text { second }\end{array}$ \\
\hline Fahrenheit degrees & $5 / 9$ & $\begin{array}{l}\text { Celsius degrees or } \\
\text { Kelvins* }\end{array}$ \\
\hline feet & 0.3048 & metres \\
\hline feet per second & 0.3048 & metres per second \\
\hline inches & 0.0254 & metres \\
\hline $\begin{array}{l}\text { inches per inch per degree } \\
\text { Fahrenheit }\end{array}$ & $5 / 9$ & $\begin{array}{l}\text { metres per metre } \\
\text { per Kelvin }\end{array}$ \\
\hline miles (U. S. statute) per hour & 1.609347 & kilometres per hour \\
\hline pounds (force) per square inch & 0.006894757 & megapascals \\
\hline pounds (force) per square inch & 6894.757 & pascals \\
\hline pounds (mass) per cubic foot & 16.01846 & $\begin{array}{l}\text { kilograms per cubic } \\
\text { metre }\end{array}$ \\
\hline square feet per hour & 0.0000258064 & $\begin{array}{l}\text { square metres per } \\
\text { second }\end{array}$ \\
\hline
\end{tabular}

* To obtain Celsius (C) temperature readings from Fahrenheit (F) readings, use the following formula: $C=(5 / 9)(F-32)$. To obtain Kelvin $(K)$ readings, use: $K=(5 / 9)(F-32)+273.15$. 
THERMAL STUDIES OF HEMSS

CYLINDRICAL TEST BEDS

CONTAINING SRI-RMG-2C4 GROUT

\section{Introduction}

1. This study was conducted at the U. S. Army Engineer Waterways Experiment Station (WES) to evaluate the heat generated by SRI-MRG-2C4 grout cast in large cylindrical test beds. Merritt CASES, Inc., and Physics International Company are conducting the "High-Explosive Model Structure Simulation (HEMSS) Program" for the Defense Nuclear Agency (DNA) to investigate the simulation of nuclear test effects on deepbased structures using high explosives (HE) in rock simulant test beds. The 2C4 grout is a tuff simulant. This grout, originally developed at WES and later modified by Stanford Research Institute (SRI), was chosen from among several other grout mixtures after comparing its mechanical properties with those of Nevada Test Site tuff. Its static response is well documented. However, the effects of heat of hydration when the grout is cast in large volumes were unknown. The composition in percent by weight of SRI-RMG-2C4 is:

Type G portland cement (or Type I-II)

32.691

Sand (20-40) Monterey

21.896

Barite (barium sulfate)

20.848

Bentonite (gel)

D65 (concrete friction reducing compound)

0.078

Water

21.650

2. When this study began, two cylinders designated HEMSS No. 1 and No. 2, $2.13 \mathrm{~m} \mathrm{(7} \mathrm{ft)*} \mathrm{in} \mathrm{diameter} \mathrm{and} 4.27 \mathrm{~m} \mathrm{(14} \mathrm{ft)} \mathrm{in} \mathrm{height,} \mathrm{had}$ been cast. A $0.3048-\mathrm{m}(1-\mathrm{ft})$ diameter vertical hole was located concentric with the axis of each cylinder. It was understood that the holes were not vented. The assumption was made at WES that near-adiabatic

* A table of factors for converting non-SI units of measurement to SI (metric) units is presented on page 3 . 
conditions existed at the hole at the inner surface of the cylinders. Thermistors had been used to measure temperatures in the cylinders for approximately the first 6 days after placement. The thermistors were located on a radius at equal increments of $0.229 \mathrm{~m}$ ( $9 \mathrm{in.}$ ) between the inner and outer surfaces of the cylinders. Peak temperatures recorded in HEMSS No. 1 and No. 2 at a distance of $0.229 \mathrm{~m}$ ( 9 in.) from the inner surface were 108 and $128 \mathrm{C}$ (226 and $262 \mathrm{~F}$ ).

3. The objectives of this study, narrowed from those originally proposed because of a reduced level of funding, included efforts to duplicate analytically the thermal histories of the HEMSS cylinders. In subsequent simulations it was intended to determine the effects of several temperature control measures that could be used in subsequent castings. Finally it was intended to conduct simulations of temperature history and resulting thermal strain in the $2.13-\mathrm{m}$ (7-ft) diameter and in proposed 3.66 - and $6.10-\mathrm{m}$ (12- and 20-ft) diameter cylinders.

4. Two computer programs were used in the study. These are two-dimensional finite-element programs ${ }^{1,} 2$ developed at the University of California, Berkeley, by Wilson, Sandhu, and associates for the U. S. Army Engineer District, Walla Walla. These programs were developed to compute thermal histories and resulting stress-strain histories within mass concrete structures. The programs permit simulation of incremental construction (placement of concrete by lifts), allow varying boundary conditions, and require time-dependent heat generation and mechanical properties.

5. Computer simulations for HEMSS cylinders were conducted in four groups of runs.

a. Group I. Duplicate the results of HEMSS No. 1 inclading establishing estimated thermal properties.

b. Group II. Evaluate the effects of several temperature control measures.

c. Group III. Temperature predictions for HEMSS No. 3.

d. Group IV. Temperature and thermal stress-strain analysis of 2.13-, 3.66-, and 6.10-m (7-, 12-, and 20-ft) diameter cylinders based upon conditions obtained from HEMSS No. 3 measurements. 
6. It was only feasible to do a limited amount of testing to establish the thermal properties of $2 \mathrm{C} 4$ grout for computer input. It was therefore necessary to estimate the properties based upon information available such as the mixture proportions and materials and measured temperatures in the HEMSS No. 1 cylinder. Very little documentation of thermal properties exists for grouts. Estimates of $2 \mathrm{C} 4$ thermal properties were modifications of known thermal behavior of concrete. It is known that the specific heat of concrete increases as temperature increases. It was suspected, and while the report was in progress, learned that the specific heat of the cement and water undergoes an irreversible change during hydration. The work documenting this phenomenon has not yet been received; however, it is known that the specific heat is lowered during hydration. In conventional concrete the total effect of the change is very small because the percentage of water by mass of the mixture is very 1ow. This change in effect reduces the specific heat of water from $4186.8 \mathrm{~J} / \mathrm{kg} \cdot \mathrm{K}\left(1.0 \mathrm{Btu} / 1 \mathrm{~b} \cdot{ }^{\circ} \mathrm{F}\right)$ to $837.4-1256.0 \mathrm{~J} / \mathrm{kg} \cdot \mathrm{K}\left(0.2-0.3 \mathrm{Btu} / 1 \mathrm{~b} \cdot{ }^{\circ} \mathrm{F}\right)$ or near to the specific heat of the cement. In grouts, and in particular in $2 \mathrm{C} 4$ grout, the water content by mass is greater than 20 percent. Since the cement content is very high, the effect on reducing the specific heat of the mixture due to the hydration phase change is greater than in concrete.

7. The specific heat of concrete or grouts is also highly temperature dependent. ${ }^{3}$ For example, specific heat of concrete increases approximately 20 percent as the temperature increases from $21 \mathrm{C}(70 \mathrm{~F})$ to $66 \mathrm{C}$ (150 F) with approximately 20 percent additional increase to $93 \mathrm{C}$ (200 F). Although the increase is less in mixtures containing more water, as is the case with grout, one may assume a 30-40 percent increase in specific heat for 2C4 grout between placement at $21 \mathrm{C}(70 \mathrm{~F})$ and peak temperatures over $93 \mathrm{C}(200 \mathrm{~F})$. The implications of temperature dependence and hydration phase change of specific heat in this study are large. During the initial period when intense hydration is occurring, the specific heat is increasing due to the temperature rise and decreasing with increasing 
hydration or age. As a result of these two inverse functions of temperature and age during temperature rise, the heat required to raise the temperature will be greater than the heat lost as the temperature drops an equivalent amount.

8. Prior studies at WES which included computer calculations of temperature histories in structures containing portland cement concrete mixtures have not considered temperature-dependent thermal properties because the lean concrete mixtures used and substantial temperature controls employed do control temperature rise and temperature dependence. For this reason computer programs currently used were prepared to consider only age-dependent properties. The temperature- and age-dependent properties characteristic of the materials and conditions in the HEMSS cylinders could not be incorporated without additional computer program development. Therefore, thermal properties were established for $2 \mathrm{C} 4$ grout which would yield acceptable comparative thermal simulation with the HEMSS cylinders. A brief discussion of the development of input thermal properties to the computer program follows. A value of $1457 \mathrm{~J} /$ $\mathrm{kg} \cdot \mathrm{K}\left(0.348 \mathrm{Btu} / 1 \mathrm{~b} \cdot{ }^{\circ} \mathrm{F}\right)$ for specific heat was used. This is the initial theoretical value calculated from the mixture proportions and the specific heat of each component material. A value for thermal conductivity was obtained as follows. Conductivity is the product of specific heat, thermal diffusivity, and density. Thermal diffusivity was determined in accordance with CRD-C $36 .^{4}$ Three $76.2-$ by $152.4-\mathrm{mm}$ (3- by 6-in.) cylinders of $2 \mathrm{C} 4$ grout were cast with copper constantan thermocouples embedded at the centroid of each cylinder. Diffusivity conducted on the cylinders at 3 -days age yielded $4.129 \times 10^{-7} \mathrm{~m}^{2} / \mathrm{sec}\left(0.016 \mathrm{ft}^{2} / \mathrm{hr}\right)$. A density of $2160 \mathrm{~kg} / \mathrm{m}^{3}\left(134.78 \mathrm{lb} / \mathrm{ft}^{3}\right)$ was chosen from data provided by CASES. Calculated thermal conductivity was $1.305 \mathrm{~W} / \mathrm{m} \cdot \mathrm{K}(0.754 \mathrm{Btu}$. $\left.\mathrm{ft} / \mathrm{hr} \cdot \mathrm{ft} \mathrm{t}^{2} \cdot{ }^{\circ} \mathrm{F}\right)$.

9. The additional thermal property required is adiabatic temperature rise which provides the heat of hydration history. Experimental testing for adiabatic temperature rise was not included originally because it was known that the high temperatures of $2 \mathrm{C} 4$ grout exceeded the operating limit of existing facilities. During the course of the 
study other existing equipment was being modified to allow at least abbreviated adiabatic tests of mixtures of high temperature rise. Satisfactory operations were not achieved in time for this study. An adiabatic temperature rise history was then obtained from the measured temperature in HEMSS No. 1. It was assumed that temperatures measured during the first day after placement at the location nearest to the axis of the cylinder were adiabatic. To establish the adiabatic history after the first day it was necessary to establish the heat of hydration of the first day relative to the total heat generation possible. Using the measured temperature rise of $66 \mathrm{C}(150 \mathrm{~F})$ after the first day, a specific heat of $1457 \mathrm{~J} / \mathrm{kg} \cdot \mathrm{K}\left(0.345 \mathrm{Btu} / 1 \mathrm{~b} \cdot{ }^{\circ} \mathrm{F}\right)$ for the grout, and the specified cement content, the heat of hydration calculated was $0.364 \mathrm{MJ} / \mathrm{kg}(87 \mathrm{ca} / \mathrm{g})$. This is greater than that typical for 28-day isothermal heat of hydration test results of Type "G" cement; it is also approximately twice that normally measured at 1-day age. Typical 28-day heat of hydration values are perhaps 80-90 percent of the potential heat generation possible in standard tests. It was concluded that because of the initially high temperatures accelerating the rate of hydration that only an additional 10 percent of the total heat would be generated by 28 days and that by 28 days hydration would have ceased. The remaining adiabatic temperature rise history after first day was then fabricated assuming an $11 \mathrm{C}$ (20 F) rise between 1 and 28 days age.

\section{Group I temperature runs}

10. Runs 1-6 were made to establish that input data chosen were sufficiently correct to duplicate the measured temperatures in HEMSS No. 1. A finite-element model was prepared. This model (Figure 1) was a segment of a horizontal plane through the cylinder. Heat was assumed to flow radially or only through the inner or outer cylindrical surfaces. The vertical hole in the center of the cylinder was assumed to be sealed from outside air; thus, in runs 1-6 heat was assumed lost only through the outer surface. In runs 1-6 input properties and ambient air velocities used for the convection heat-transfer coefficient at the outside surface were varied slightly to obtain a set of input data that produced best correlation with measured temperatures. Placement temperature was 
assumed to be $24 \mathrm{C}(75 \mathrm{~F})$ and ambient air was assumed still and $23 \mathrm{C}$ $(73 \mathrm{~F})$. Ambient air velocity was ultimately increased to $0.0762 \mathrm{~m} / \mathrm{sec}$ $(2.5 \mathrm{ft} / \mathrm{sec})$ in run 6 . Table 1 lists the pertinent input data for runs 1-6 as well as all other runs in this study. Figure 2 shows calculated temperatures in run 6 versus measured temperatures in HEMSS No. 1 . The slower rate of temperature drop in run 6 when compared to HEMSS No. 1 after 2 days probably results from some or all of the following: incorrect assumed air velocity, use of constant rather than temperature dependent thermal properties in the calculations, and heat losses to the ends of the cylinder where no such loss was assumed in the calculations. Input data used in run 6 were, however, selected as the best set for subsequent runs. Adiabatic temperature rise used in run 6 as well as all subsequent runs is shown in Figure 3.

Group II temperature runs

11. Runs 7-9 were made to evaluate several potential temperature , control measures. One method was to reduce placement temperature. Run 7 was similar to run 6 except that placement temperature was reduced from $24 \mathrm{C}(75 \mathrm{~F})$ to $10 \mathrm{C}(50 \mathrm{~F})$. Adiabatic conditions were assumed at the inner surface. Run 7 showed that a $14 \mathrm{C}(25 \mathrm{~F})$ reduction in placement temperature reduced peak temperatures by approximately the same amount, or $108 \mathrm{C}(226 \mathrm{~F})$ reduced to $94 \mathrm{C}(202 \mathrm{~F})$. Past experience has shown that an equivalent reduction between peak and placement temperatures will occur only when peak temperature is reached very soon after placement or when substantial time passes between placing sequential lifts in a structure. Run 8 was conducted to examine the effects of forced ventilation on the surface of the $0.3048-m$ ( $1-f t)$ diameter hole. It is obvious because of geometry that given equal air temperature and air velocity that substantially more heat will flow from the outside than from the inside surface of a hollow cylinder. The smaller the ratio of radii of the inner and outer surfaces, the greater is this difference. Since the cylinder rests on end, ventilation of the hole can only occur from the top surface. In run 8 a ventilation pipe was assumed positioned in the hole; the bottom of the pipe was assumed a foot or so above the bottom of the hole. A blower having a capacity of $0.472 \mathrm{~m}^{3} / \mathrm{sec}(1000 \mathrm{ft} / \mathrm{min})$ 
was assumed to blow down the pipe venting upward between the pipe and surface of the hole. A pipe diameter of $0.203 \mathrm{~m}$ ( $8 \mathrm{in.}$ ) was chosen because the cross-section for inlet and outlet were equal in a $0.3048-\mathrm{m}$ (12-in.) diameter hole. Based upon these dimensions and the air flow specified, a velocity of $13.4 \mathrm{~m} / \mathrm{sec}$ (44 fps) was assumed to ventilate the inner surface of the cylinder. All other parameters were the same as run 6. Peak temperature in run 8 was $102 \mathrm{C}$ (215 F) occurring equidistant between the inner and outer surface of the cylinder at 1.0 day. This is 0.25 days earlier and $1.7 \mathrm{C}(3 \mathrm{~F})$ less than occurred in run 6 at the same location. Comparison of temperatures near the inner surface of the cylinders shows $108 \mathrm{C}(226 \mathrm{~F})$ in run 6 at 1.25-days age versus $37 \mathrm{C}(99 \mathrm{~F})$ occurring at 0.5-days age in run 8 during forced ventilation. Run 8 demonstrates a substantial reduction in peak temperature at the inner surface even though peak temperature within the cylinder is not lowered very much. The position at which peak temperature occurs may be important. Although a thermal stress simulation was not made in this study for the unvented hole, it is probable that when highest temperatures occur at the center of the cylinder, thermal stress will be higher than in one cooled at the center.

12. Run 9 was made using the $10 \mathrm{C}(50 \mathrm{~F})$ placement temperature with forced ventilation at the inner surface. Peak temperature was $89 \mathrm{C}$ (192 F) occurring at the same location as in run 8. The reduction in peak temperature was equivalent to the reduction in placement temperature. The results of runs $7-9$ (Figures 4-6) show that a reduction in placement temperature is effective in reducing peak temperatures. Although forced ventilation at the inner surface does not substantially reduce temperatures at a point equidistant between the inner and outer surfaces, temperatures at the inner surface are reduced more than 50 percent. It was recommended to Merritt CASES, Inc., that both control measures be employed on future HEMSS cylinders.

Group III temperature runs

13. These runs were requested by Merritt CASES, Inc., in support of casting the HEMSS No. 3 cylinder. The objectives were to evaluate the effects of the diurnal ambient temperature cycle, different times of 
placement during the day, and the several attainable placement temperatures. HEMSS No. 3 was placed 8 August 1978. Estimates were made by Merritt CASES, Inc., for realistic placement temperatures attainable in August using chilled mixing water. These were $13 \mathrm{C}(55 \mathrm{~F})$ and $18 \mathrm{C}$ (65 F) for placements beginning at $6 \mathrm{a} . \mathrm{m}$. and $6 \mathrm{p.m}$., respectively. The higher afternoon temperatures are due to solar heating of the materials and equipment during the day. It was assumed that placements of the grout at midheight of the cylinder would occur $3 \mathrm{hr}$ after placement began. This is the assumed location of the temperature simulations. Figure 7 shows the estimated diurnal ambient temperatures provided by Merritt CASES, Inc., that were used in runs 10-12. Runs 10 and 11 were simulations of morning and evening placement. Zero time on the ambient temperature curves were $9 \mathrm{a} . \mathrm{m}$. and $9 \mathrm{p} . \mathrm{m}$., respectively, and placement temperatures were $13 \mathrm{C}(55 \mathrm{~F})$ and $18 \mathrm{C}(65 \mathrm{~F})$, respectively. The inner surface was ventilated with ambient air at $9.1 \mathrm{~m} / \mathrm{sec}(30 \mathrm{ft} / \mathrm{sec})$, an estimate of actual air velocity from a $0.425 \mathrm{~m}^{3} / \mathrm{sec}\left(900 \mathrm{ft}^{3} / \mathrm{min}\right)$ blower assuming some losses due to the 180-degree turn at the bottom of the hole. Air velocity assumed at the outer surface of the cylinder was $4.48 \mathrm{~m} / \mathrm{sec}$ (10 $\mathrm{mph}$ ), which is the daily average velocity. Solar radiation effects were not considered.

14. Peak temperatures were $92 \mathrm{C}(198 \mathrm{~F})$ and $97 \mathrm{C}(206 \mathrm{~F})$ for runs 10 and 11, respectively, midway between the inner and outer surfaces, or $1.1 \mathrm{C}(2 \mathrm{~F})$ less than the difference in placement temperatures. Observing that these differences are nearly equivalent, it can be concluded that placement during the morning subjecting the mass initially to the higher temperatures during the afternoon does not affect peak temperatures when compared to evening placement followed by cooler nighttime temperatures. This applies to the case when direct solar radiation is ignored. Therefore, the criterion that should govern selection of the best placement time is the one that most easily allows lowest placement temperatures. The effects of direct solar radiation on the outer surface steel forms could change this conclusion if the forms are sufficiently heated to reduce early cooling. However, this is not likely for $2 \mathrm{C4}$ grout cast in at least the dimensions of HEMSS No. 1-No. 3 . The rate 
of initial hydration overpowers the boundary condition.

15. Run 12 was the same as run 10; that is, morning placement at $12.8 \mathrm{C}(55 \mathrm{~F})$ except that adiabatic conditions were maintained at the inner surface. Peak temperature at the midpoint between inner and outer surfaces was $94 \mathrm{C}(202 \mathrm{~F})$ or $2.2 \mathrm{C}(4 \mathrm{~F})$ higher than in run 10 at the same location. However, inner surface temperatures were 97 C (207 F) compared with $47 \mathrm{C}(117 \mathrm{~F})$ in run 10 . Although peak temperatures differ by only $5 \mathrm{C}$ (9 F) between runs 10-12, positive ventilation should be used because less volume in the cylinders is subjected to the excessively high temperatures and in all probability potential thermal stress is less. Time histories of temperature change for these runs are shown in Figures 8-10 at the six thermistor locations specified for HEMSS No. 3 . These data were discussed by telephone with Merritt CASES, Inc., including recommendations for casting the HEMSS No. 3 cylinder. Pertinent data from runs 7-12 were forwarded to Merritt CASES, Inc., on 15 September 1978.

\section{Group IV temperature runs}

16. Following receipt of temperatures measured in HEMSS No. 3 , several simulations (runs 13-19) were made to duplicate the results, to evaluate the boundary conditions to include solar radiation, and to provide the basis for comparative simulations including thermal stress analysis for 2.13-, 3.66-, and 6.10-m (7-, 12-, and 20-ft) diameter cylinders. The table below contains the radial locations of thermistors provided by Merritt CASES, Inc. These thermistor designations will be used in the discussion that follows.

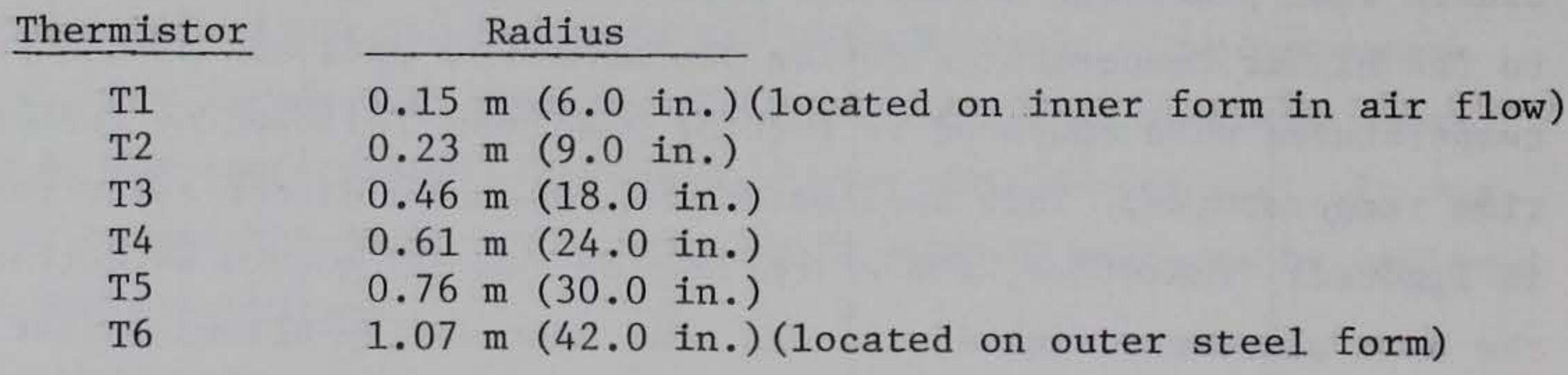

17. The measured temperature histories in HEMSS No. 3 are shown in Figure 11. Several observations were possible. First, acknowledging that the surface temperature would not be correct, run 13 was made to 
see if by correcting run 10 for the actual placement temperature of $25.5 \mathrm{C}(78 \mathrm{~F})$ whether peak temperatures would be duplicated. Peak temperature in run 13 was $102 \mathrm{C}(216 \mathrm{~F})$ comparing with $101.7 \mathrm{C}(215 \mathrm{~F})$ in HEMSS No. 3. Secondly, thermistor T1 located on the inner surface in the air flow recorded temperatures approximately 8-11 C (15-20 F) below ambient temperature at all times. The question that arose was did the thermistor measure air temperature or is the temperature measured the effect of phenomena that lowered the thermistor temperature below that of the air such as might be expected with evaporative cooling. This question gains importance when trying to establish the actual boundary conditions for computer simulation. Runs 13-19 established that the inner surface air temperature was, as measured, lower than ambient air temperature. Considerable speculation arose as to the cause; however, since no cause can be proven, the subject was dropped.

18. The last point to be discussed pertaining to the HEMSS No. 3 . temperatures is the outer surface temperatures. Gage T6 was located on the southern face. Therefore, it recorded surface temperatures that included the grout temperature plus temperature rise due to solar heating. After examining Figure 11 it is reasonable to conclude that the surface temperature history exclusive of solar effects lies along a line of best fit through the minimum temperatures reached at night. The effects due to diurnal air temperature is a temperature swing of perhaps $1.6-5.5 \mathrm{C}$ (3-10 F) above this line at approximately $2 \mathrm{p} . \mathrm{m}$. If we assume an air temperature range between $29 \mathrm{C}(85 \mathrm{~F})$ and $40 \mathrm{C}(105 \mathrm{~F})$ for the first several days after placement, followed by a reported cooling resulting in temperatures between $18 \mathrm{C}(65 \mathrm{~F})$ and $29 \mathrm{C}(85 \mathrm{~F})$ for several additional days, then the peak surface temperatures are slightly below the peak solair temperatures. Sol-air temperatures are used by the American Society of Heating, Refrigeration and Air-Conditioning Engineers (ASHRAE). ${ }^{5}$ Solair temperature is a combination of ambient temperature and solar effects to represent an equivalent ambient temperature that is used to calculate cooling requirements in buildings. The use of the sol-air concept allows the convection heat-transfer method in the temperature program to account for solar radiation. This was the first opportunity at WES to use the 
sol-air concept having measured effects in hand to verify results.

19. Merritt CASES, Inc., requested that simulations on the 2.13-, $3.66-$, and $6.10-\mathrm{m}(7-, 12-$, and $20-\mathrm{ft})$ cylinder be made using the actual conditions deduced for HEMSS No. 3. Also specified to be used was a $0.61-\mathrm{m}(2-\mathrm{ft})$ diameter axial hole in the $3.66-\mathrm{m}$ and $6.10-\mathrm{m}$ (12- and 20-ft) diameter cylinders exposed to the same temperature environment and forced air velocity as the $2.13-\mathrm{m}(7-\mathrm{ft}$ ) cylinder that had a $0.3048-\mathrm{m}$ (1-ft) diameter hole. All earlier temperature runs were calculated through 7 days, the maximum duration of measured temperatures after placement. Since the $2.13-\mathrm{m}$ (7-ft) cylinder did not completely achieve temperature equilibrium during this time, it was decided that the 2.13-m and 3.66-m (7- and 12-ft) cylinder simulations should be run for 14 days and the $6.10-\mathrm{m}(20-\mathrm{ft})$ cylinder for 28 days. The boundary ambient conditions used in these runs were the modified results of gages $\mathrm{T} 1$ and $\mathrm{T} 6$ checked out in trial runs 13-19 to 7 days. After 7 days, constant inner and outer ambient temperatures of $18 \mathrm{C}(65 \mathrm{~F})$ and $29 \mathrm{C}(85 \mathrm{~F})$, respectively, to the duration of each run were used. Forced cooling of the inner surface was assumed to continue after 7 days.

20. A finite-element model was prepared for each cylinder. Each 'model comprised an arc of $90 \mathrm{deg}$ to allow displacement restraint to be applied in stress analysis runs. Each model consisted of the same number of nodes and elements. Nodes were located radially to provide the best description of temperature gradient and thermal stress and strain. Figure 12 shows the model for the 2.13-m (7-ft) cylinder. Figure 13 shows the radial node and element centroid layouts used for the three cylinder diameters.

21. Run 20 was the final simulation of HEMSS No. 3 . Figures 14 and 15 show calculated temperatures on two time scales. Figure 14 is for comparison with measured temperatures in HEMSS No. 3. Figure 15 is for comparisons with runs made on the 3.66- and 6.10-m (12- and 20-ft) cylinders. Results in Figure 14 compare favorably with measured temperatures (Figure 11) with the following exceptions. Comparisons of temperatures at gage $\mathrm{T} 1$ should not be made since the temperatures measured by the gage are assumed to be air temperature while the calculated values 
at the same position represent grout surface temperature. Gage T2 should be used to assess the measured and calculated values near the inner

surface. Measured and calculated temperatures for gage T6 are comparable. The measured values from gage T5 (Figure 11) appear to be lower than should be expected within the first several days after placement. The temperature should be much closer to that measured by gage T4 since the locations are symmetric about the midpoint between surfaces and cooling conditions are comparable at each surface at that time. The calibrations at higher temperatures for T5 should be checked if possible.

22. Runs 21 and 22 were made with the 3.66- and 6.10-m (12- and 20-ft) diameter cylinders, respectively. Peak temperatures reached $109 \mathrm{C}$ (229 F) and $116 \mathrm{C}(240 \mathrm{~F})$, respectively. The maximum temperature achieved at a placement temperature of $25.5 \mathrm{C}$ (78 F) should be $116 \mathrm{C}$ (240 F) provided that the adiabatic temperature rise curve used is correct after 7 days age. Figures 16 and 17 show temperature histories in runs 21 and 22. In order to show the effects of increased diameter more effectively temperatures are plotted for nodes in runs 21 and 22 that are located at proportionally the scaled distances apart as all the gage locations in HEMSS No. 3 and run 20. These figures show the increasingly longer time required to cool. Also evident is the proportionally larger volume of grout subjected to long-term high temperatures. In fact peak temperatures in the $6 \cdot 10-\mathrm{m}(20-\mathrm{ft})$ cylinder have only lowered to $66 \mathrm{C}(151 \mathrm{~F})$ at 28 days.

\section{Thermal Stress-Strain Simulation}

23. Thermal stress-strain simulations of runs 20-22 were conducted using the University of California program described earlier. This program uses time-dependent mechanical properties and thermal loads input from the temperature program to calculate thermal stress and strain at times subsequent to placement.

24. All mechanical properties were assumed for $2 \mathrm{C} 4$ grout in the simulation. Modulus of elasticity provided by Merritt CASES, Inc., for age 14 days was $18,205 \mathrm{MPa}\left(2.64 \times 10^{6} \mathrm{psi}\right)$. A linear function for 
modulus of elasticity versus the $10 \mathrm{~g}$ of time passing through the 14-day value was assumed. Figure 18 shows the assumed relationship. Linear coefficient of thermal expansion was estimated to be $3.33 \times 10^{-6} /{ }^{\circ} \mathrm{C}$ $\left(6.0 \times 10^{-6} /{ }^{\circ} \mathrm{F}\right)$. This value may be low for grout, but no corroborating data could be located, especially for early ages, for a better estimate. Poisson's ratio used was 0.28 .

25. It was assumed that creep is high in grout especially at the temperatures encountered. Since no data were located, estimated values double those of concrete were used. Creep values are input to the program as relaxation curves used in McHenry's equation. 6, 7

$$
\varepsilon_{c}(\sigma, t, T)=\sigma \sum_{i=1}^{N} A_{i}(T)\left(1-e^{-m_{i}(t-T)}\right)
$$

where

$$
\begin{aligned}
\varepsilon_{c} & =\text { creep strain } \\
t & =\text { time after placement } \\
T & =\text { age at loading } \\
\sigma & =\text { stress }
\end{aligned}
$$

$\mathrm{N}=2$ gave satisfactory fit with the assumed data. Figure 19 shows relaxation curves for creep coefficients A1 and A2. Constants chosen for $\mathrm{m} 1$ and $\mathrm{m} 2$ were 0.34 and 0.52 , respectively.

26. When creep is considered in the program, stresses at each time step in the analysis are modified for stress relaxation allowing no strain for the interval up to the next analysis time. The creep parameters are stored and the change in stress is stored as residual stress to be included in the next time step analysis. When these stored values are applied during the next time step analysis, strains due to creep are eliminated. Thus, strains output at any time step are elastic strains. Nodal displacements are accumulated and reflect the total distortion within the model. This requires a word of caution: displacement and not strain values should be used when comparing measured versus calculated distortion. Elastic strain values from this program are compared against tensile strain capacity to assess potential for cracking.

27. The final input value is the initial stress-free temperature 
distribution in the model. This is the temperature calculated individually for each element and is the reference for computing stress. The time at which stress-free temperature is computed is the age where elastic properties begin to develop. This was assumed to be at $6 \mathrm{hr}$ for $2 \mathrm{C} 4$ grout. These data are calculated by the temperature program for subsequent use in the stress program.

28. Four thermal stress-strain analysis computer runs were made for this study. Temperature runs 20-22 for the 2.13-, 3.66-, and 6.10-m (7-, 12-, and 20-ft) diameter cylinders provided therma1 loads. Run S20A was an analysis of the $2.13-\mathrm{m}(7-\mathrm{ft})$ cylinder without creep, and runs S20-S22 were analyses of all three cylinders with creep. The initial 7 days of simulation in each temperature run used a diurnal temperature cycle, and thus surface temperatures varied with the changing ambient temperatures during each day. Thermal stress analyses are more than an order of magnitude more costly to run compared to the temperature calculations. Therefore, it was necessary to use longer time steps between successive calculations for each analysis. Except for increments of 0.25 days and 0.5 days used for days 1 and 2 , respectively, all remaining time intervals were 1 or 2 days. Thus, the effect of diurnal cycle upon thermal stress was not computed. The effect calculated was approximately that associated with mean daily surface temperatures.

2.13-m (7-ft) cylinder

29. The results of runs $\mathrm{S} 20$ and $\mathrm{S} 20 \mathrm{~A}$ are the thermal stresses and strains presumed to exist in HEMSS No. 3. These runs as we11 as S21-S22 indicated that major and minor principal stresses and strains were so oriented as to be tangential and radial stress and strain. Stresses and strains produced from each set of radial rows of elements were identical. Since comparison with estimated tensile strain capacity was used to assess potential cracking and since internal measurement of displacement rather than stress is made, the discussion of these runs is based upon calculated strains.

30. Figure 19 shows radial temperature gradients and the resulting tangential strain gradients for analyses with and without creep at successive ages. In these runs, as well as in those for the larger cylinders, 
initial peak strains occur between 0.75 and 1.25 days age. The strain distribution is characterized by highest tensile strain at the inner surface, somewhat lower tensile strain at the outer surface, and peak compressive strain in between. Increasing restraining volume with increasing radius contributes to the higher tensile strains at the inner surface. In both cases peak tensile strain occurred at 0.5 days age or the first change of temperature relative to the stress-free temperature at 0.25 days. It is also evident in Figure 20 that highest surface tensile strains are a function of intensity or slope of the thermal gradient and not the total temperature differential. Compressive strains peaked within a day later at a time where maximum curvature of the temperature gradient at peak temperature coincided with maximum temperature differential. Peak tensile strains were 195 millionths and peak compressive strains were 104 millionths with and without creep. As time passes strains begin to decrease due to stress relaxation and cooling. The largest differences with and without creep occur near temperature equilibrium. For example, compressive and tensile strain at 9 days without creep were 123 and 86 millionths, respectively. With creep these strains were 65 and 46 millionths, respectively.

31. Some questions remain concerning the accuracy of the creep correction modeled in this program. It appears that larger stress relaxation should occur at very early age especially when stresses and strains are nearly equivalent to yield values. It is recognized that additional research and computer program development are needed in this area. From the beginning of the study it was agreed by a11 parties concerned that due to lack of actual mechanical properties and due to known computer program deficiencies these results should not be expected to indicate too much more than a comparative pattern of behavior.

$3.66-$ and $6.10-\mathrm{m}$

(12- and 20-ft) cylinders

32. Runs S21 and S22 were conducted on 3.66- and 6.10-m (12- and 20-ft) diameter cylinders, respectively. Tangential tensile strains at the inner surface were 267 and 296 millionths, respectively, occurring at 0.75 days. Figures 21 and 22 show temperature and tangential and 
radial strain gradients for the 3.66 - and $6.10-\mathrm{m}$ (12- and 20-ft) cylinders, respectively. As noted earlier, temperatures in both cylinders did not reach equilibrium at the end of the runs. Therefore, tangential stress and strain are continuing to increase in compression at the inner and outer surfaces and in tension in between as cooling continues. As each increase in diameter produced higher strains due to the initial temperature rise, strains produced during cooling are also higher. Radial strains are lower in magnitude, but respond similarly to tangential strains during cooling.

33. Figure 23 shows estimated tensile strain capacity used in thermal stress-strain runs. These values are twice those measured for mass concrete. These values may be substantially lower for grout but no data exist to establish a better estimate. Tensile strains plotted in Figures 19-22 can be compared to values for tensile strain capacity in Figure 23 at equal ages. In all cases surface tensile strains occurring early are five to six times higher than estimated strain capacity. Tensile strains that occur within the mass during cooling are all lower than strain capacity at the corresponding ages. It should be stressed that the analysis is elastic which may contribute to substantial deviation from actual conditions. These simulations do show comparative effects in the three cylinder sizes.

\section{Conclusions and Recommendations}

34. As a result of this study, many observations, conclusions, and recommendations based upon both analysis of results and review of pertinent literature are possible. Two basic considerations result. The initial concern is potential excessive thermal stress and strain caused by the restraining mass and thermal gradient. The second is the potentially detrimental or unknown effects on the grout due to the excessive temperatures during early curing.

35. This study showed that the finite-element temperature program in use at WES could provide sufficiently accurate results of temperature rise and decay in the HEMSS cylinders based upon assumed 
thermal properties and boundary conditions provided that the time rate of heat generation or measured temperature rise are available. Evaluation of the effectiveness of control measures can be made.

36. This study showed that peak temperature in cylinders at least $2.16 \mathrm{~m}$ ( $7 \mathrm{ft}$ ) in diameter can only be effectively controlled by limiting placement temperature. The rate of heat generation is so high that boundary conditions can only affect the rate of later cooling and cannot control peak temperatures.

37. Calculations of thermal stress and strain based upon assumed mechanical properties for $2 \mathrm{C} 4$ grout and the known thermal gradients existing in the $2.16-\mathrm{m}$ (7-ft) HEMSS cylinders indicate that high tangential tensile strains occur at the inner and outer surfaces within the first day after placement. Unless the actual cylinders show otherwise it must be assumed that thermal cracking is probable at these locations. Peak initial stress and strain occur within 0.5 days of peak temperature after which both are reduced as cooling occurs. Before temperature equilibrium, thermal stress and strain reach zero after which stress and strain increase opposite in sign to that occurring earlier until thermal equilibrium is reached. Areas initially in tension subsequently experience compression and vice versa. Although it cannot be confirmed here, conditions exist to cause early-age surface cracking to propagate into or through the radius of the cylinder as cooling progresses and tangential tension builds in the central radius area.

38. Thermal simulations of $3.66-$ and $6.10-\mathrm{m}$ (12- and 20-ft) cylinders subjected to the same conditions as HEMSS No. 3 showed an increase in peak temperature reaching a probable maximum value of $116 \mathrm{C}$ $(240 \mathrm{~F})$ in a $6.10-\mathrm{m}(20-\mathrm{ft})$ cylinder. Thermal stress and strain continue to increase with increasing diameter.

39. Based upon this study, thermal simulations under the conditions that existed in HEMSS No. 1-3 would not have produced satisfactory results without actual data from measurements of temperature rise or adiabatic heat of hydration tests. The rate of initial heat of hydration is so much higher than heat of hydration values obtained from conventional tests that calculation of peak temperature would have been at least $22 \mathrm{C}$ 
(40 F) below measured values. In addition, expected large variations in other thermal properties assumed constant in this study are probably based upon concrete data.

40. When comparing the effect of creep on thermal strain calculations, the results showed that creep does not affect early-age high stress and strain, but does lower the final stress and strain at thermal equilibrium by one-half. This is true only if the assumed values of mechanical properties are fairly accurate and if the method of modeling creep is correct.

41. Some investigators believe, based upon data obtained from measurements of strain in mass concrete structures, that stresses at early age are much lower than should exist based upon elastic properties and geometry. These measurements seem to show that as soon as cooling begins areas supposedly in compression begin to shrink as though no compression existed. Concrete that is restrained from expansion does not increase in compression as its elastic properties would indicate at early age. The result is somewhat like 100 percent creep or stress relaxation during early stages. Were this the case in the HEMSS cylinders, tensile and compressive strains would be near zero as soon as cooling began. The surface would immediately undergo compression, the interior mass undergo tension, and the magnitude of these values at thermal equilibrium would be substantially higher than calculated. It is evident that very little is known about some mechanisms occurring in mass placements containing hydrating portland cement at early age, especially at high temperatures. Therefore, the results reported here may be subject to substantial error under the circumstances.

42. The second major concern resulting from the study is that 2C4 grout subjected to extremely high temperatures at early age may develop substantially different properties than when cured at ambient temperatures. It seems necessary, especially if larger diameter cylinders are seriously considered, that at least a minimal examination of mechanical properties pertinent to the explosive tests be obtained for $2 \mathrm{C} 4$ cured through the range of temperatures expected. It is known that ultimate strength is reduced as placement and curing temperatures increase. It 
is not known how other mechanical properties are affected at high initial curing temperatures.

43. If minimal testing proves that pertinent properties change substantially from those desired, a complete test program to evaluate $2 \mathrm{C} 4$ as a function of temperature is warranted. It may be preferred in that case to choose another grout with lower quantities of cement and document it at the temperatures expected. Even if $2 \mathrm{C} 4$ is fully documented the thermal stress effects from high temperature gradient are still present.

44. Questions may arise concerning the advantages of adding pozzolans such as fly ash, etc., to replace some of the cement in $2 \mathrm{C} 4$. Pozzolan replacement will reduce the rate and amount of heat of hydration. Temperature rise may be reduced by 20 percent. Data will have to be obtained for the revised mixture. Experience at WES has shown that pozzolans become less effective in reducing temperature rise when the cement content is high. It seems as though another mixture with lower cement content would be the best alternative if $2 \mathrm{C} 4$ as presently designed is unsatisfactory.

45. No substantial decrease in peak temperatures can be obtained when placing 2C4 grout in mass unless crushed ice replaces the mixing water and materials are precooled to result in a placement temperature at or slightly higher than $4.4 \mathrm{C}(40 \mathrm{~F})$. Placement at low temperatures will retard the early, intense rate of hydration. Peak temperatures may be lowered more than the difference in placement temperatures because a lower rate of hydration will cause additional time to occur between placement and peak temperature allowing additional cooling to the air. This will probably only be possible with the $2.13-\mathrm{m}$ (7-ft) cylinders. If a $6.10-\mathrm{m}(20-\mathrm{ft})$ cylinder is cast at the placement temperatures used in HEMSS No. 3, $25.5 \mathrm{C}(78 \mathrm{~F})$, peak temperature will be approximately $13.9 \mathrm{C}(25 \mathrm{~F})$ higher than in HEMSS No. 3. Therefore, reducing the placement temperature to $4.4 \mathrm{C}(40 \mathrm{~F})$ will lower peak temperatures only slightly below those seen in HEMSS No. 3. Due to the larger diameter thermal stress and strain will be higher than in HEMSS No. 3 because volumetric restraint is increased. 
46. Many unanswered questions exist on the use of $2 \mathrm{C4}$ grout placed in mass. As discussed, the questions deal with the material's temperature dependence and quality as well as with potential excessive thermal stress and strain. To answer both questions, additional thermal and mechanical properties data are necessary for $2 \mathrm{C} 4$ grout cured at elevated temperatures. 
1. Wilson, E. L., "The Determination of Temperatures Within Mass Concrete Structures," Report No. 68-17, Dec 1968, Structural Engineering Laboratory, University of California, Berkeley, Calif.

2. Sandhu, R. S., Wilson, E. L., and Raphae1, J. M., "Two-Dimensional Stress Analysis with Incremental Construction and Creep," Report No. 67-34, Dec 1967, Structural Engineering Laboratory, University of California, Berkeley, Calif.

3. "Thermal Properties of Concrete," Boulder Canyon Project Final Report, Bulletin No. 1, Part VII, Bureau of Reclamation, 1940.

4. U. S. Army Engineer Waterways Experiment Station, CE, "Handbook for Concrete and Cement," Aug 1949, with quarterly supplements, Vicksburg, Miss.

5. American Society of Heating, Refrigerating, and Air-Conditioning Engineers, Inc., "ASHRAE Handbook and Product Directory, 1977 Fundamentals," 1977, New York, N. Y.

6. McHenry, D., "A New Aspect of Creep in Concrete and Its Application to Design," Proceedings, American Society for Testing and Materials, Vo1 43, 1943, pp 1069-1087.

7. King, I. P., "Finite Element Analysis of Two-Dimensional TimeDependent Stress Problems," Report No. 65-1, Jan 1965, Structural Engineering Laboratory, University of California, Berkeley, Calif. 
Table 1

Summary of Computer Runs for Temperature Simulation

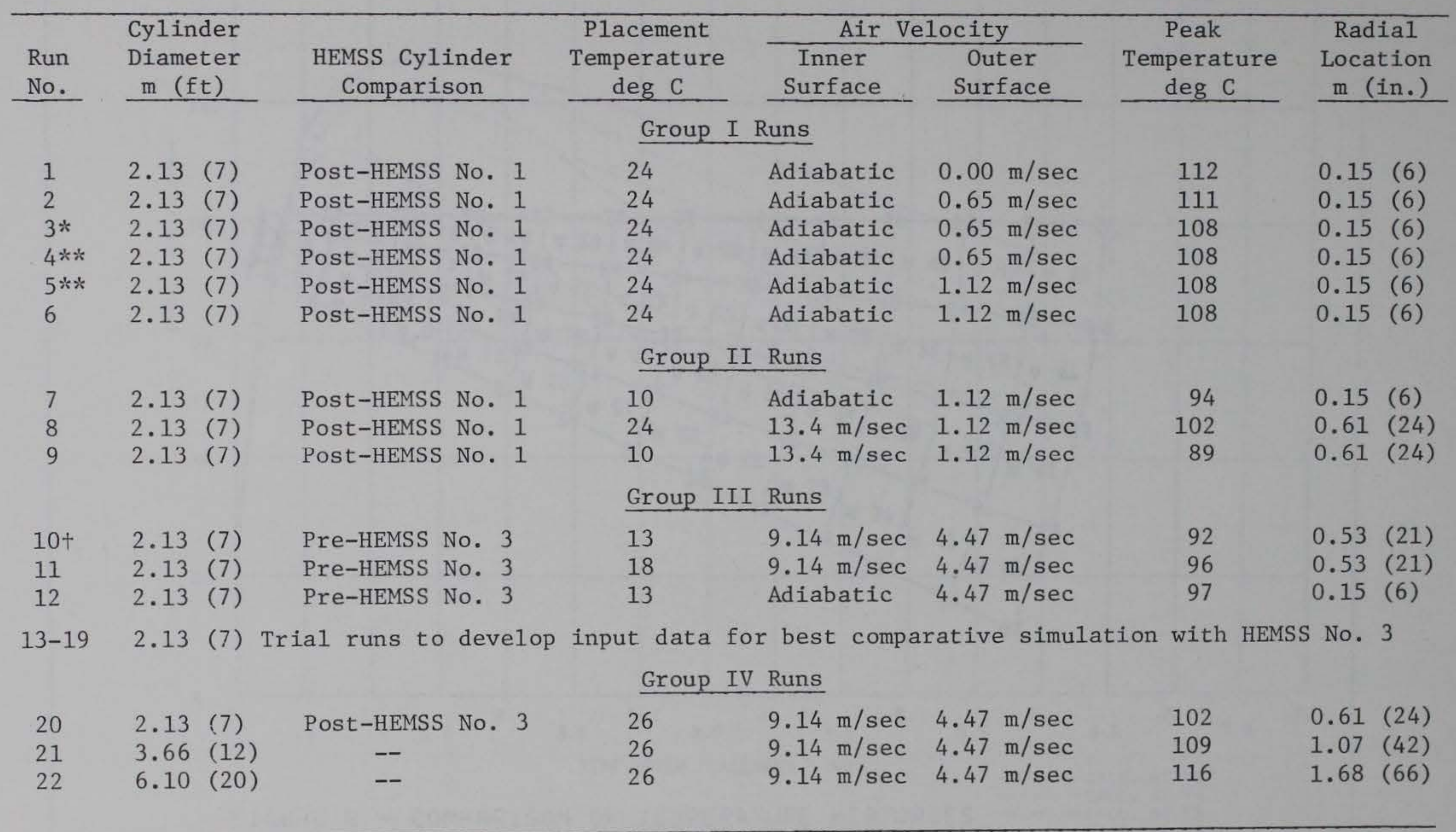

* Adiabatic temperature rise varied from runs 1 and 2 .

$* *$ Specific heat $=1675 \mathrm{~J} / \mathrm{kg} \cdot \mathrm{K}$, all other runs $=1444 \mathrm{~J} / \mathrm{kg} \cdot \mathrm{K}$.

Conductivity $=1.408 \mathrm{~W} / \mathrm{m} \cdot \mathrm{K}$, all other runs $=1.304 \mathrm{~W} / \mathrm{m} \cdot \mathrm{K}$.

+ Diurnal air temperature cycles used for runs 10-22. 


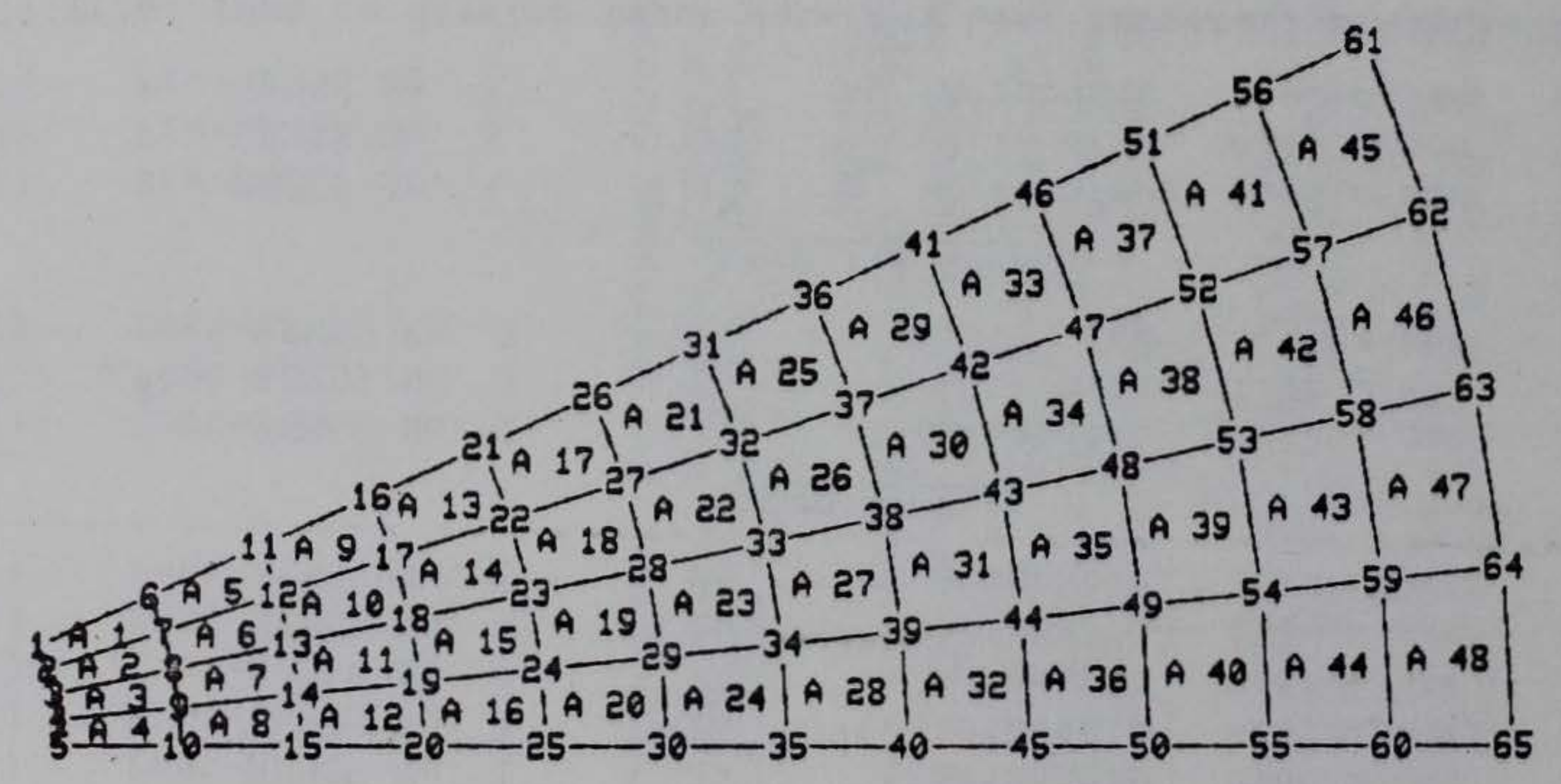

Figure 1. Finite-element model No. 1 used for temperature runs 1-19. 


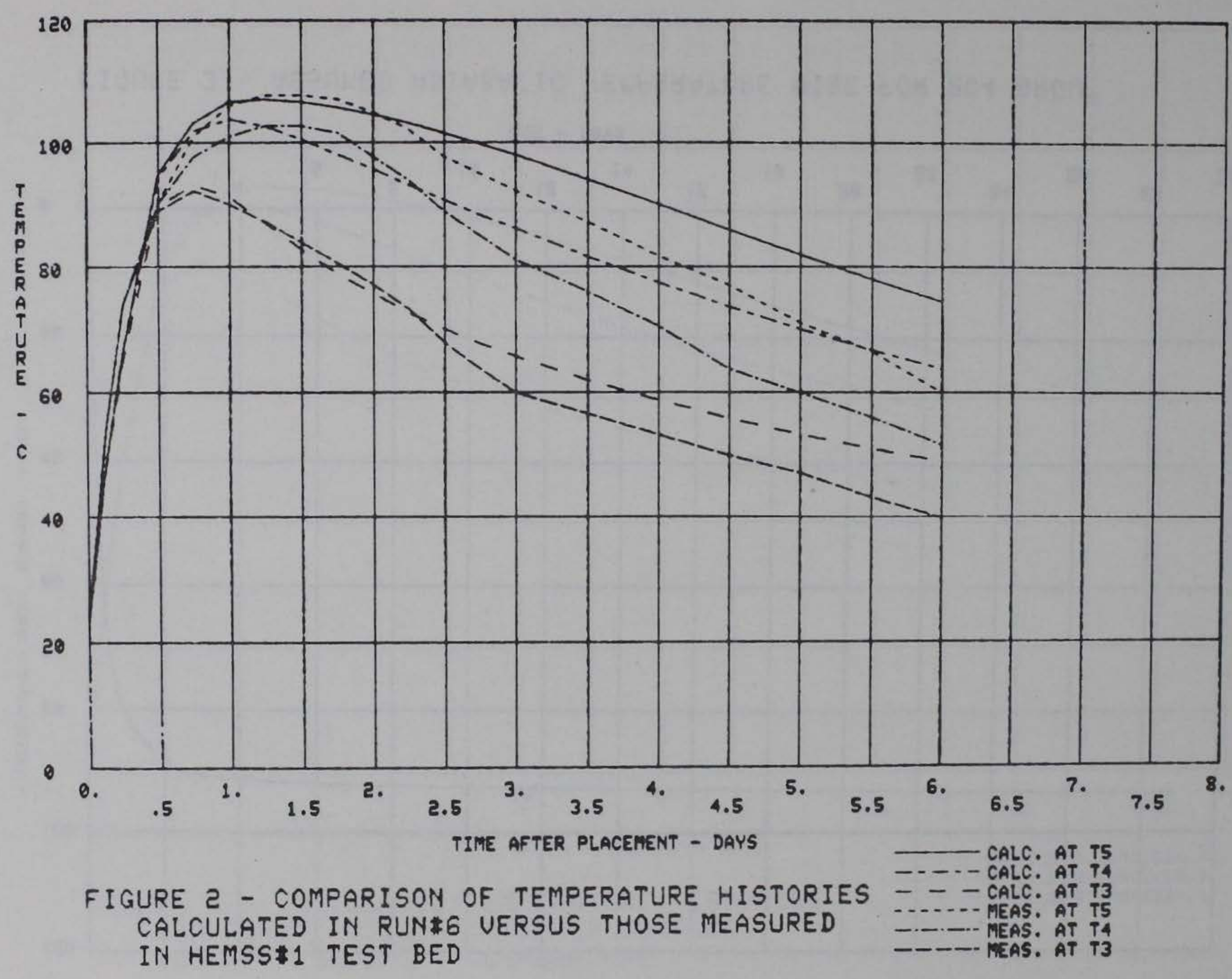




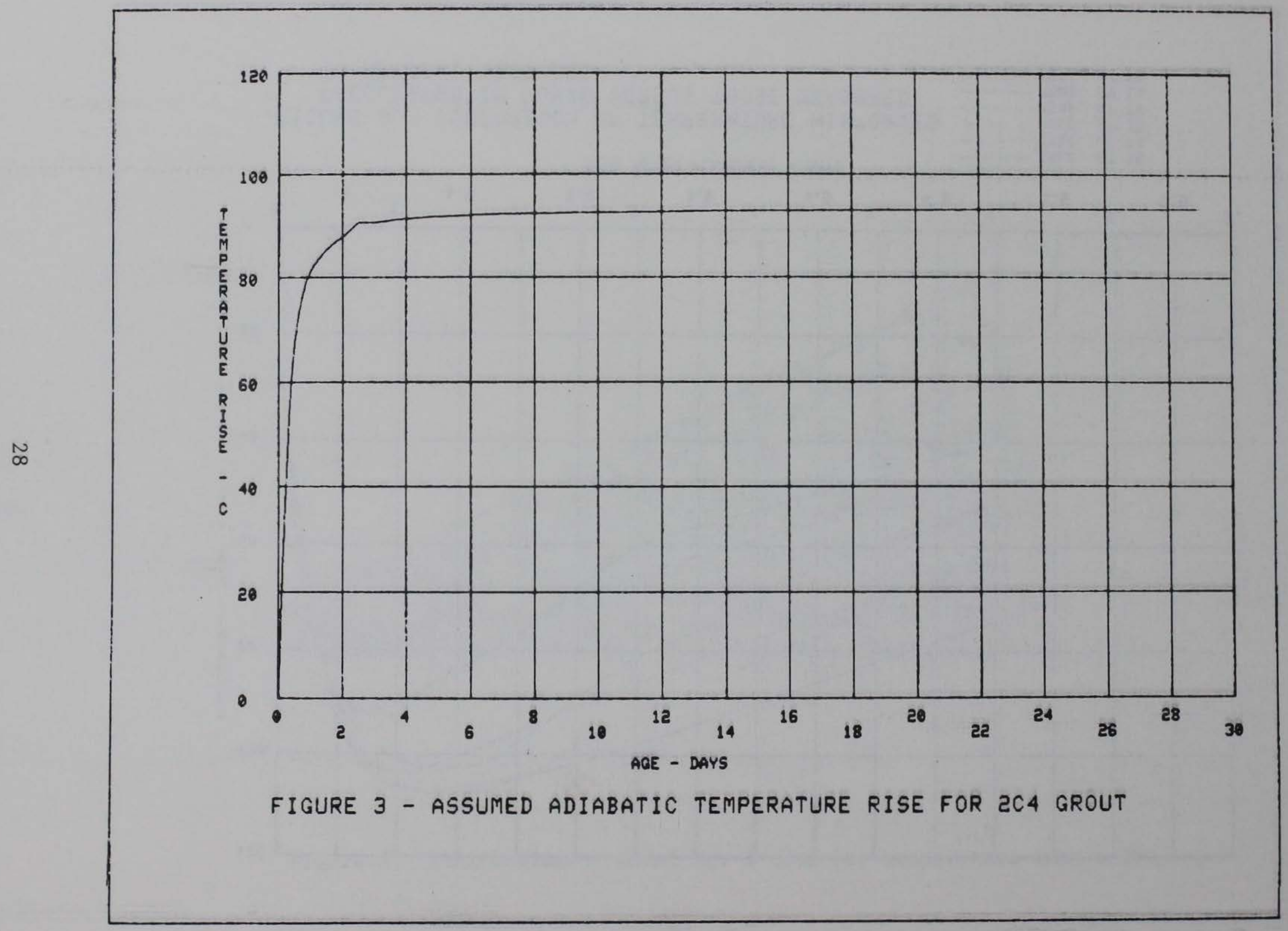




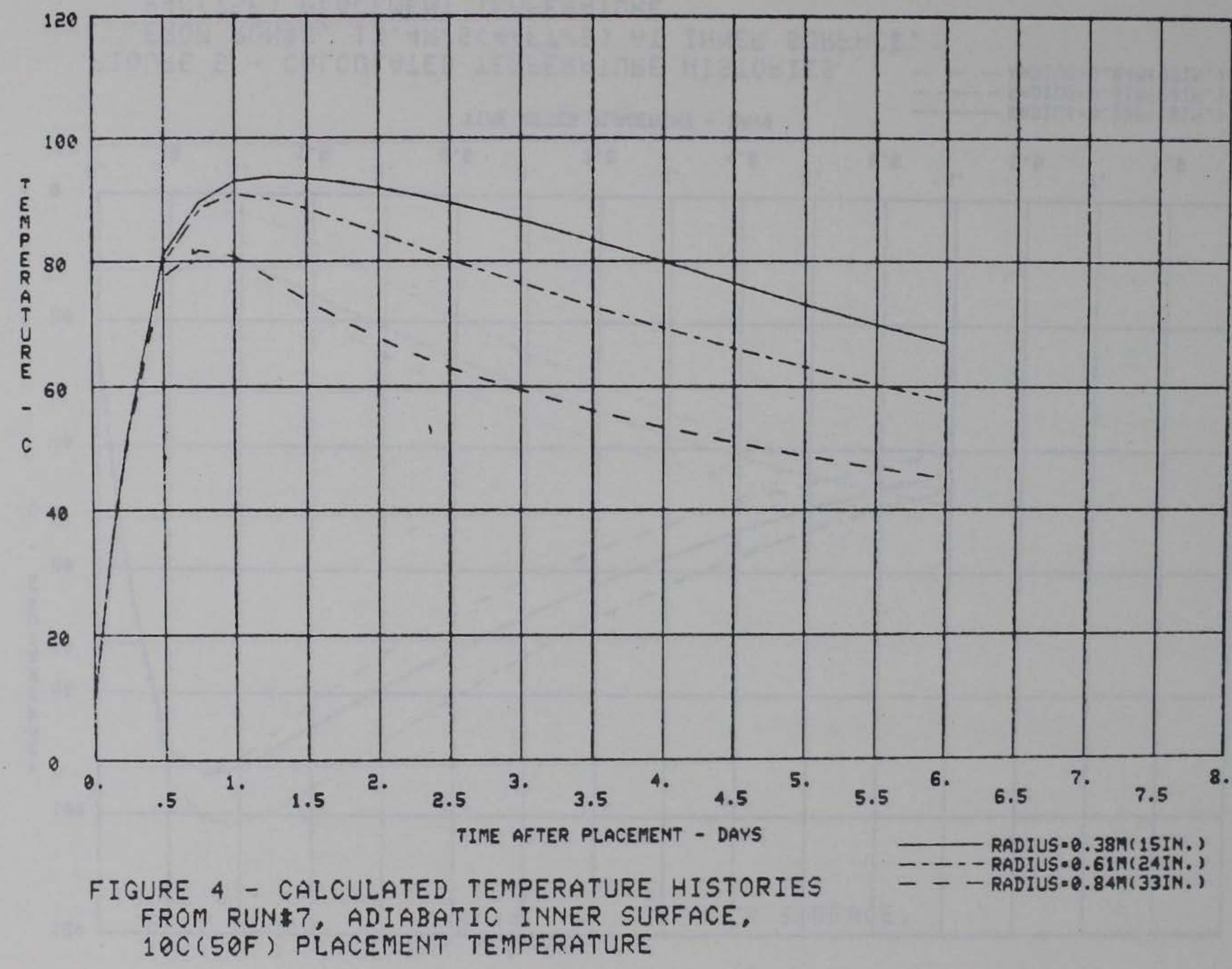




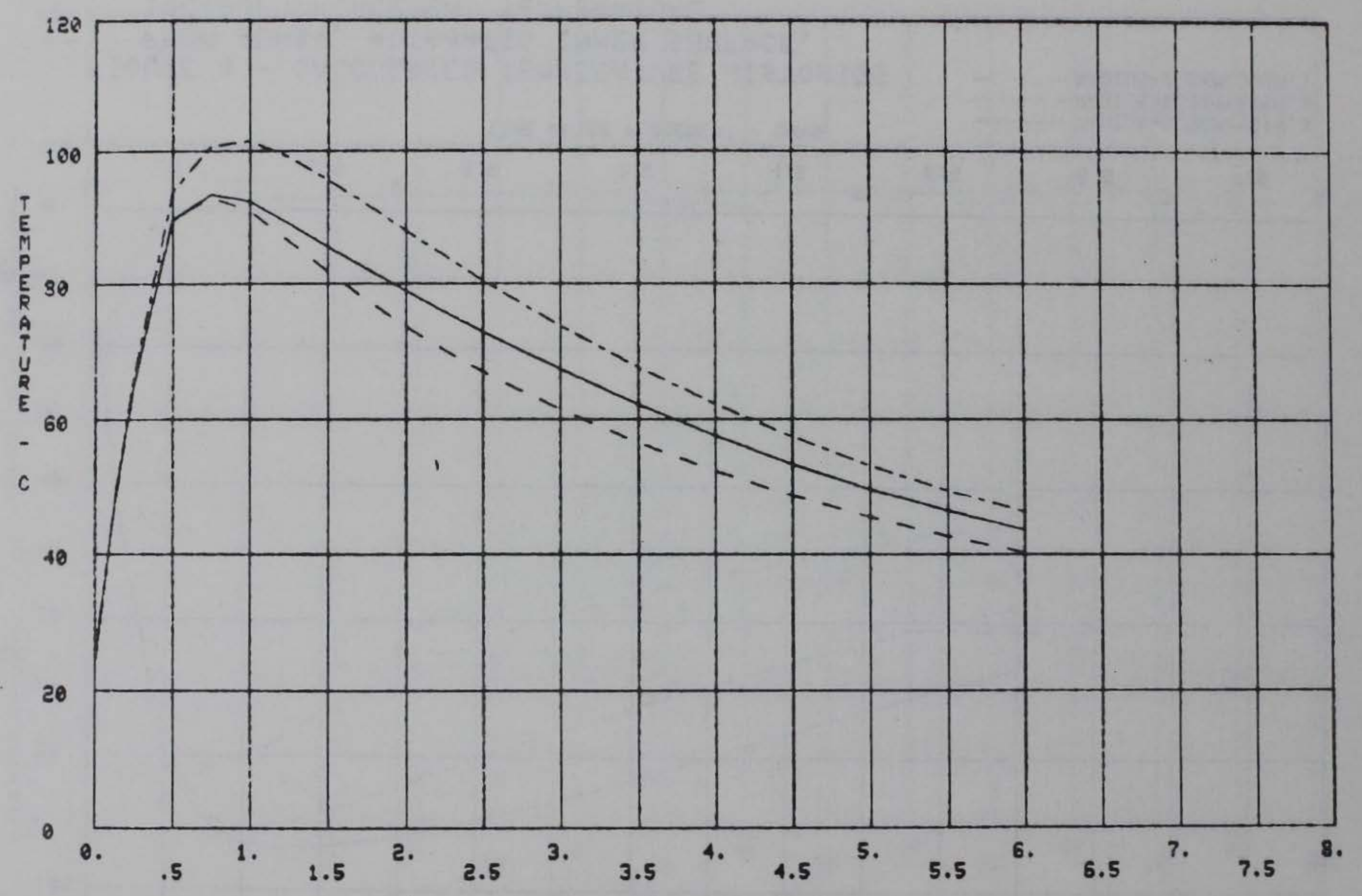
TIME AFTER PLACEMENT - DAYS

FIGURE 5 - CALCULATED TEMPERATURE HISTORIES FROM RUN $\$ 8,13.4 M / S(44 F T / S)$ AT INNER SURFACE, 24C(75F) PLACEMENT TEMPERATURE 


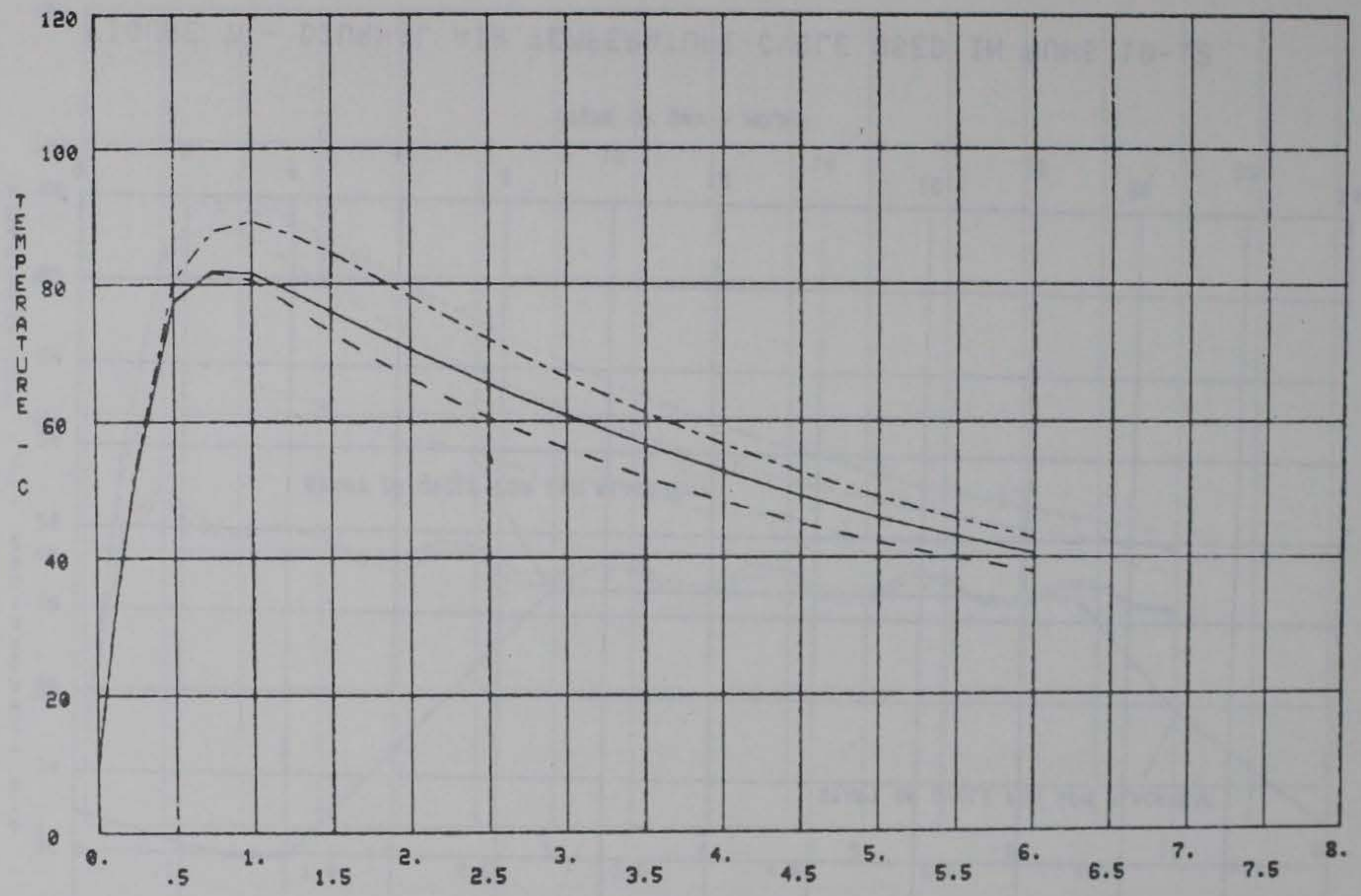

TIME AFTER PLACEMENT - DAYS

RADIUS = $0.38 \mathrm{M}(15 \mathrm{IN}$. )

FIGURE 6 - CALCULATED TEMPERATURE HISTORIES - - - RADIUS.8.84M(33IN.)

FROM RUN\$9, $13.4 M / S(44 F T / S)$ AT INNER SURFACE, $10 \mathrm{C}(50 \mathrm{~F})$ PLACEMENT TEMPERATURE 


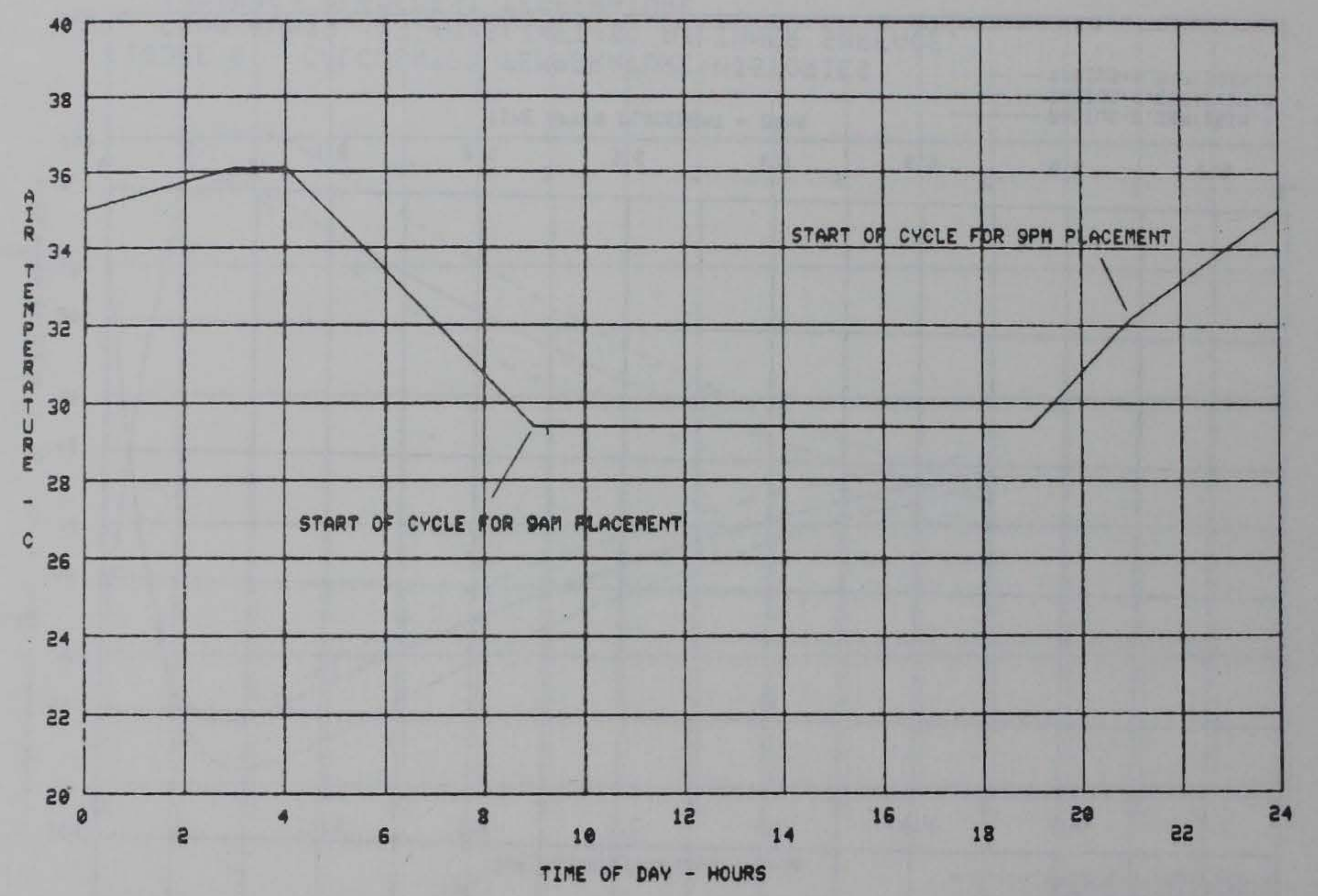

FIGURE 7 - DIURNAL AIR TEMPERATURE CYCLE USED IN RUNS 10-12 


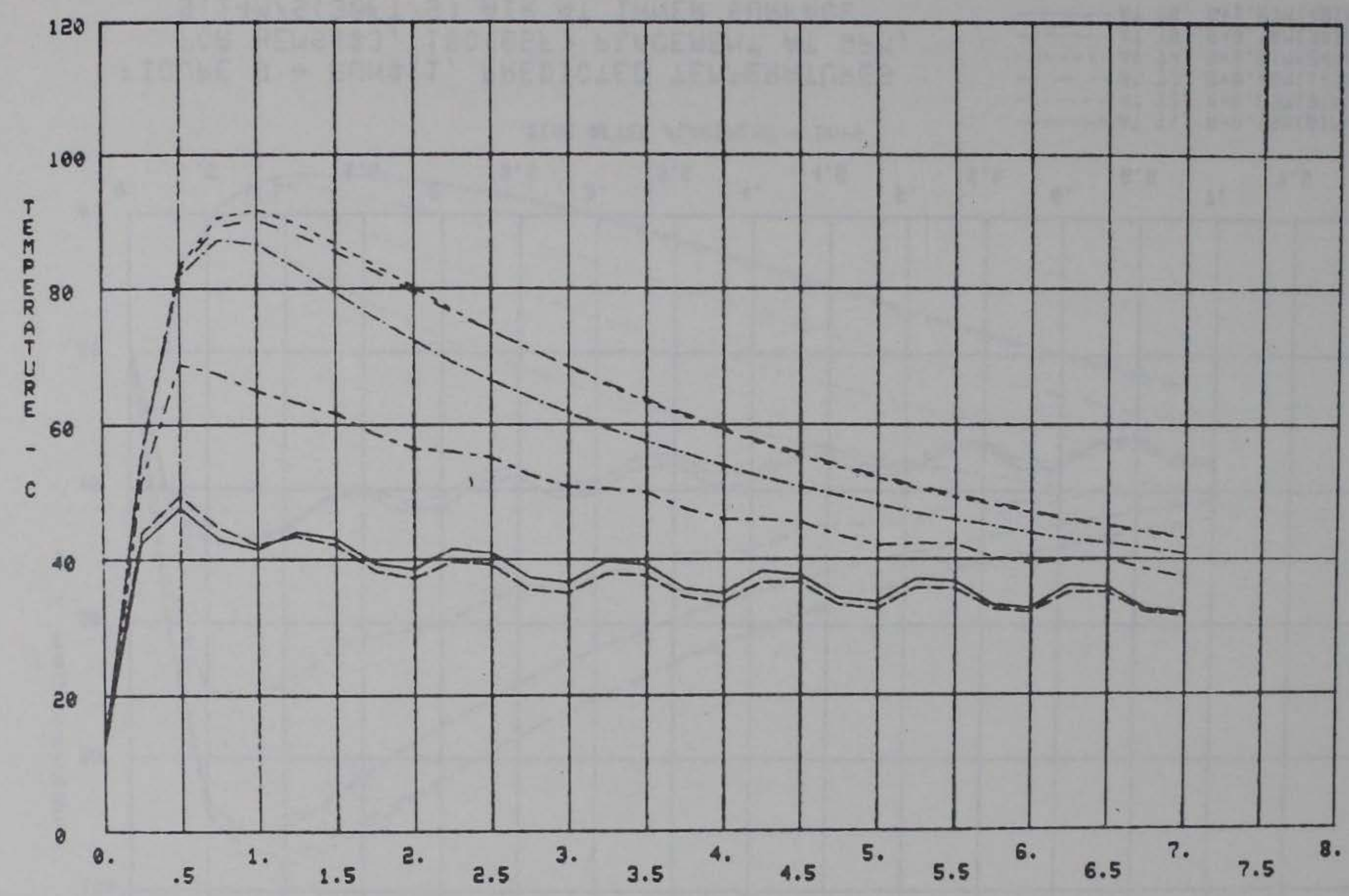

TIME AFTER PLACEMENT - DAYS

FIGURE 8 - RUN\#10, PREDICTED TEMPERATURES FOR HEMSS $\$ 3,13 C(55 F)$ PLACEMENT AT 9AM, $9.14 \mathrm{M} / \mathrm{S}(30 \mathrm{~F} T / \mathrm{S})$ AIR AT INNER SURFACE 


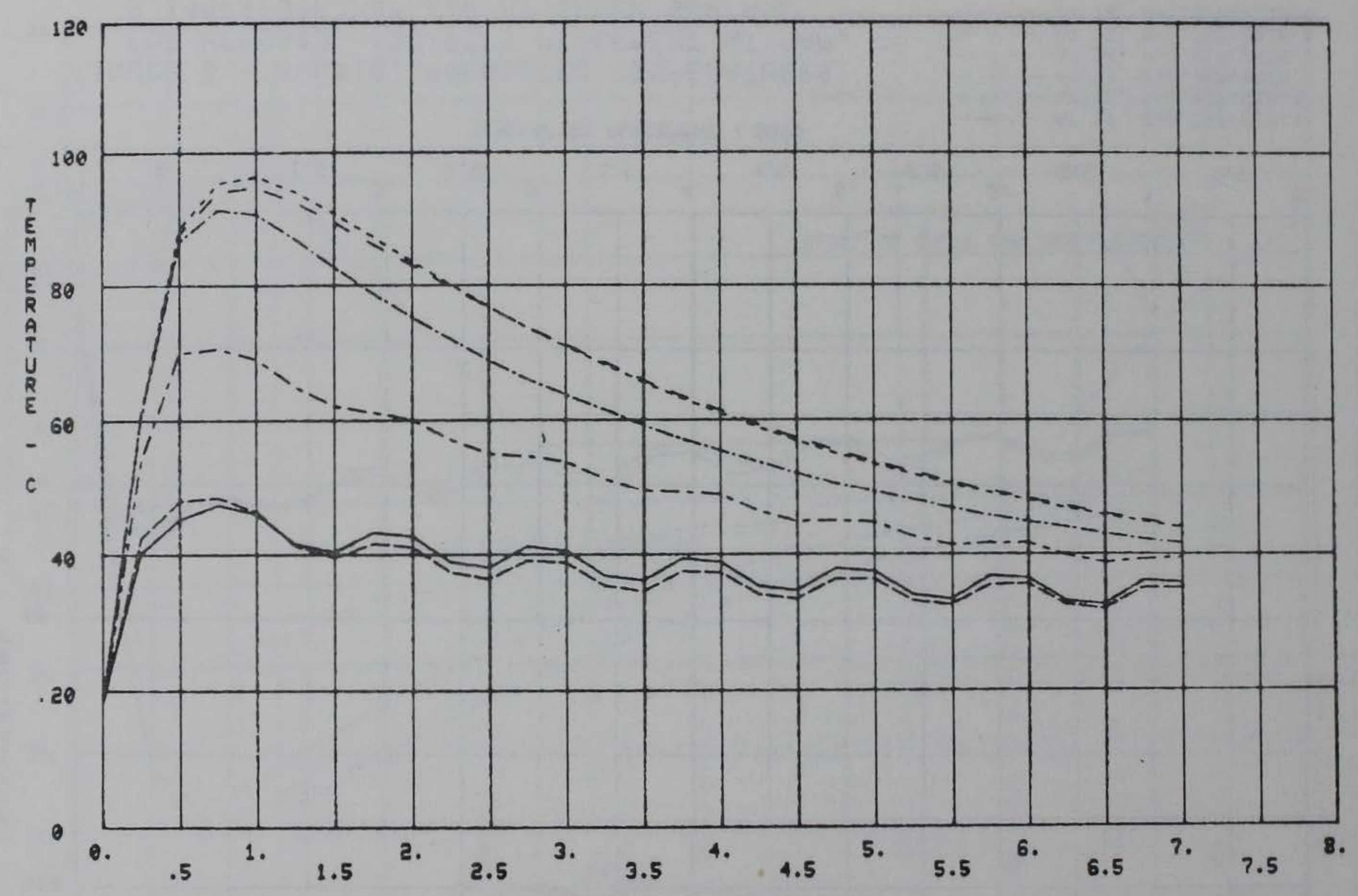

TIME AFTER PLACEMENT - DAYS

FIGURE 9 - RUN\#11, PREDICTED TEMPERATURES FOR HEMSS $\$ 3,18 C(65 F)$ PLACEMENT AT OPM, $9.14 M / S(30 F T / S)$ AIR AT INNER SURFACE 


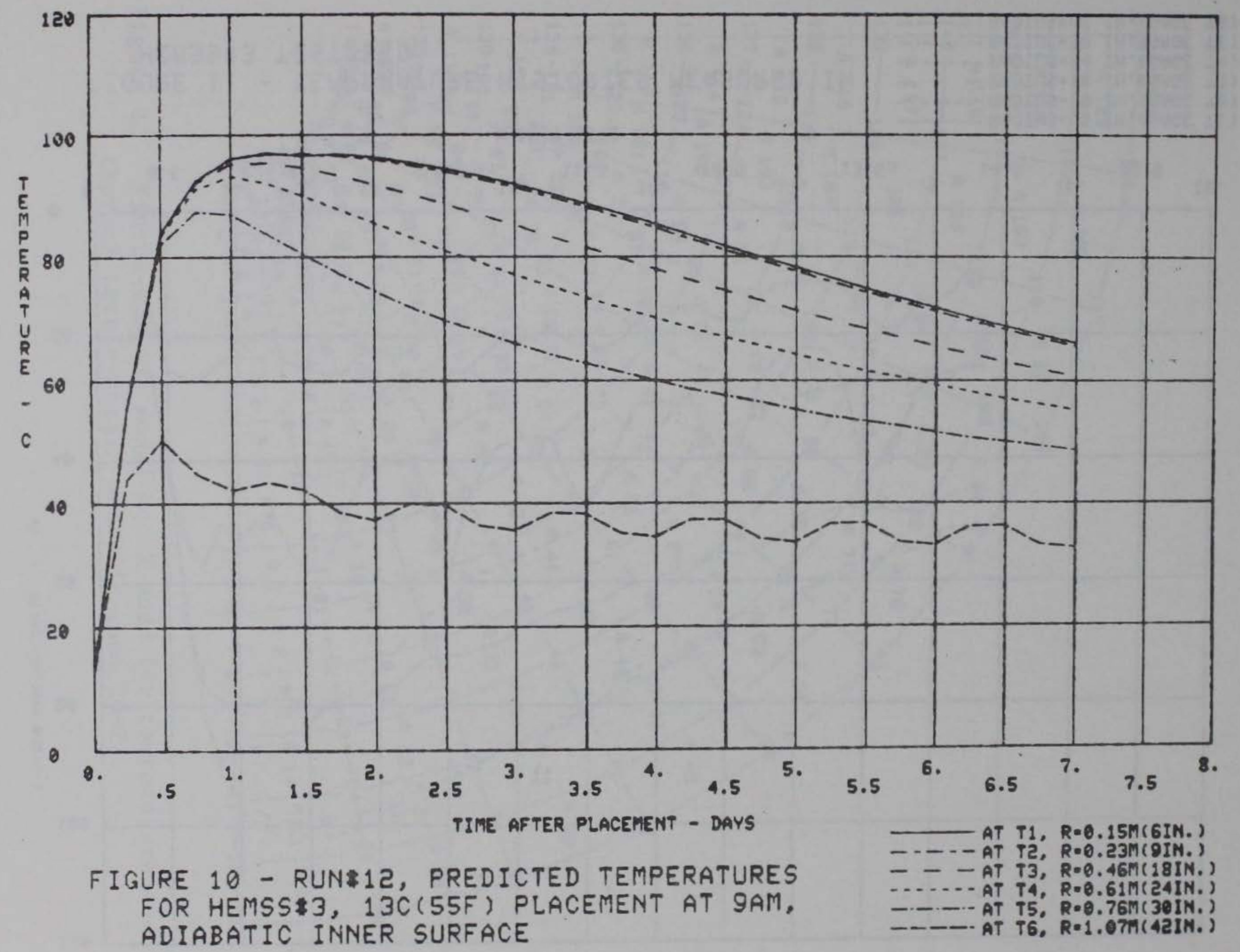




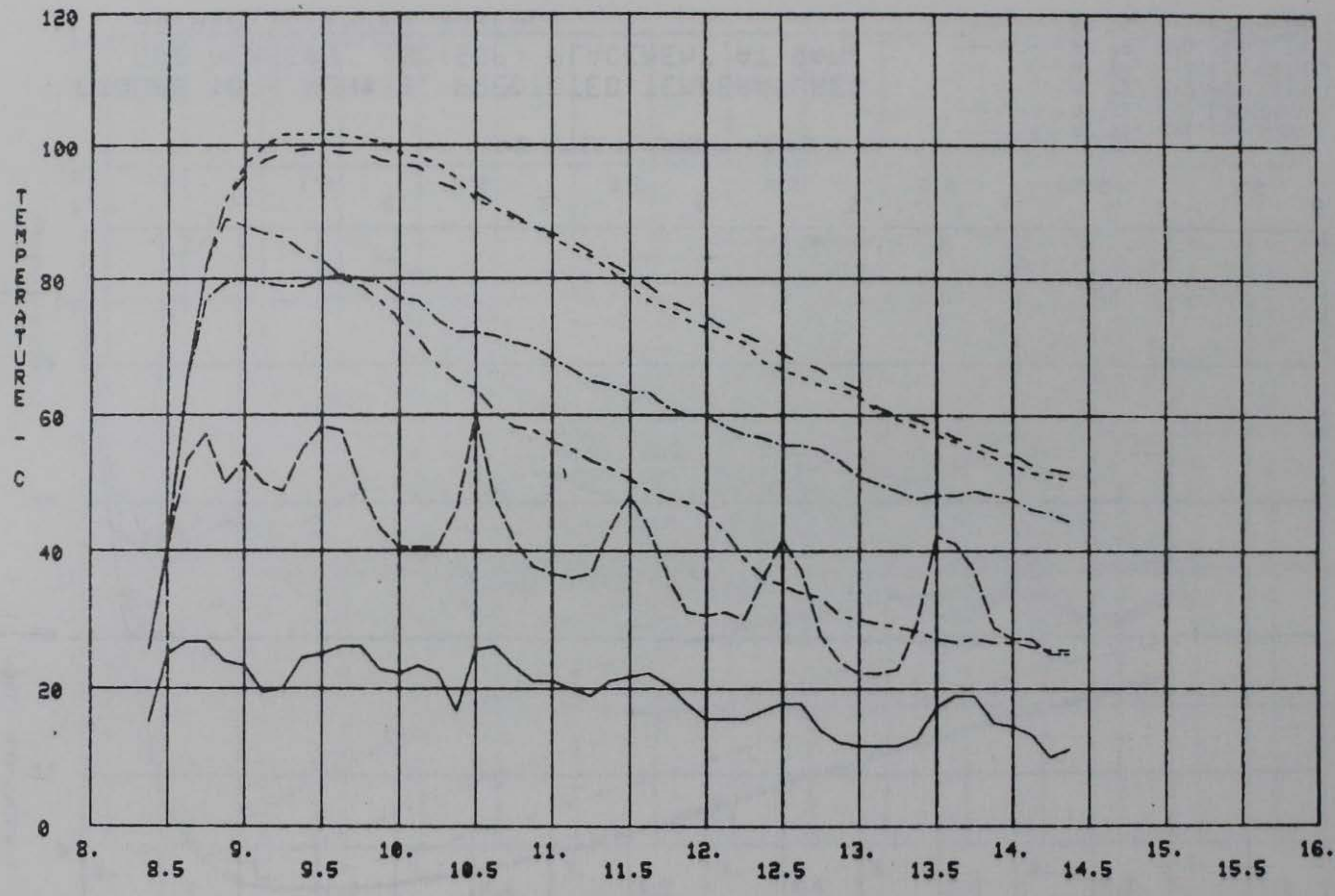

AUQUST 1978

FIGURE 11 - TEMPERATURE HISTORIES MEASURED IN HEMSS $\$ 3$ TEST BED 


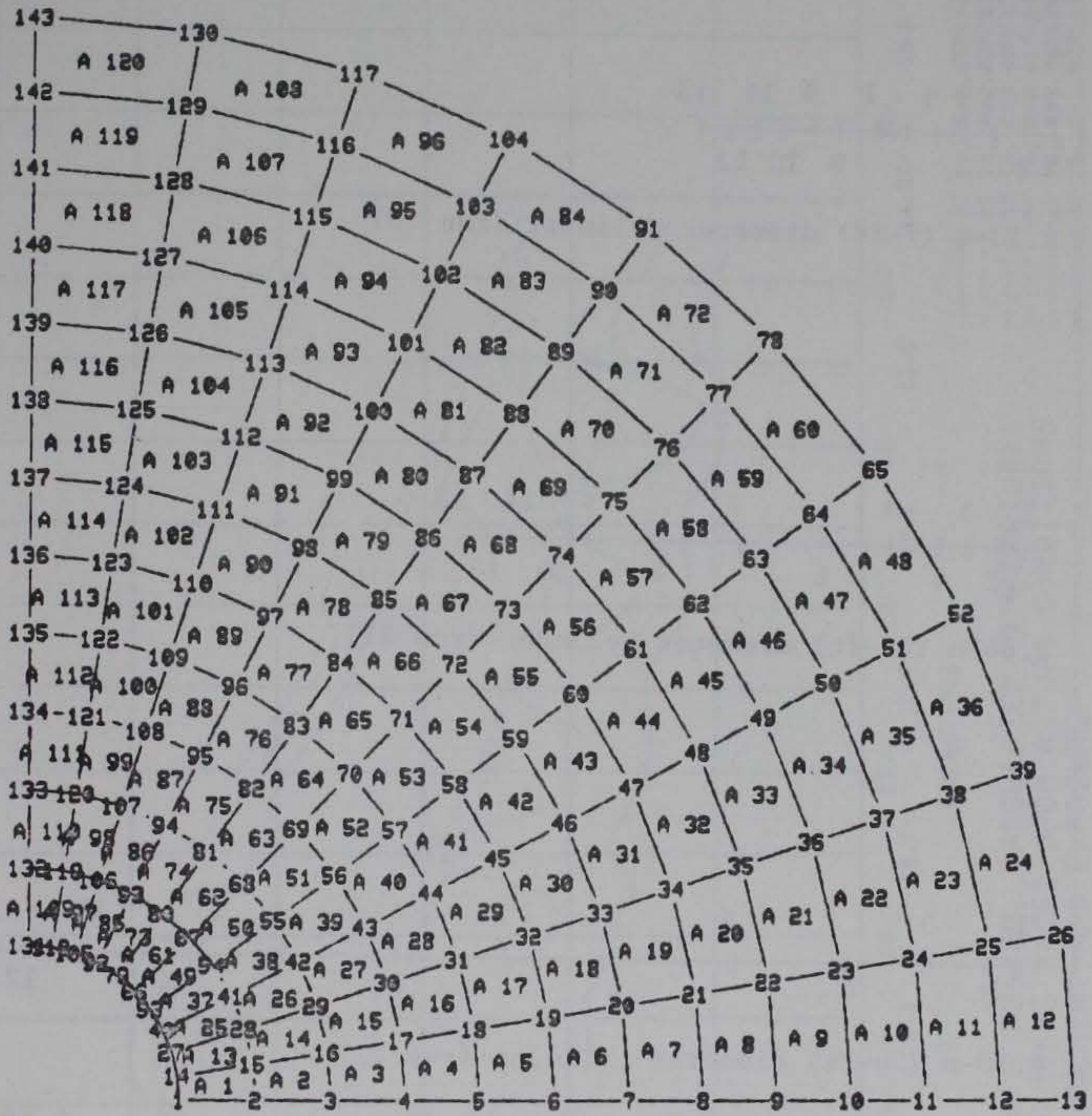

Figure 12. Finite-element model No. 2 used for temperature and thermal stress-strain analysis runs 20-22. 


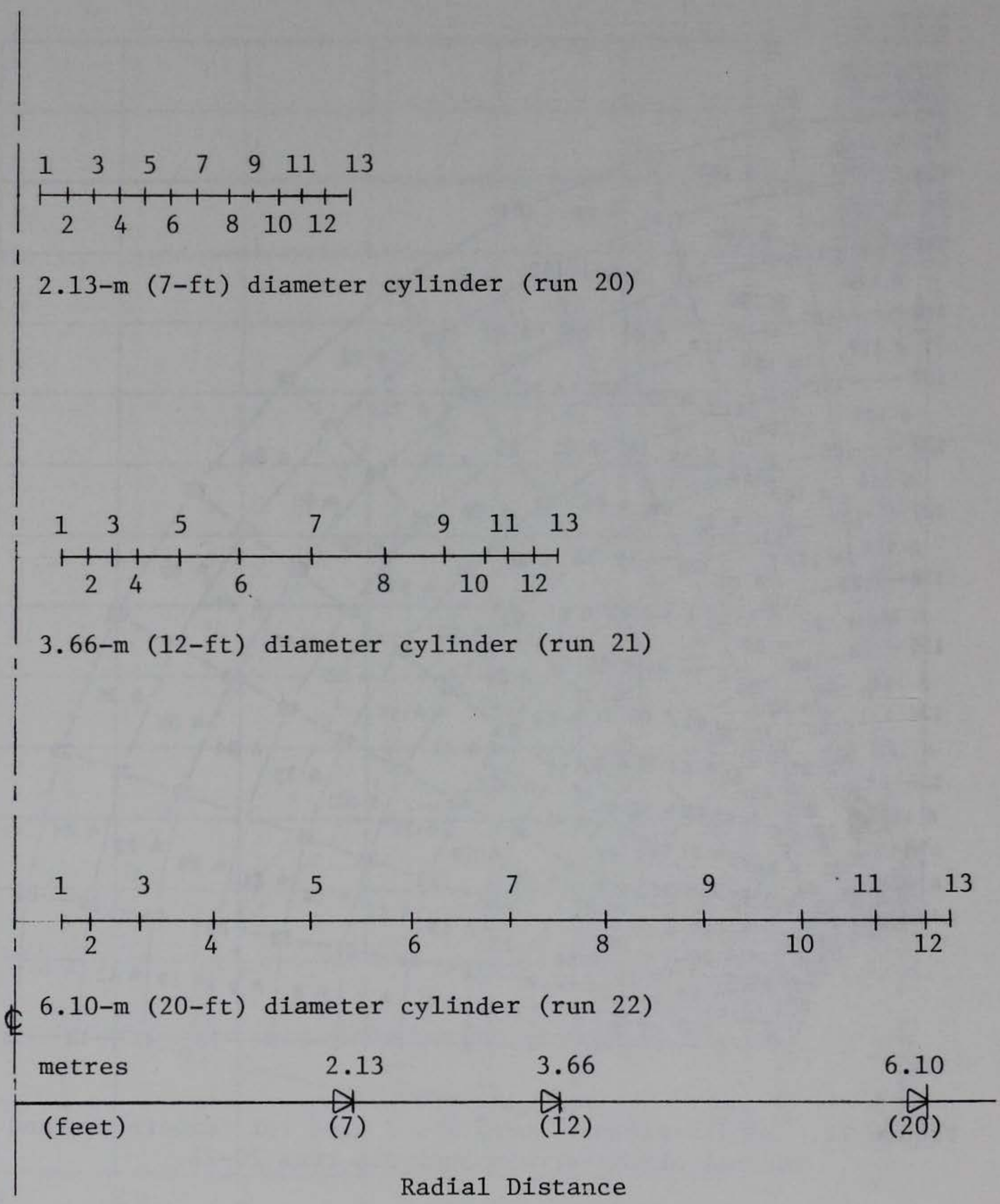

Figure 13. Radial finite-element node locations for runs 20-22. Location at which thermal stresses and strains are calculated for elements are radially midway between adjacent nodes. 


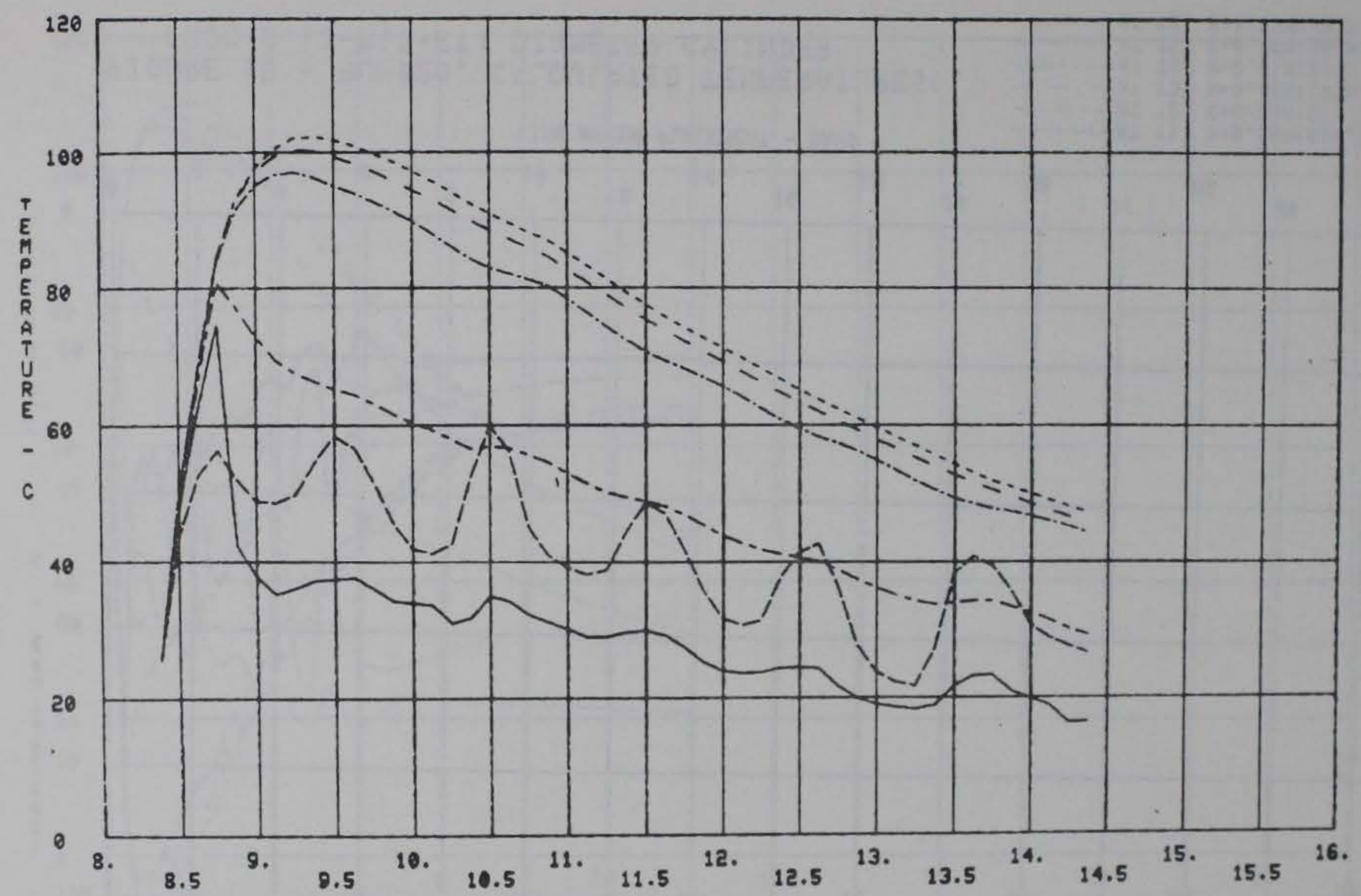

AUGUST 1978

FIGURE 14 - RUN $\$ 20$, CALCULATED TEMPERATURES FOR HEMSS 3 BASED UPON ACTUAL CONDITIONS OF PLACEMENT AND EXPOSURE 


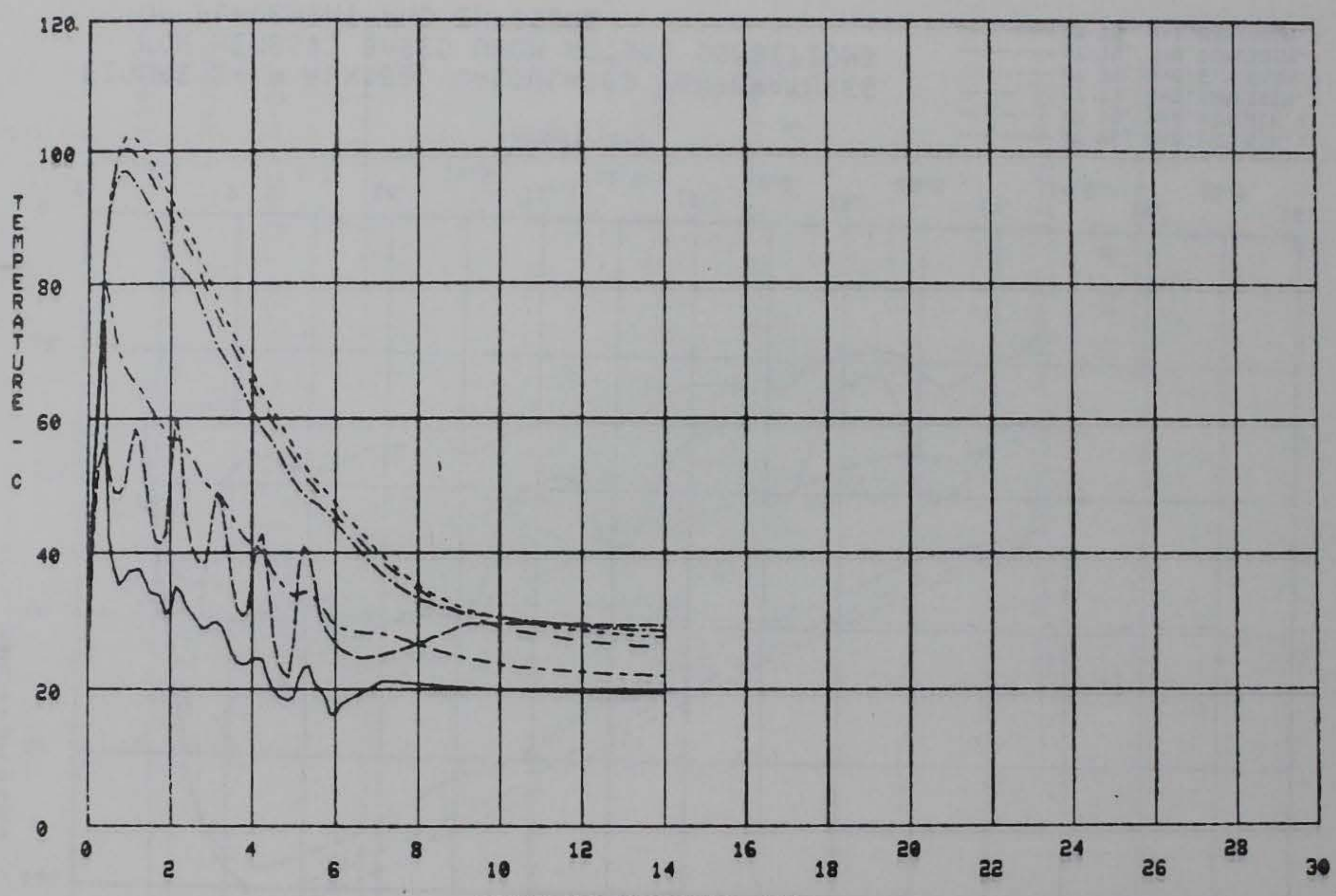

TIME AFTER PLACEMENT - DAYS

FIGURE 15 - RUN $\$ 20$, CALCULATED TEMPERATURES FROM 2.13-M(?-FT) DIAMETER CYLINDER

- AT T1, Re- $15 \mathrm{MA}(6 I \mathrm{~N}$.

- - - AT TE, R=0.23A(gIN.)

- - - AT T3, R=0.46A(18IN.)

-

- - AT T6, $R=1.27 A(42 I N$, 


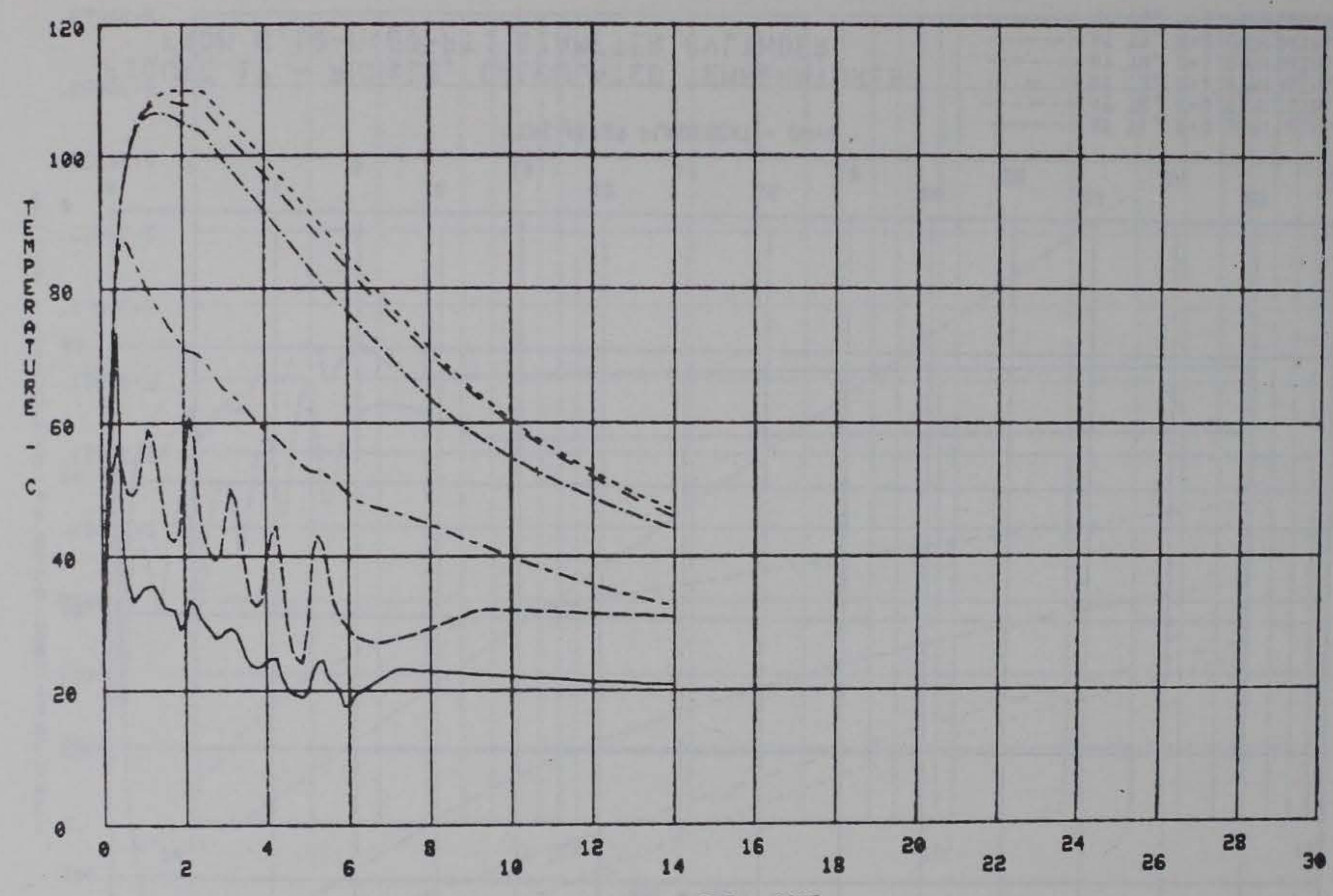

TIME AFTER PLACEHENT - DAYS

FIGURE 16 - RUN\$21, CALCULATED TEMPERATURES FROM 3.66-M(12-FT) DIAMETER CYLINDER 


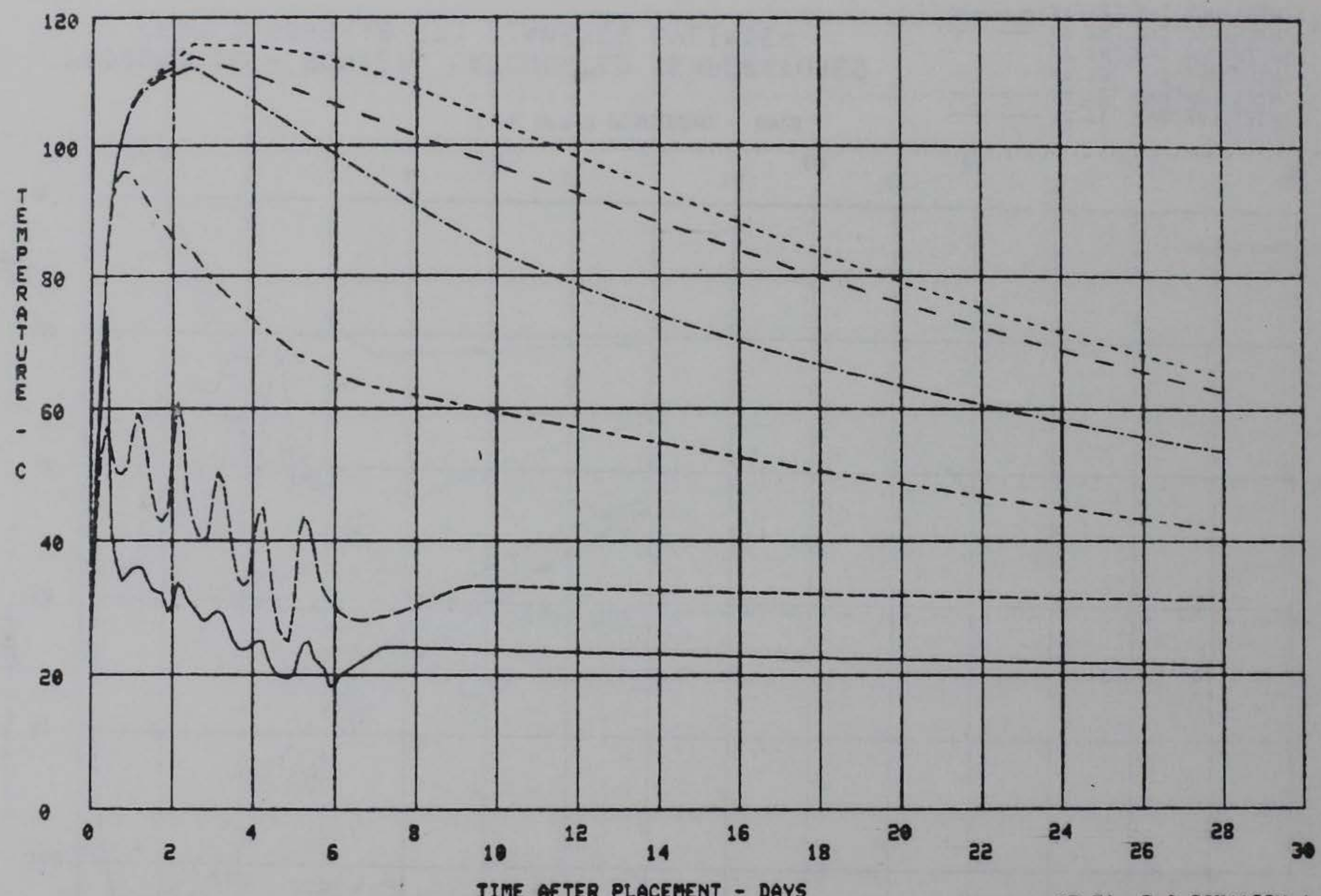

FIGLRE $1 ?$ - RUN\#22, CALCULATED TEMPERATURES FROM 6.10-M(20-FT) DIAMETER CYLINDER 


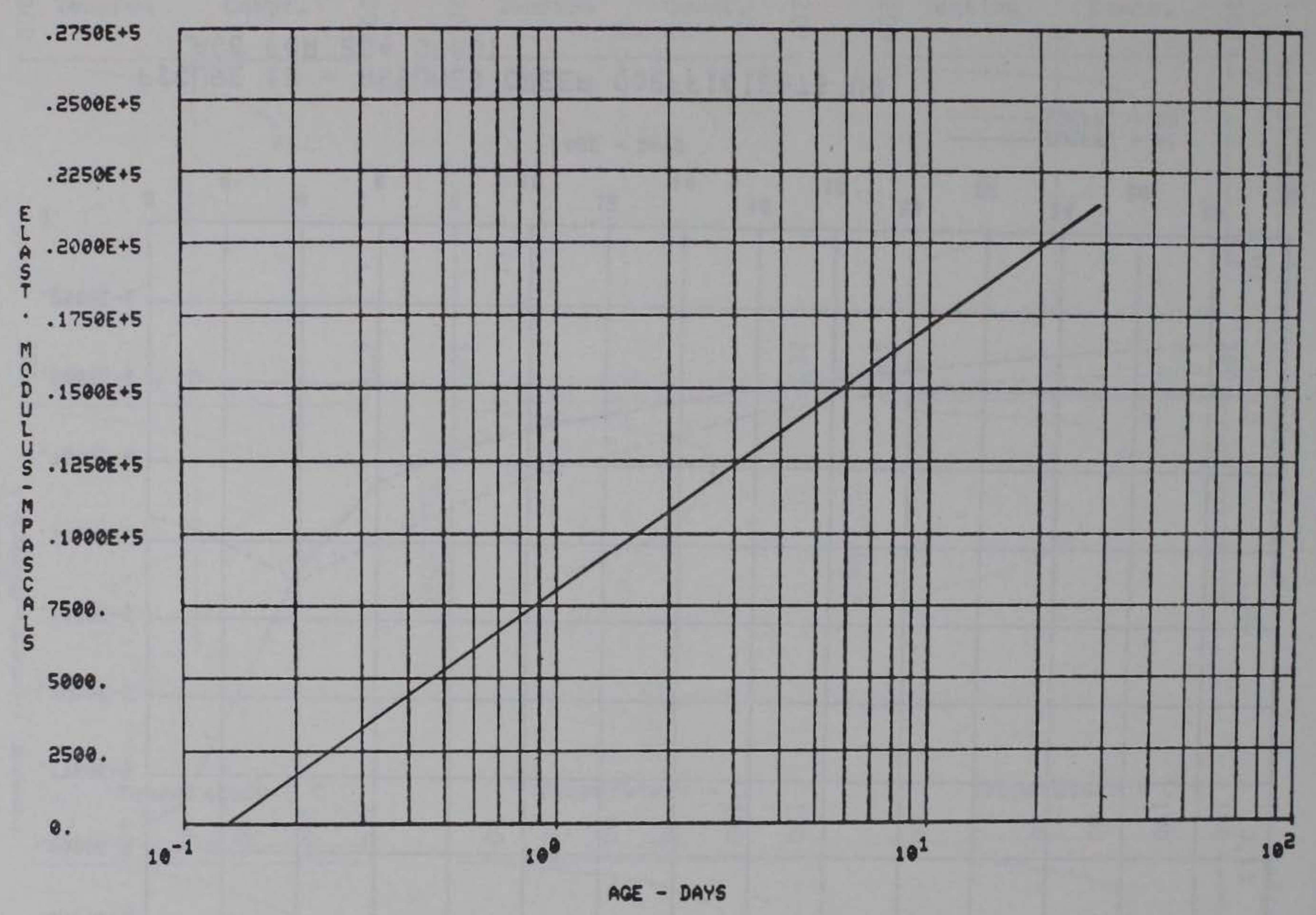

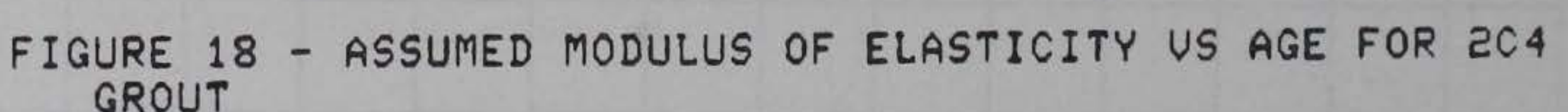




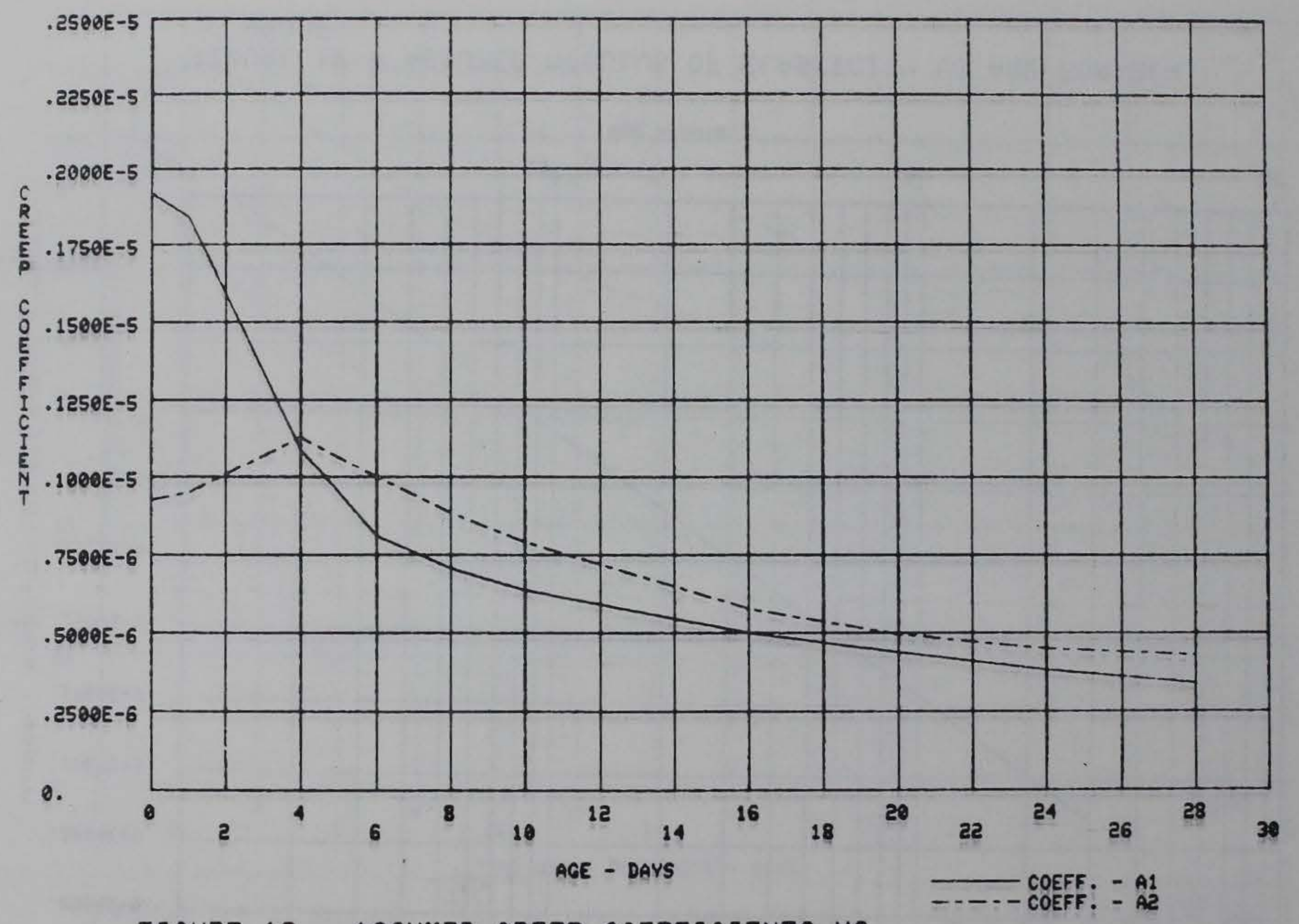

FIGURE 19 - ASSUMED CREEP COEFFICIENTS US AGE FOR 2C4 GROUT 
Tangential Strain Gradients
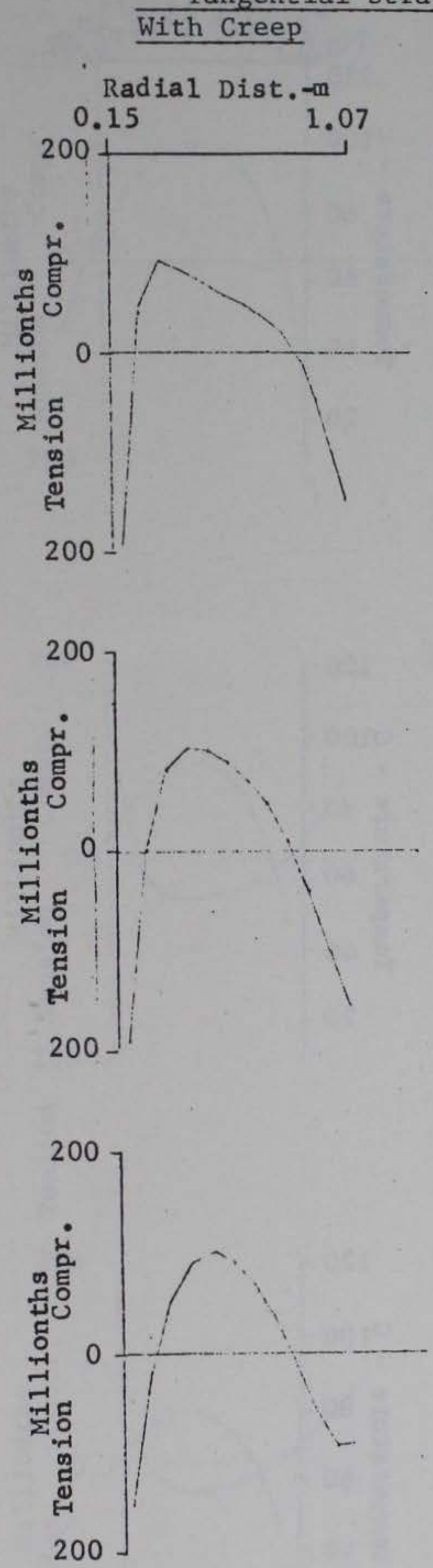

Without Creep

Radial Dist.-m

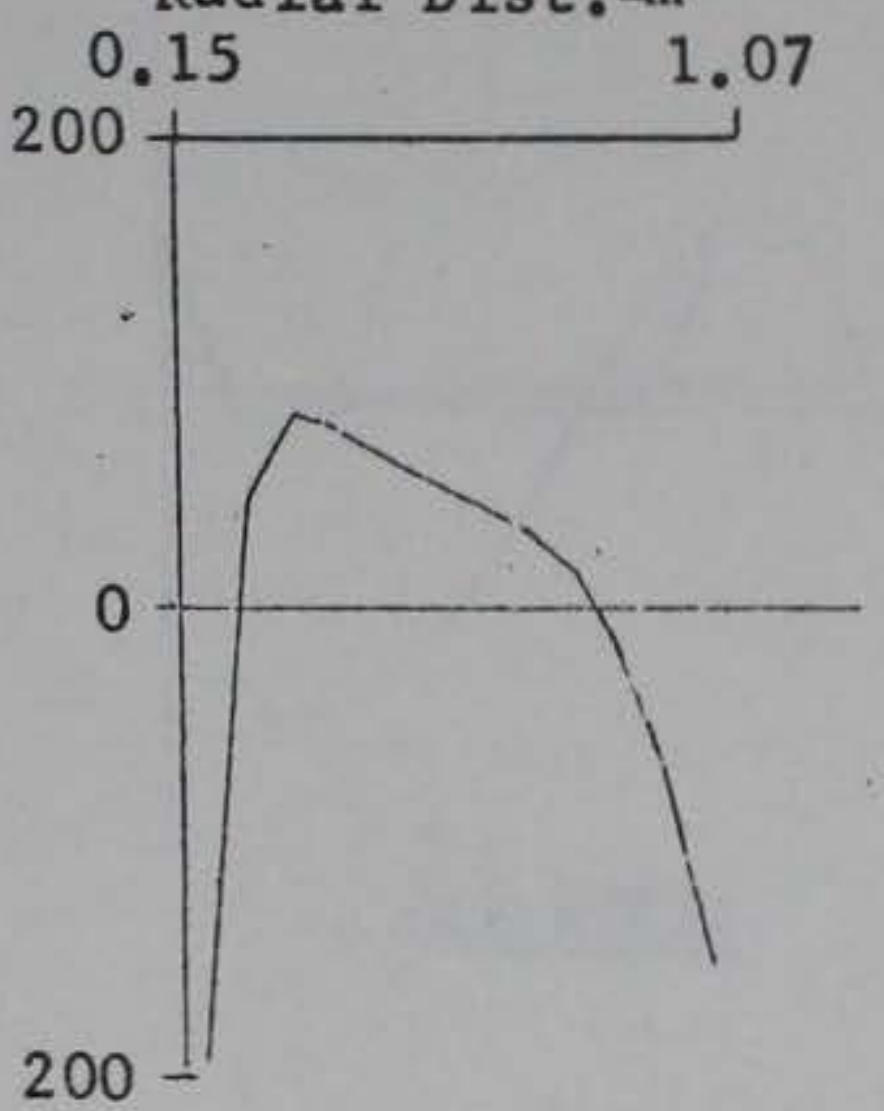

$\underline{0.50 \text { Days }}$

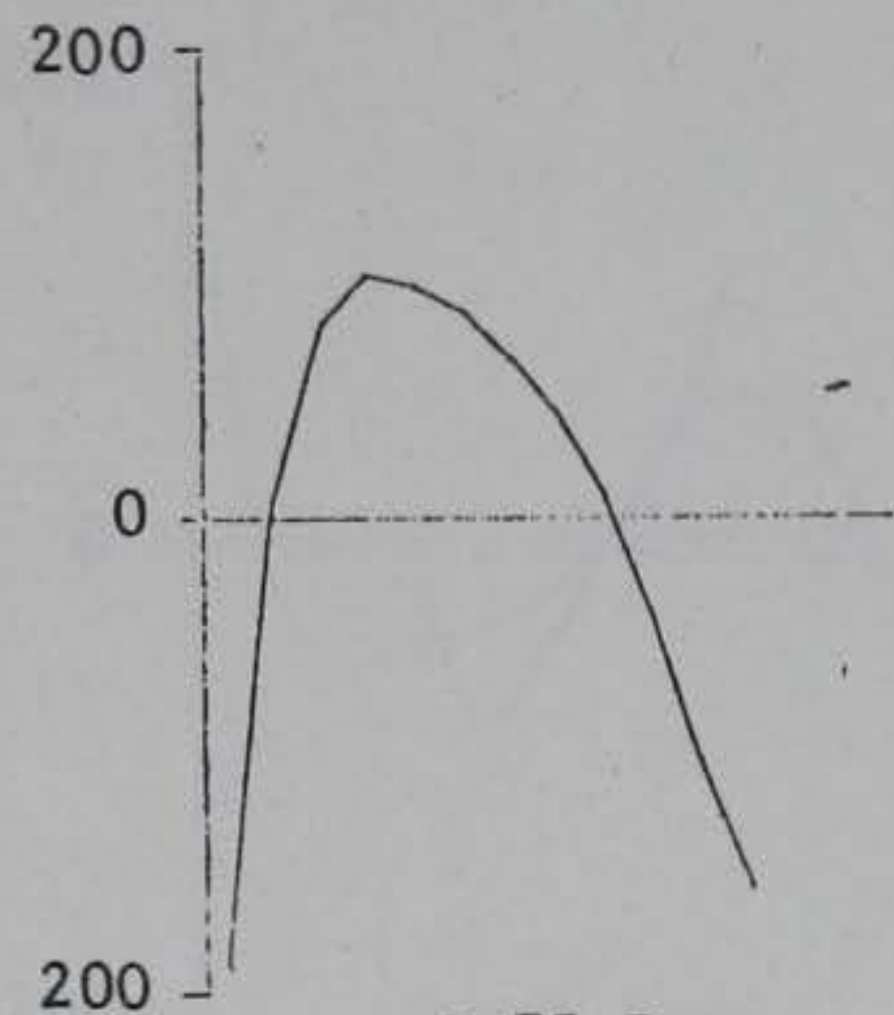

$\underline{0.75 \text { Days }}$

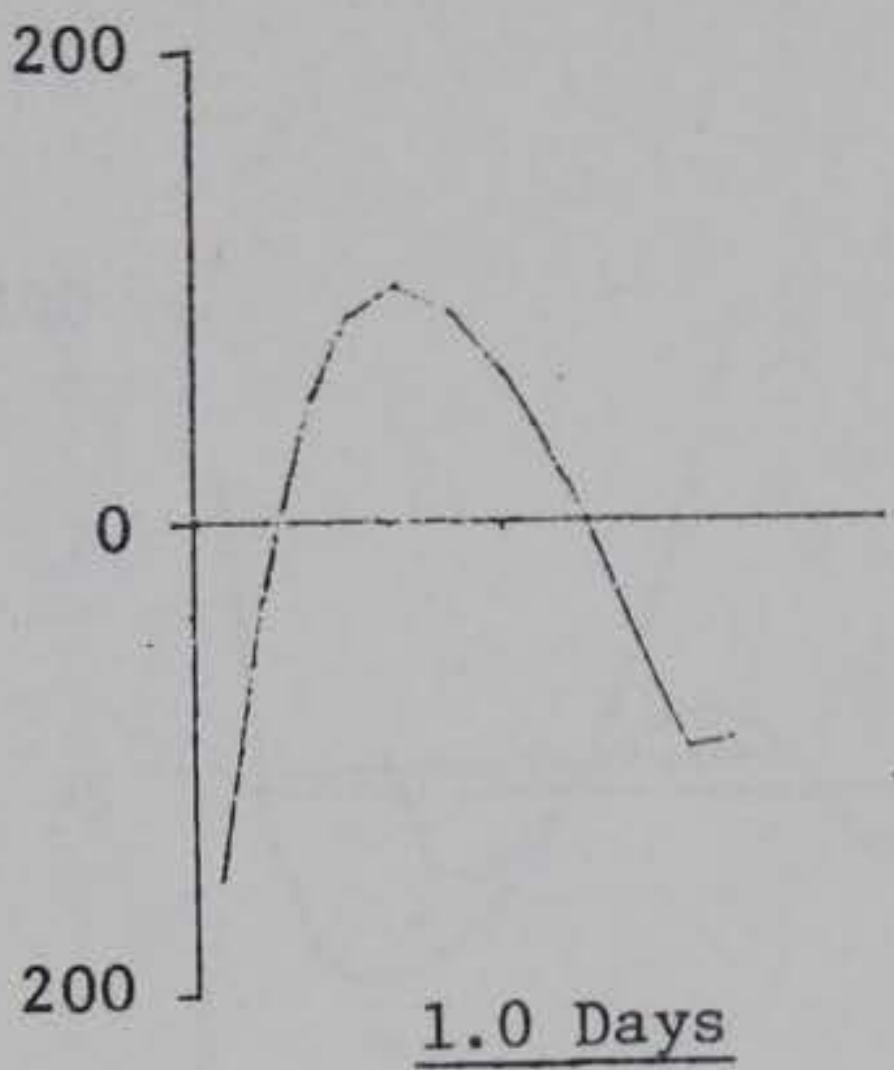

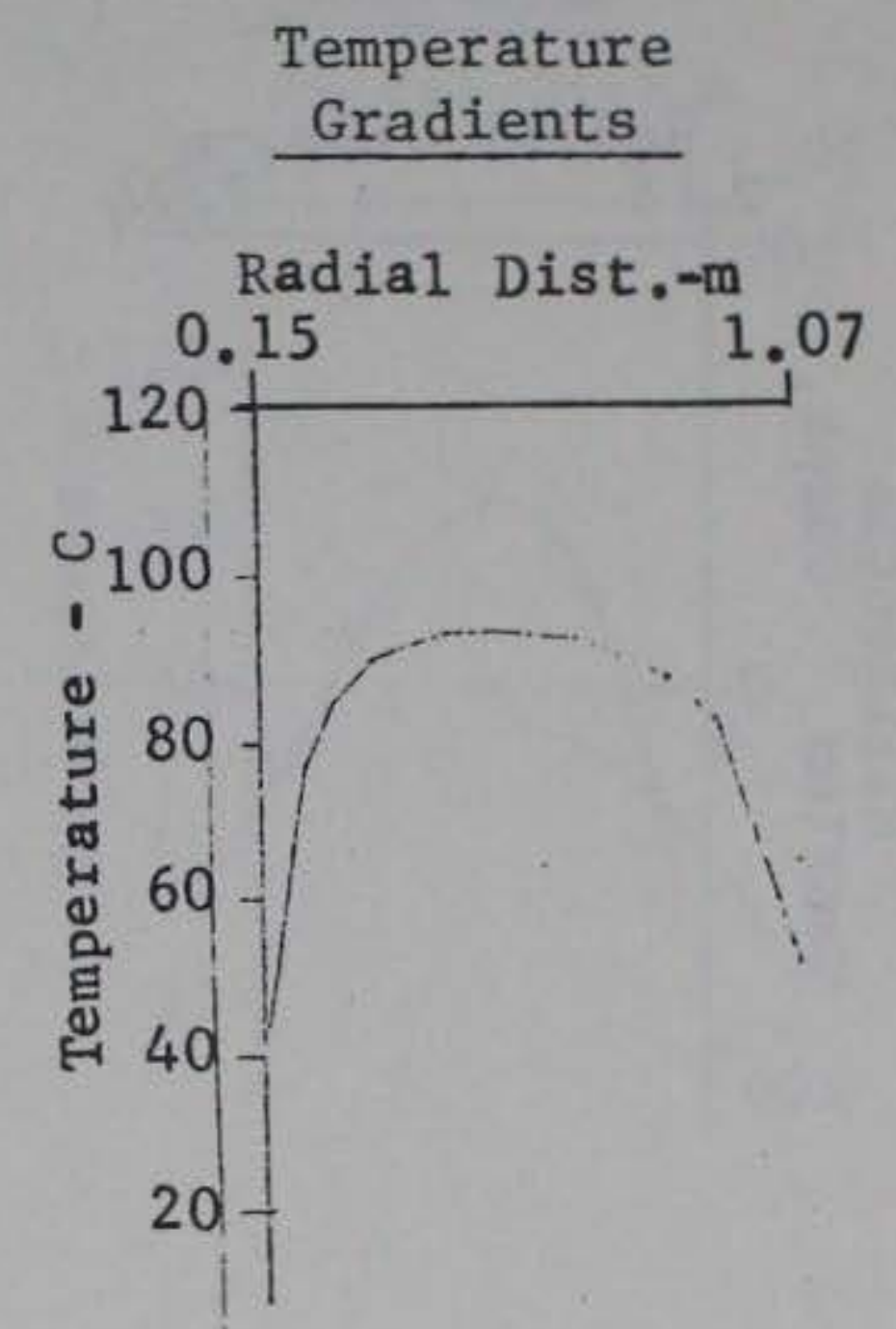
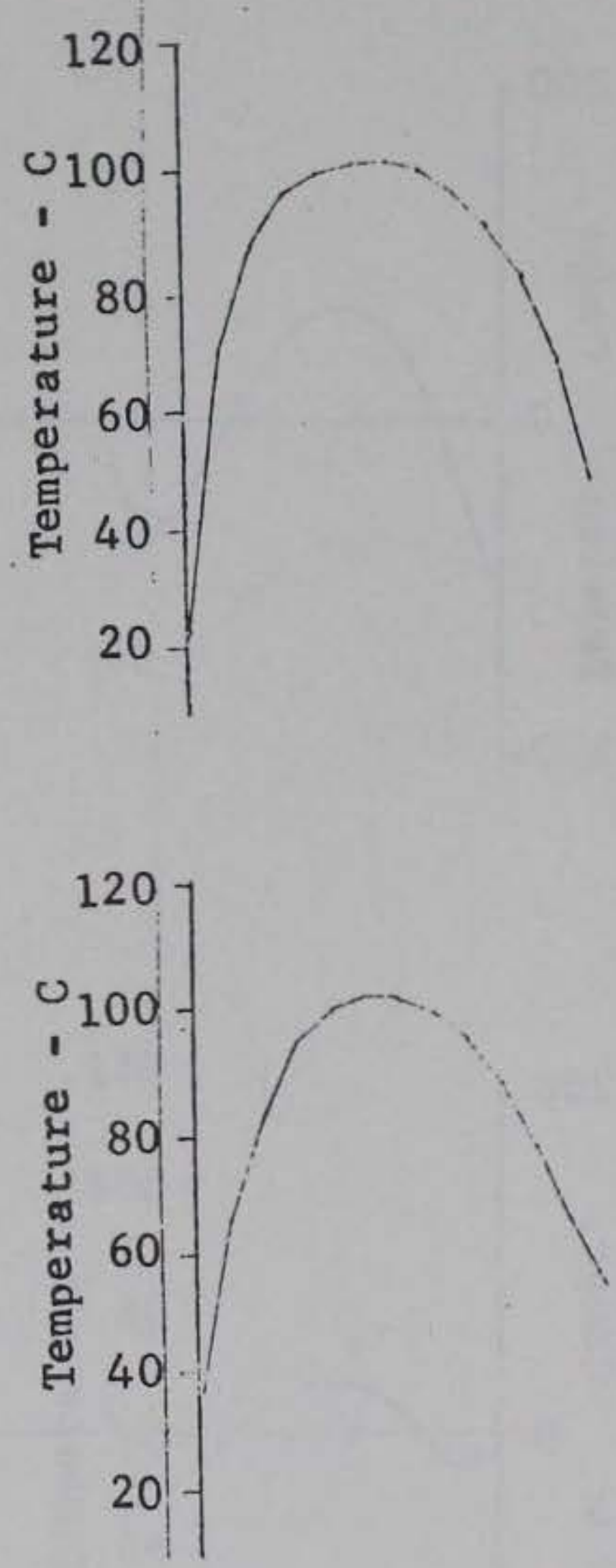

Figure 20. Computed tangential strain and temperature gradients across the radius of $2.13-\mathrm{m}$ ( $7-\mathrm{ft}$ ) diameter cylinder at successive times after placements (Sheet 1 of 3 ) 
Tangential Strain Gradients

\section{With Creep $\quad$ Without Creep}
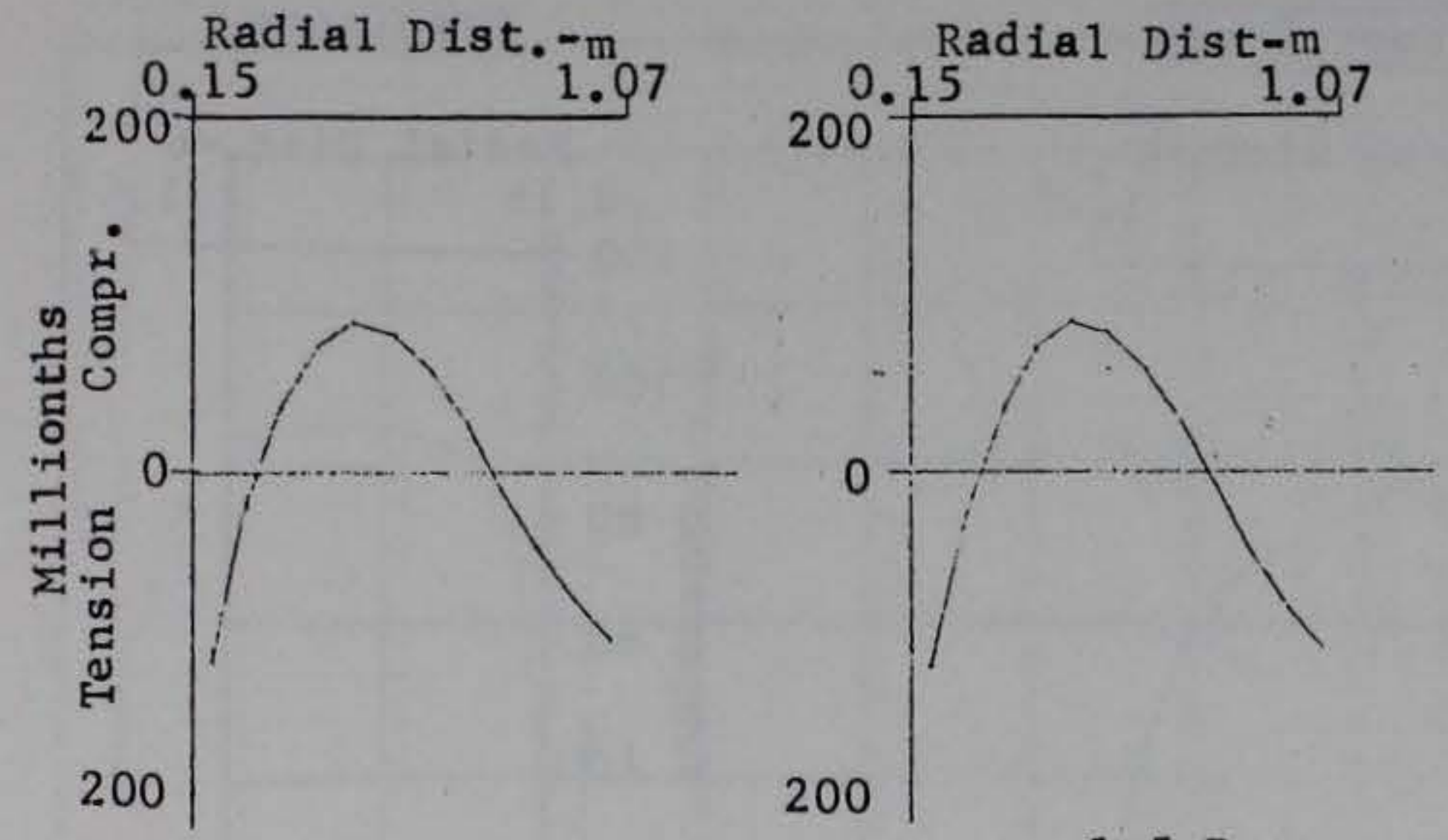

1.5 Days
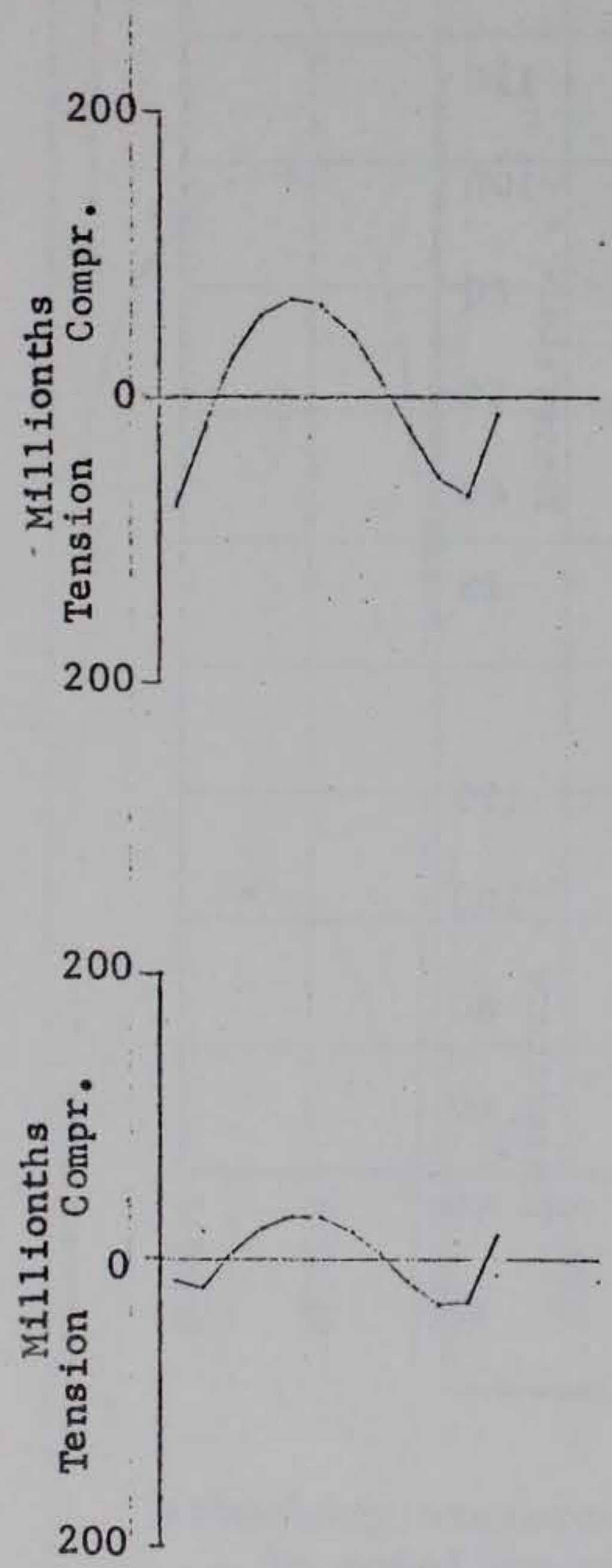

200

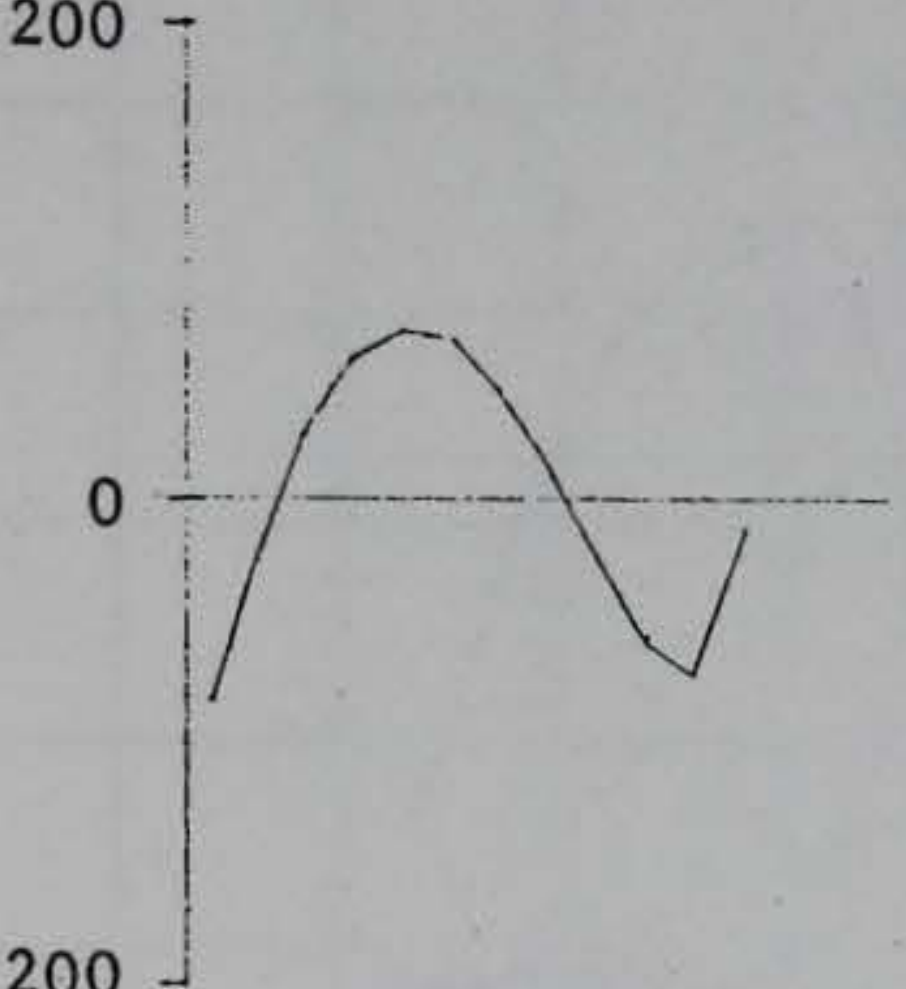

2.0 Days
Temperature

Gradients
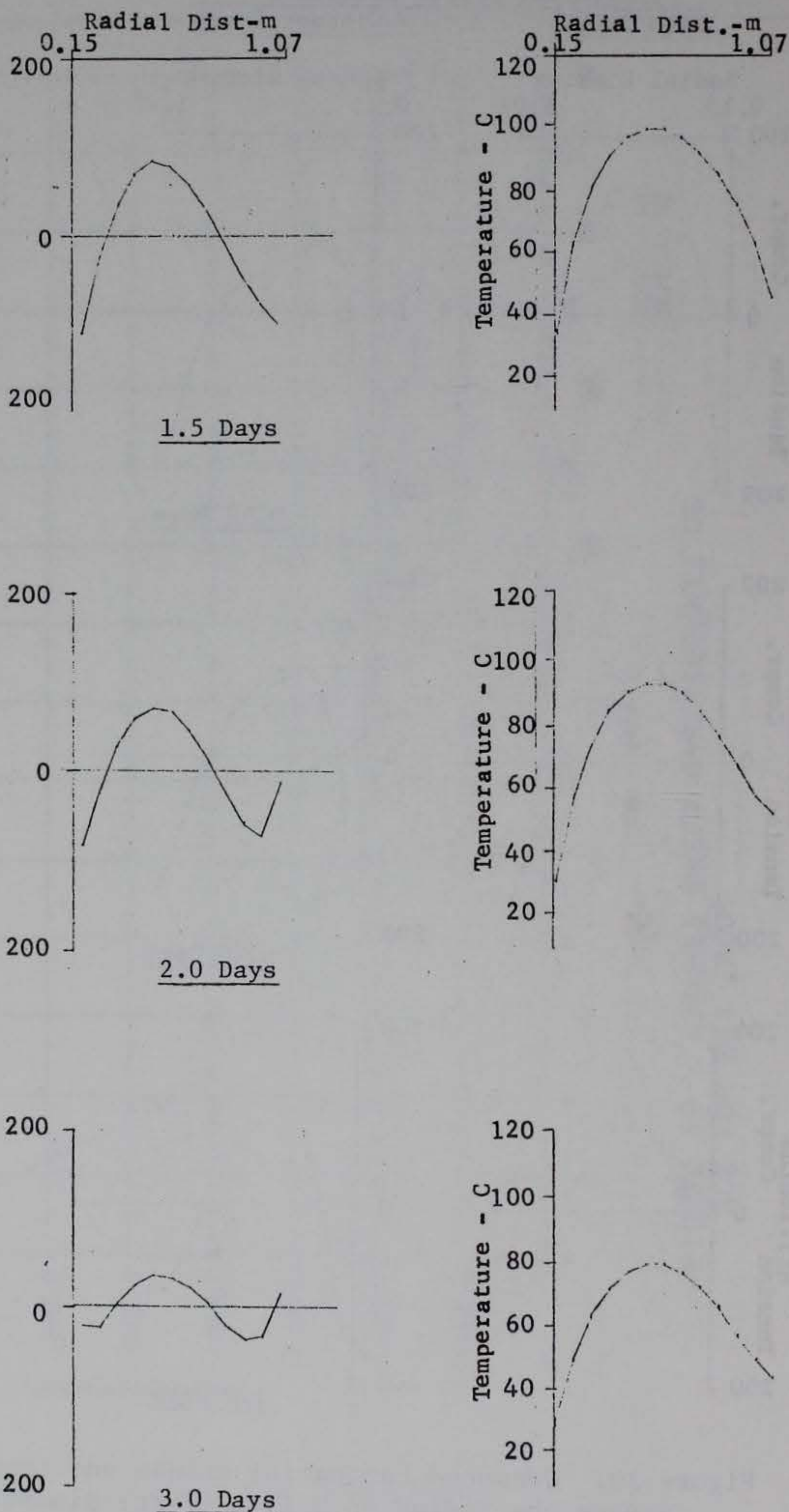

Figure 20. (Sheet 2 of 3 ) 
Tangential Strain Gradients With Creep Without Creep Radial Dist. $-\mathrm{m}$

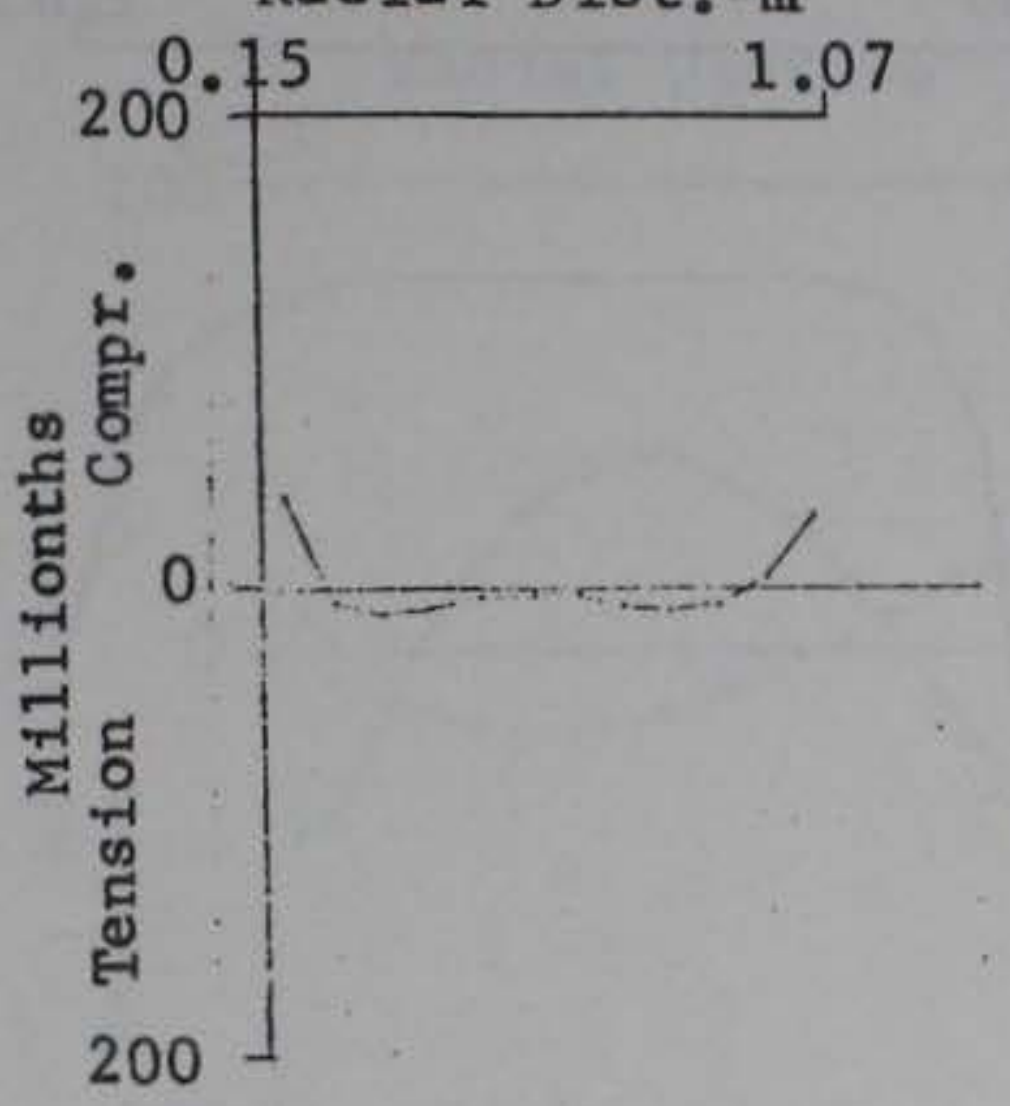

200

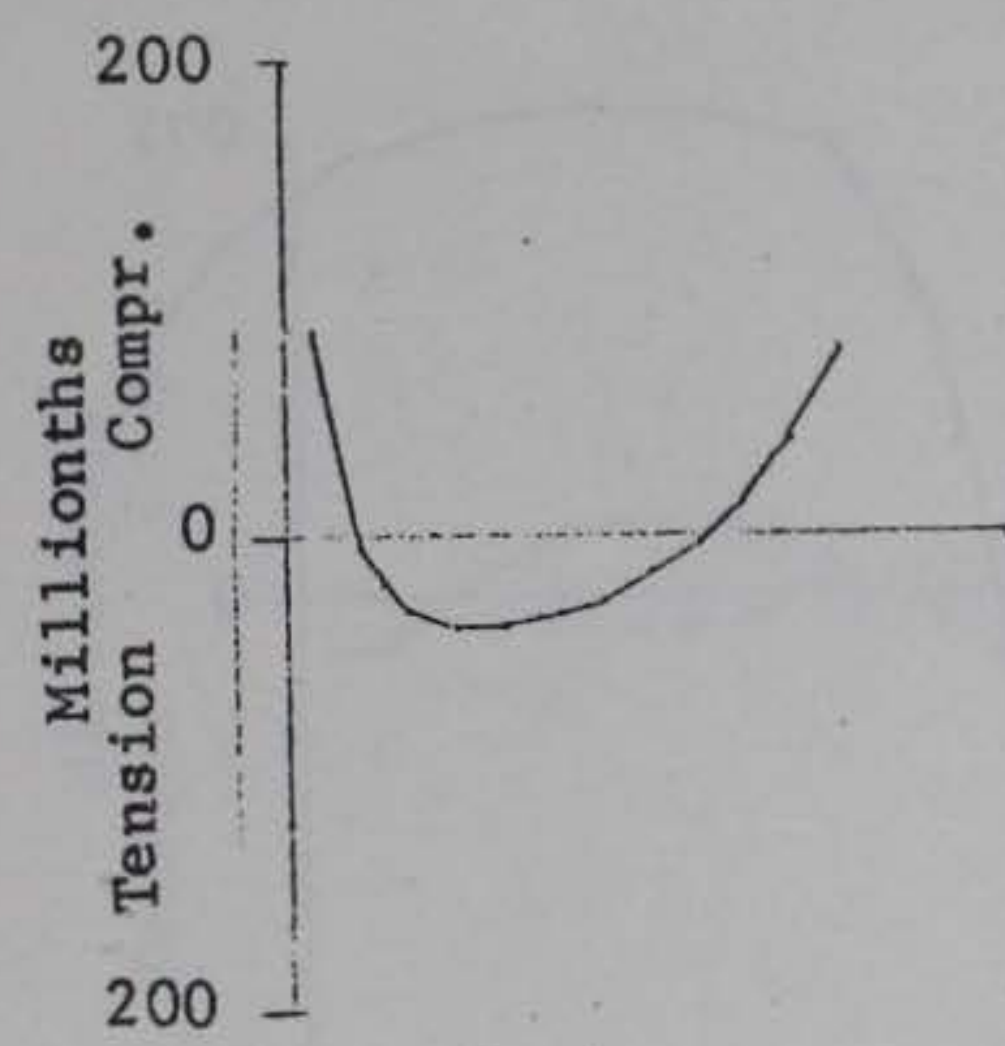

ฐ

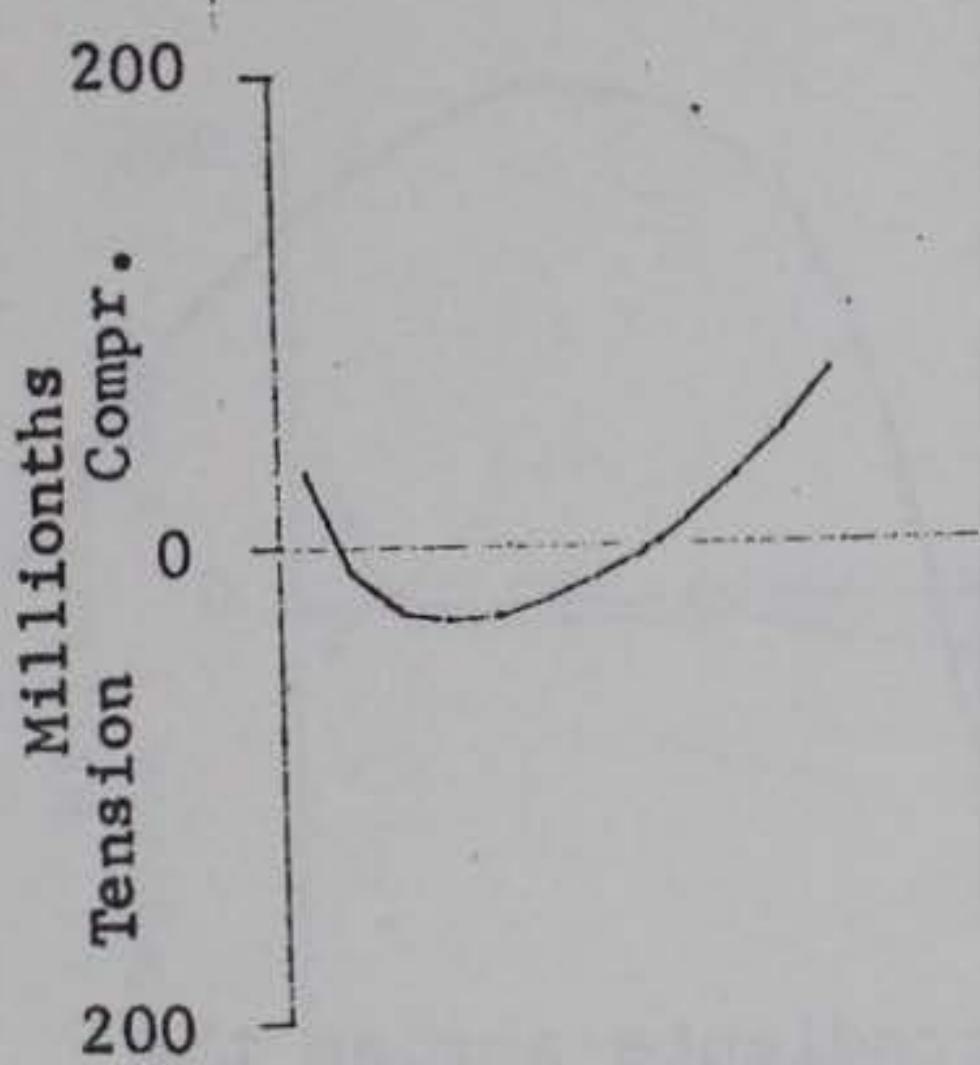

Radial Dist. $-\mathrm{m}$

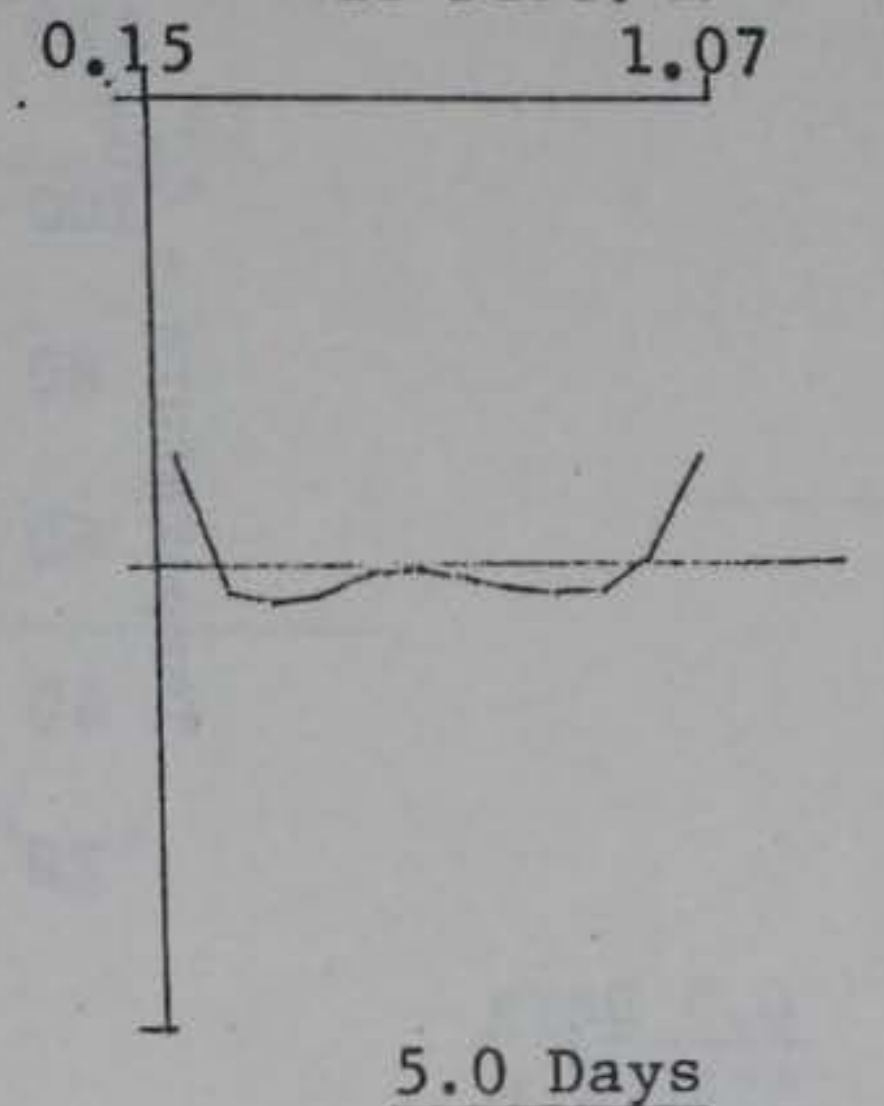

200

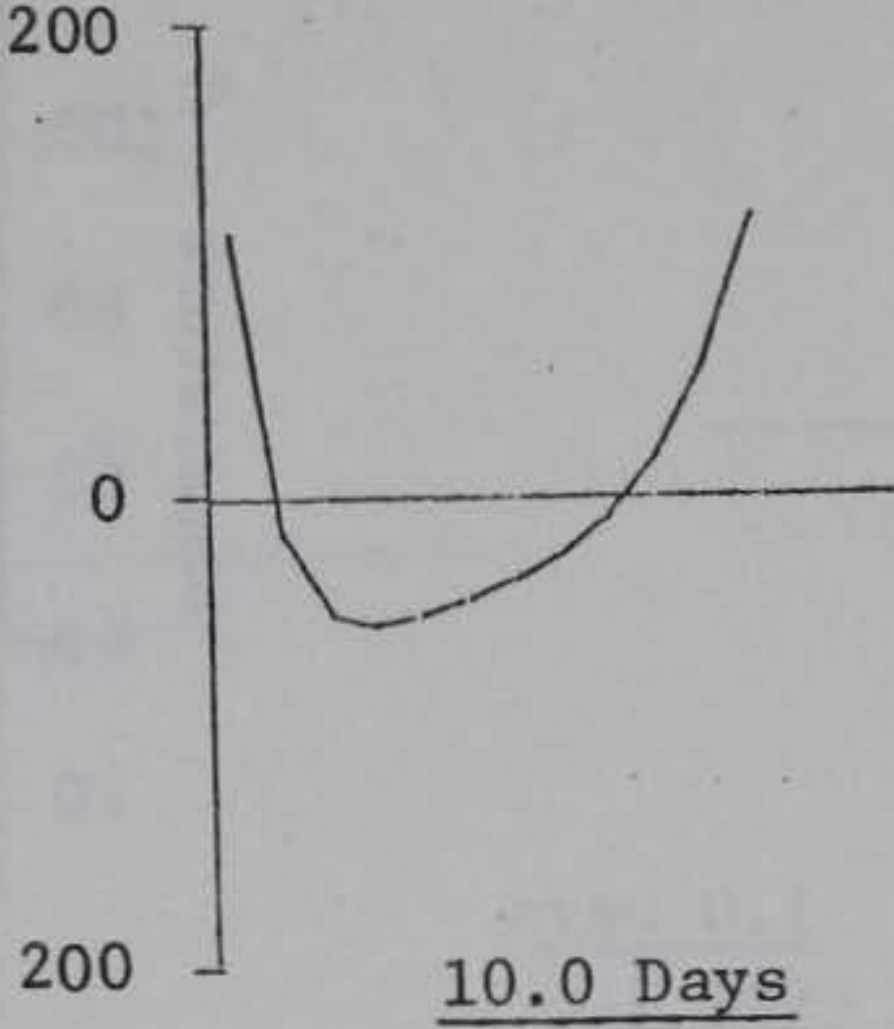

200

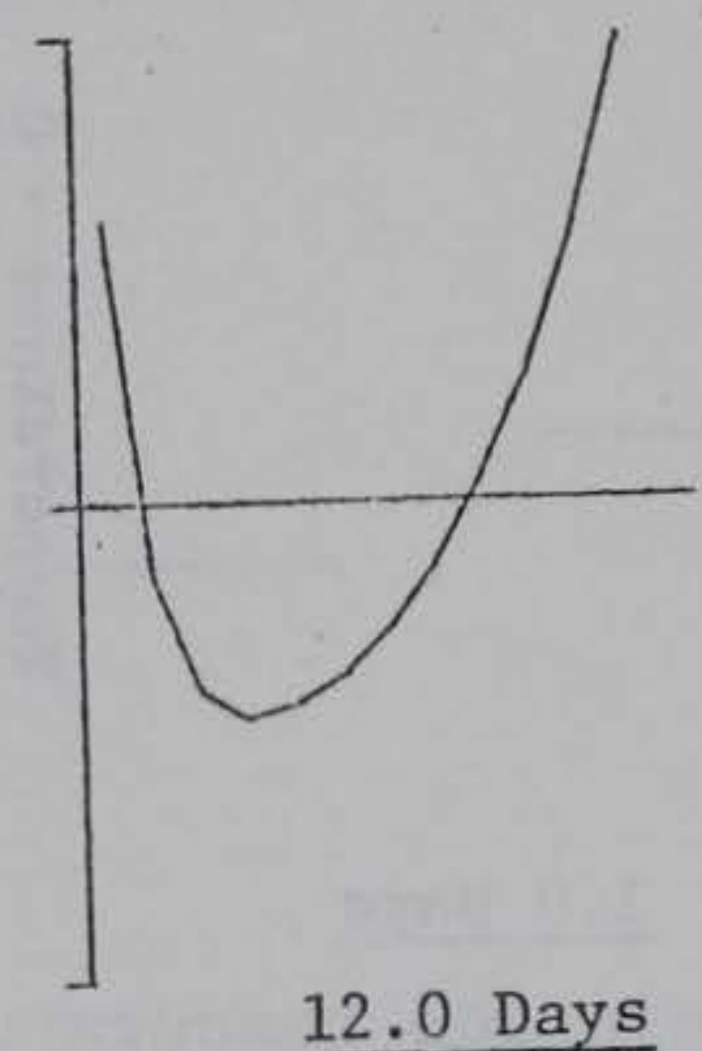

Temperature

Gradients

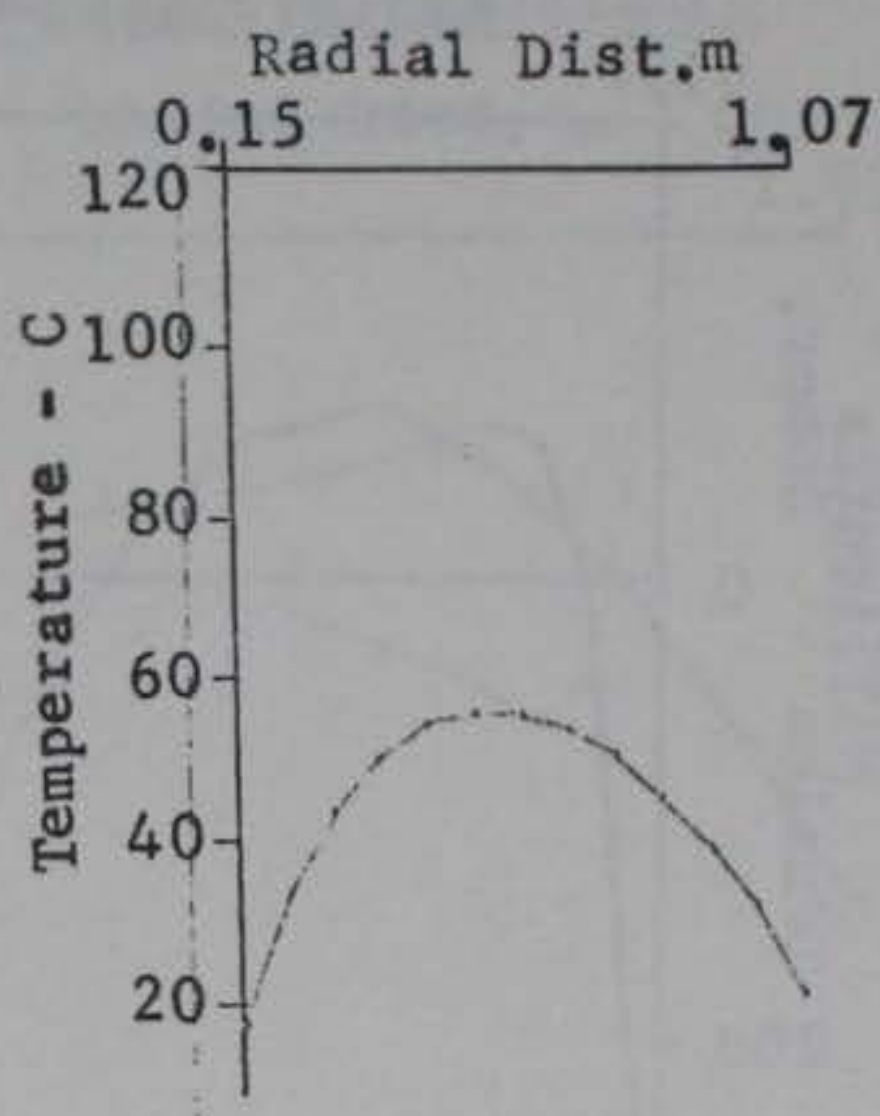

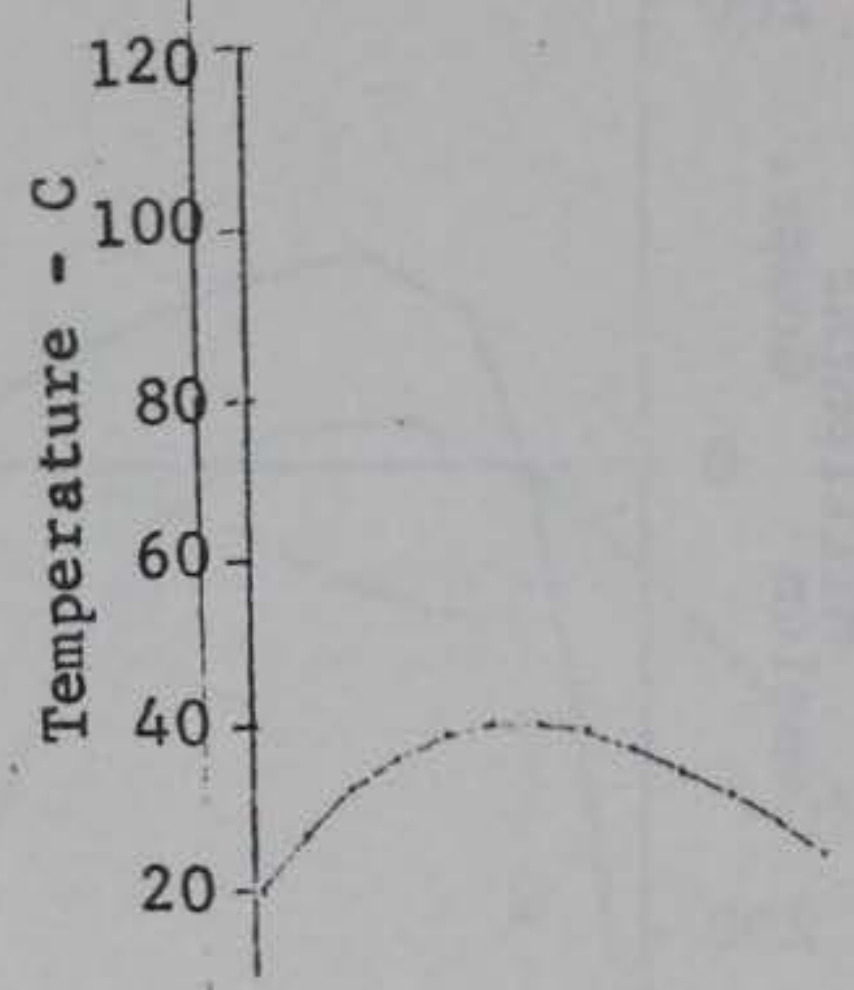

Figure 20. (Sheet 3 of 3 ) 


\section{Strain Gradients}
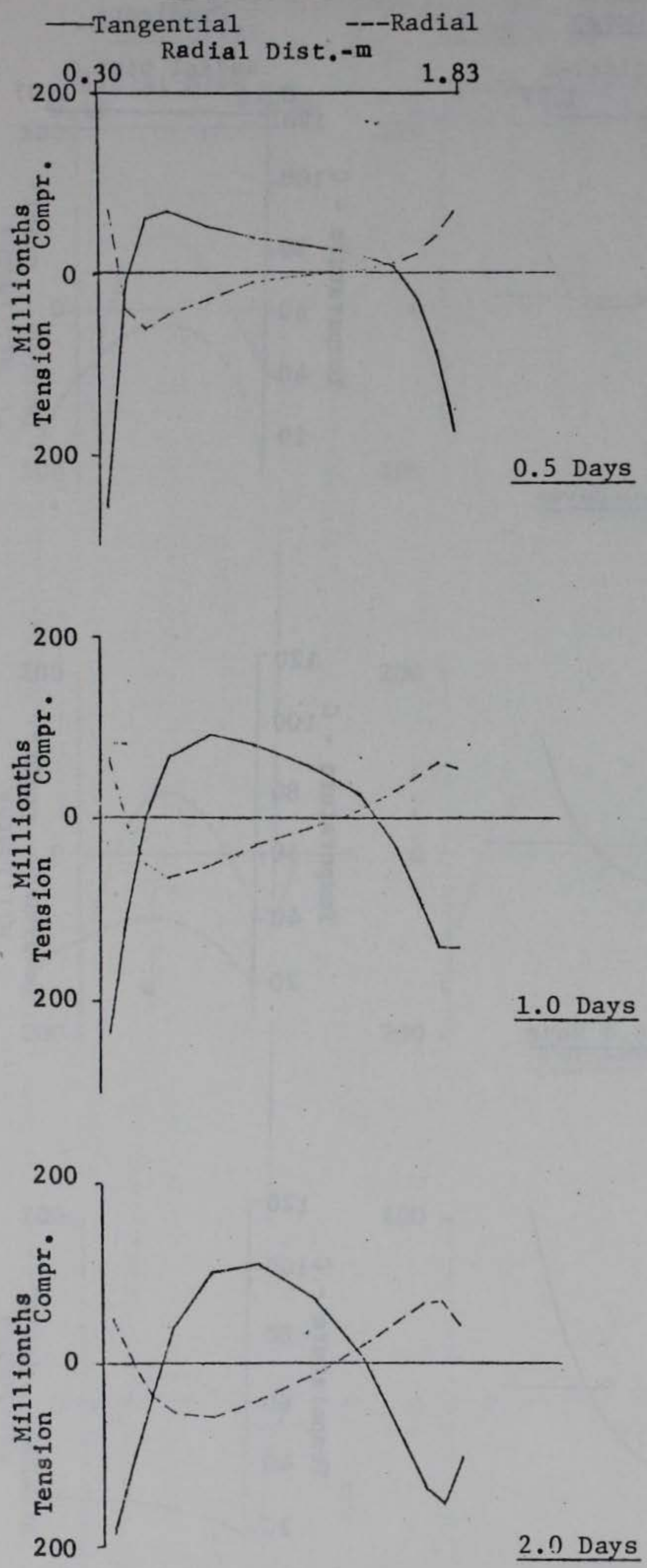

Temperature Gradients
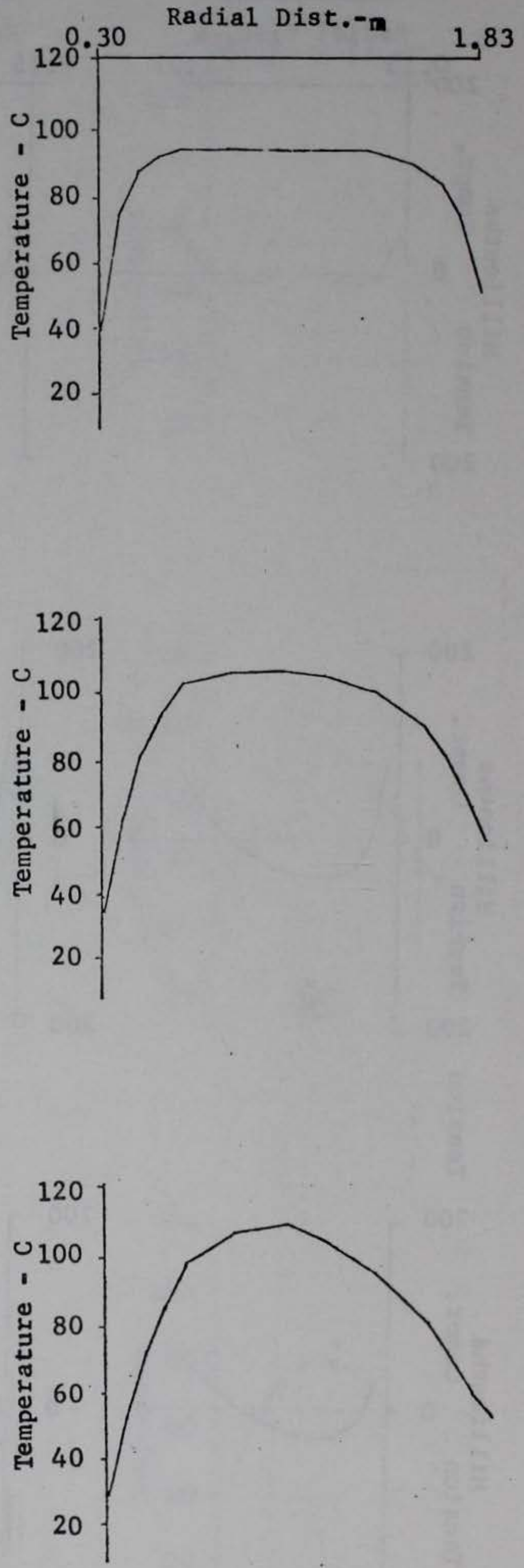

Figure 21. Computed strain and temperature gradients across the radius of $3.66-\mathrm{m}(1.2-\mathrm{ft})$ diameter cylinder at successive times after placement (Sheet 1 of 3) 


\section{Strain Gradients}
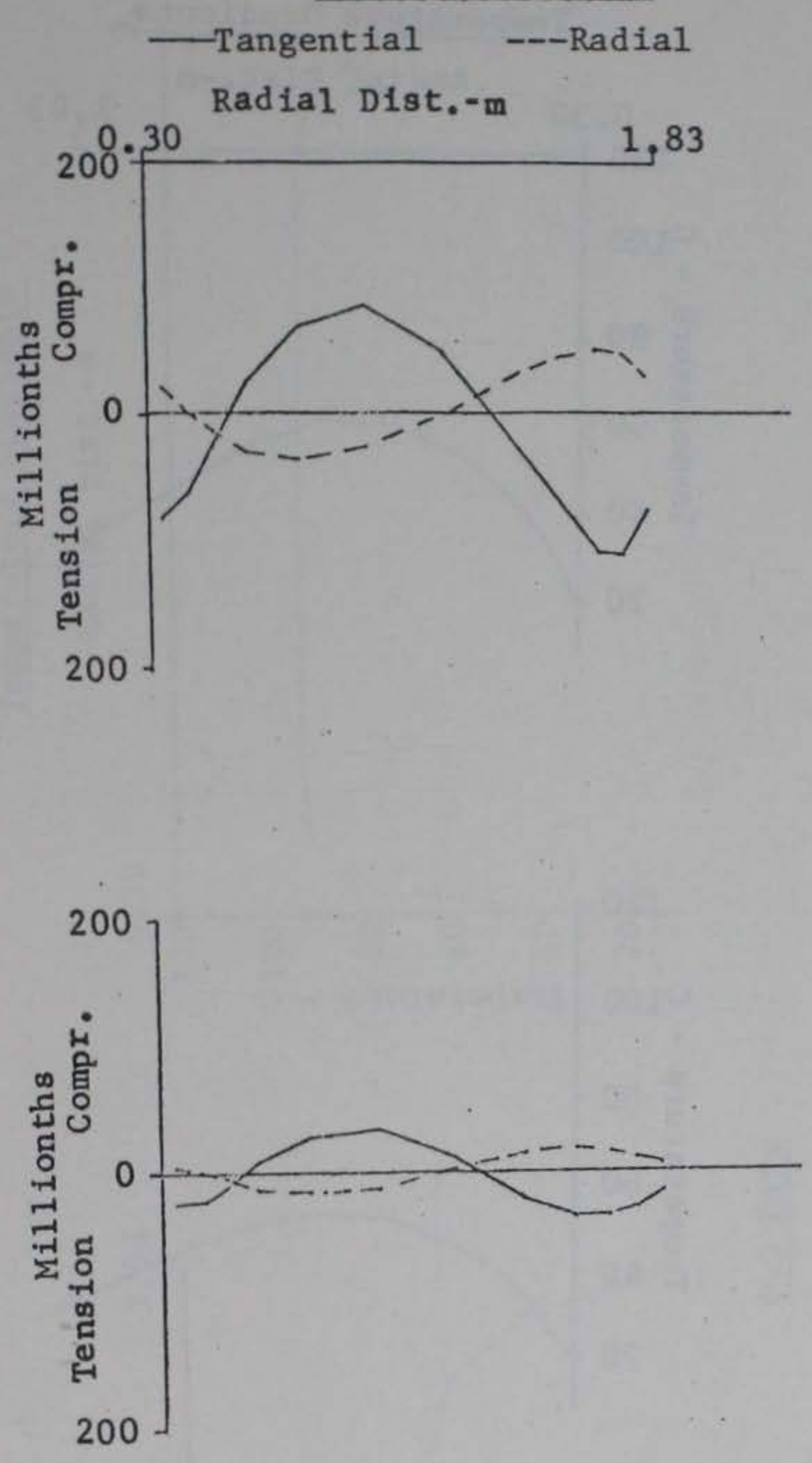

\subsection{Days}

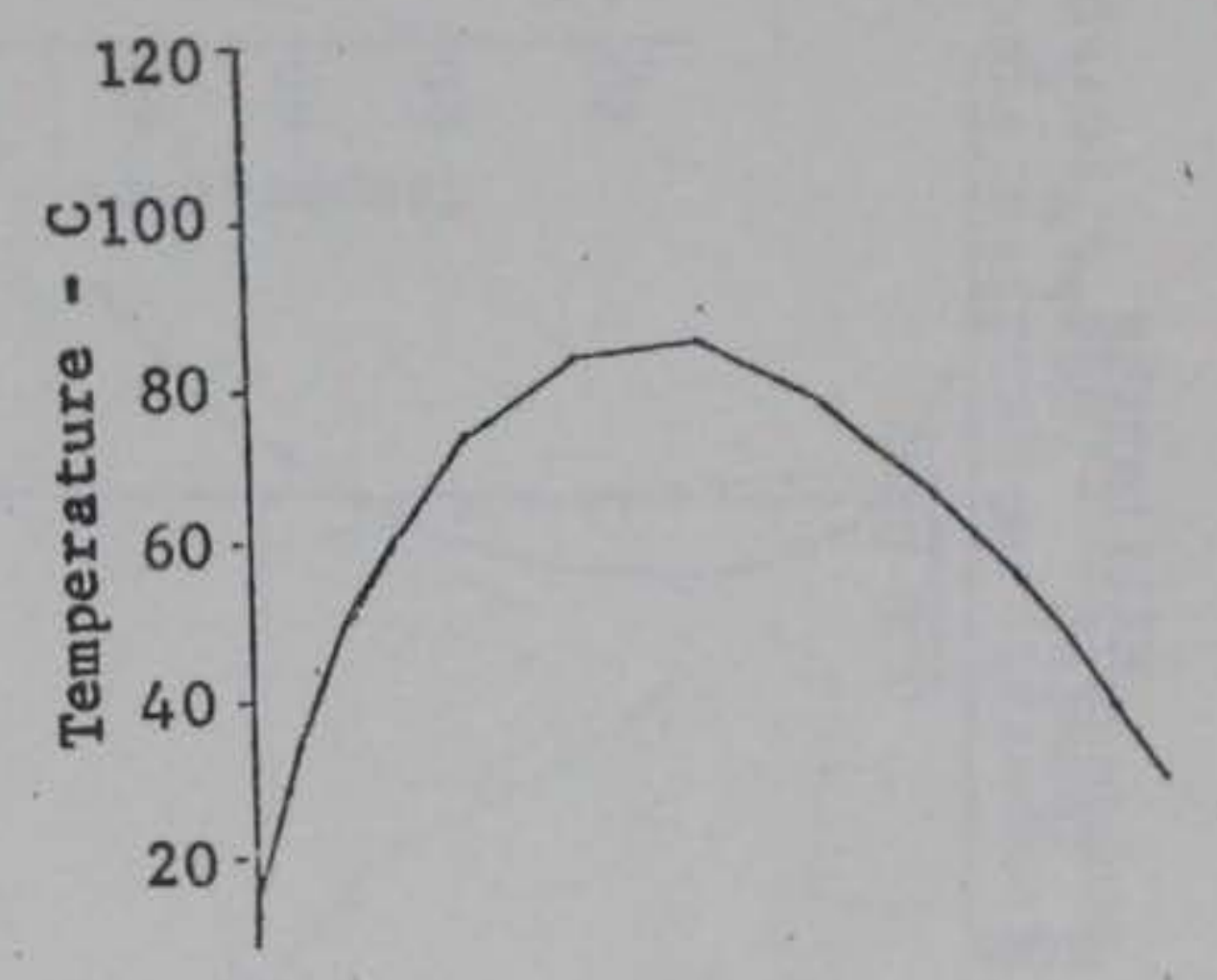

\section{Temperature Grandients}

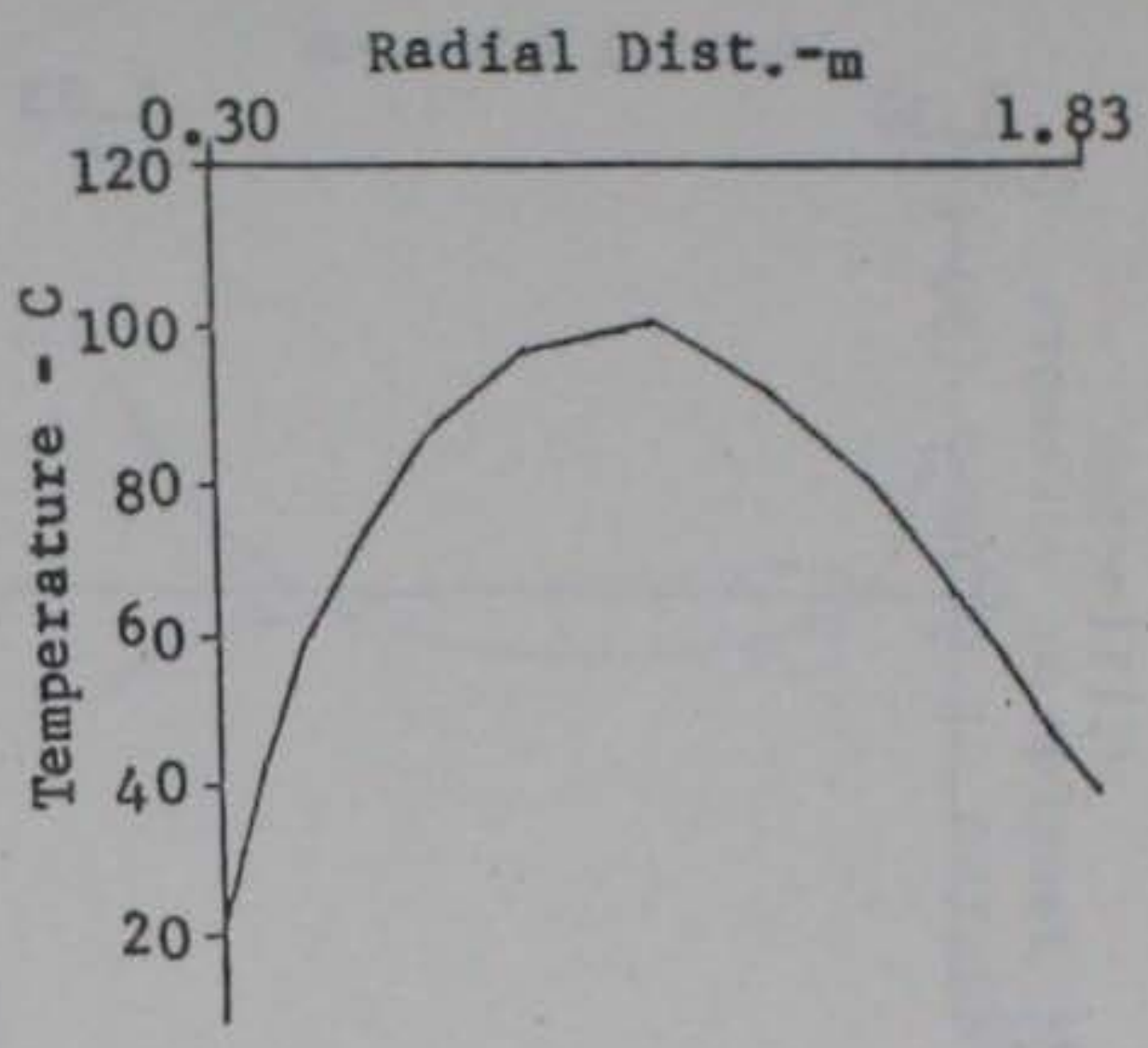

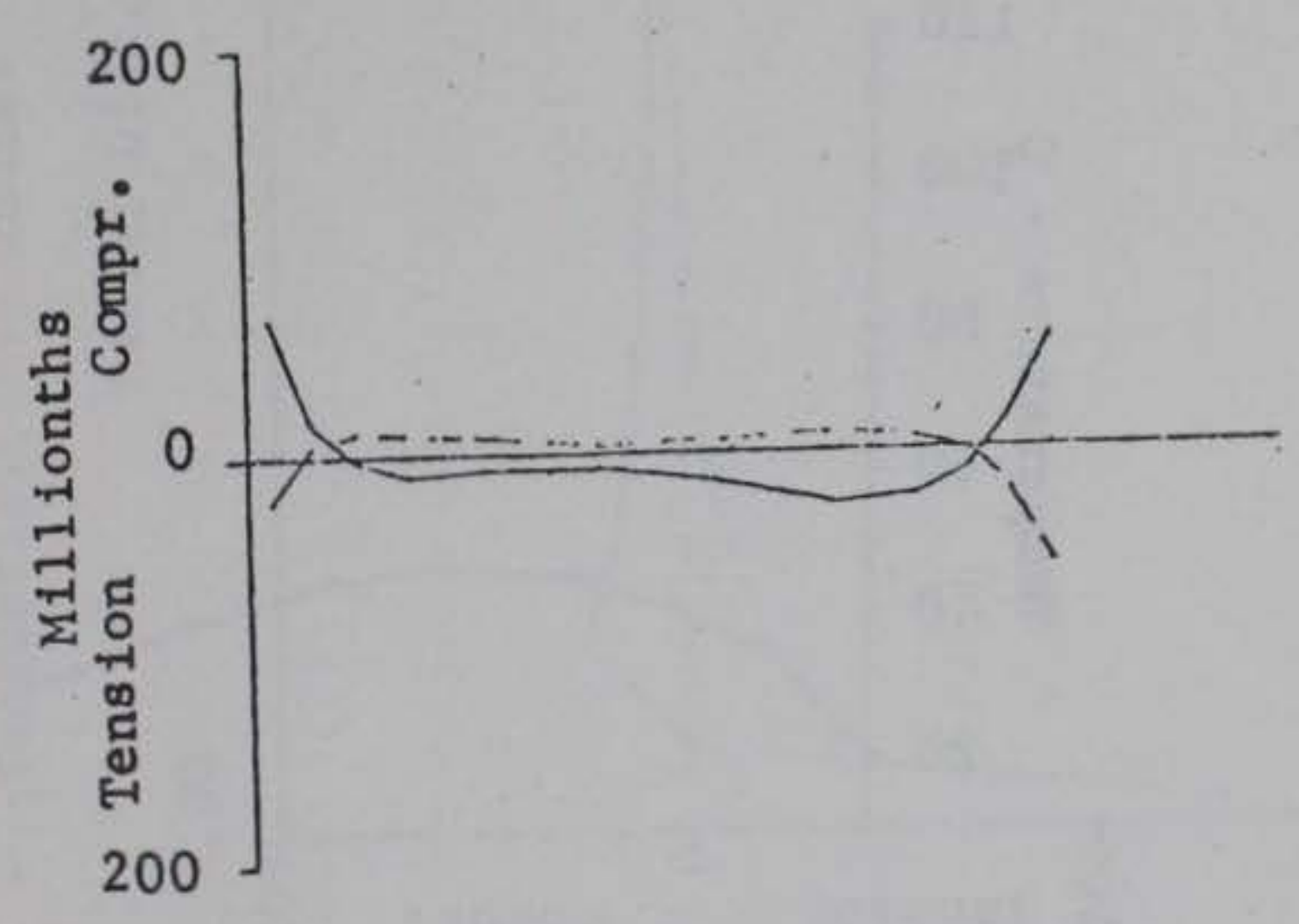

Figure 21. (Sheet 2 of 3 ) 
Strain Gradients
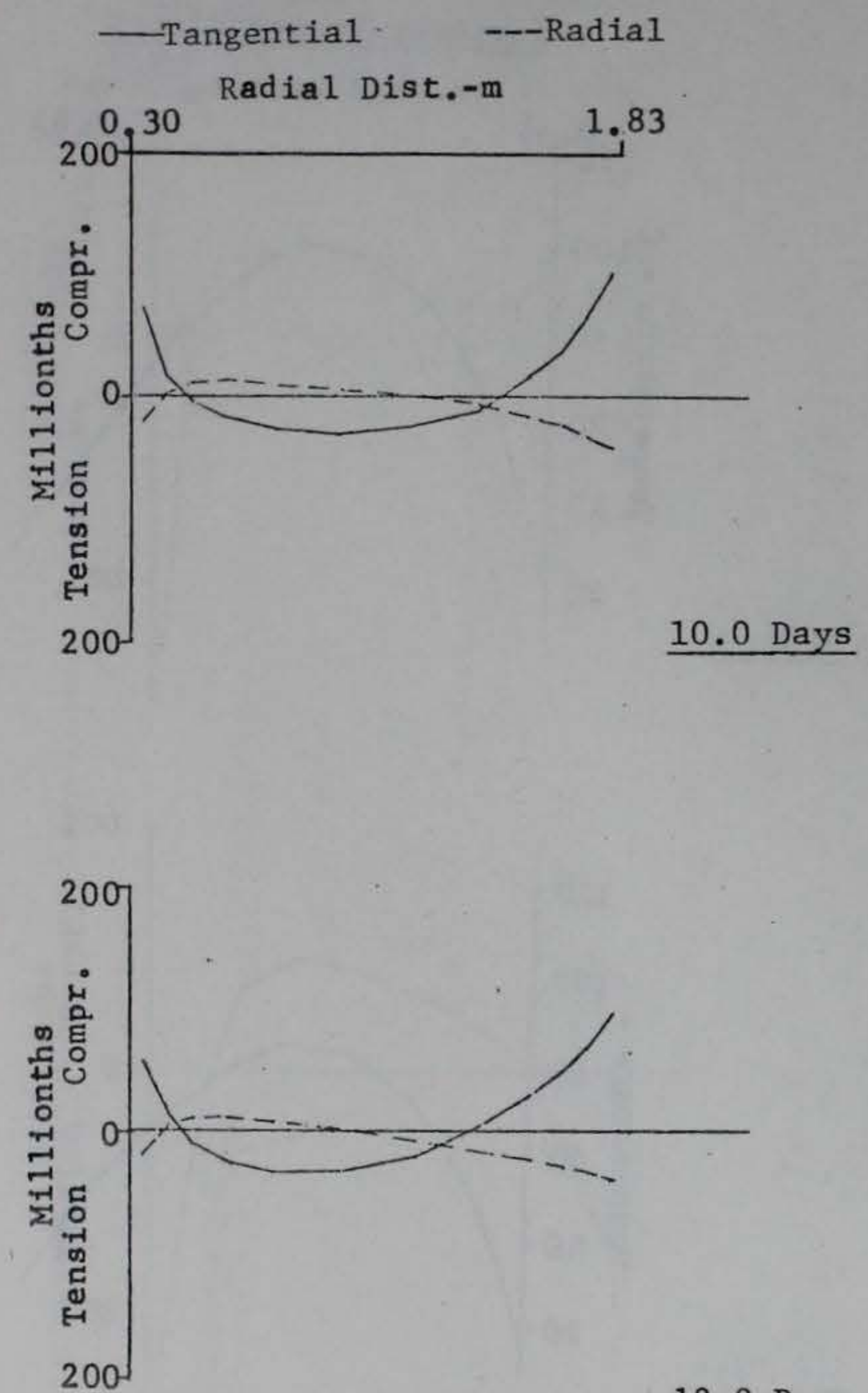

12.0 Days

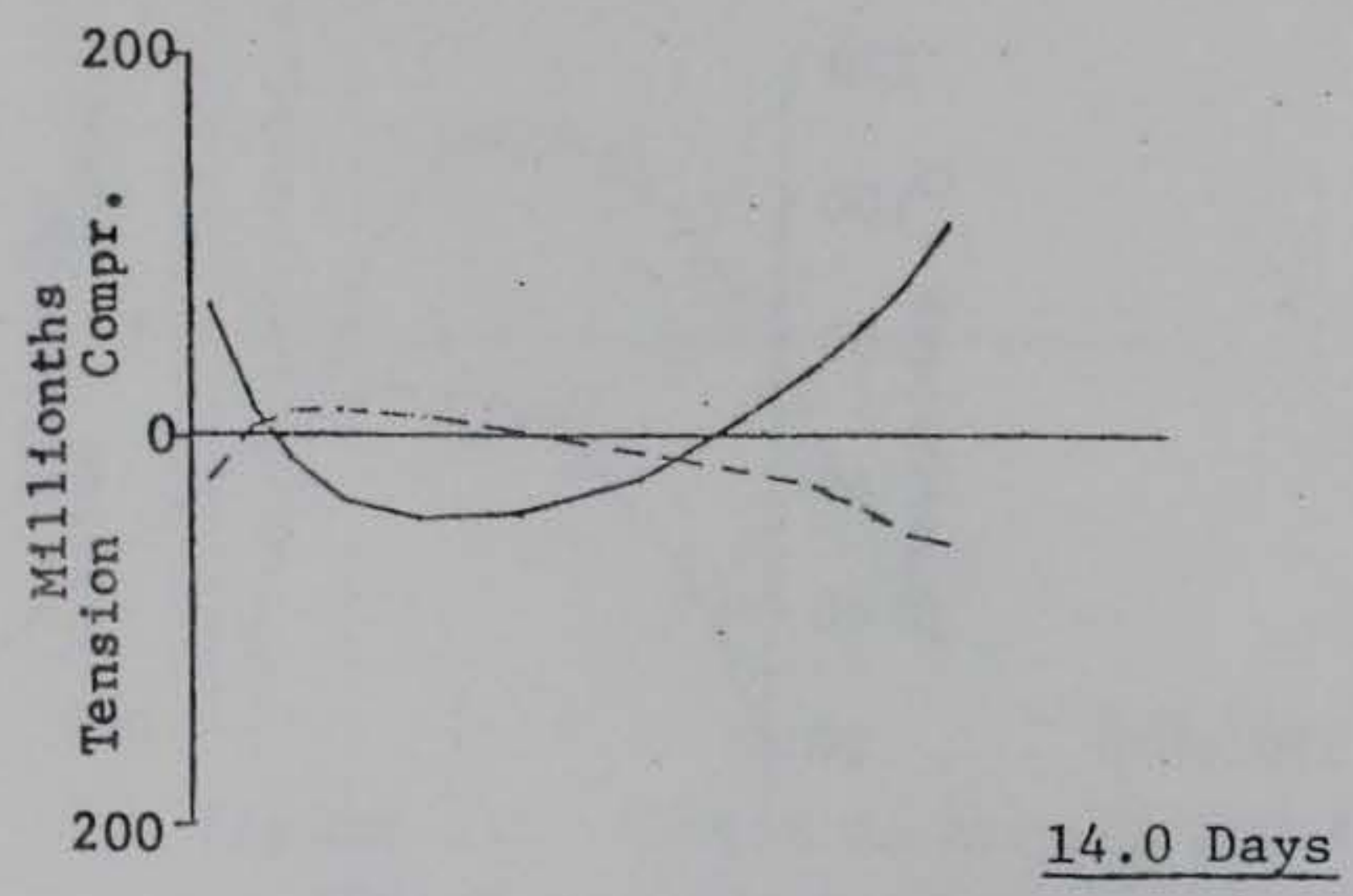

Temperature Gradients
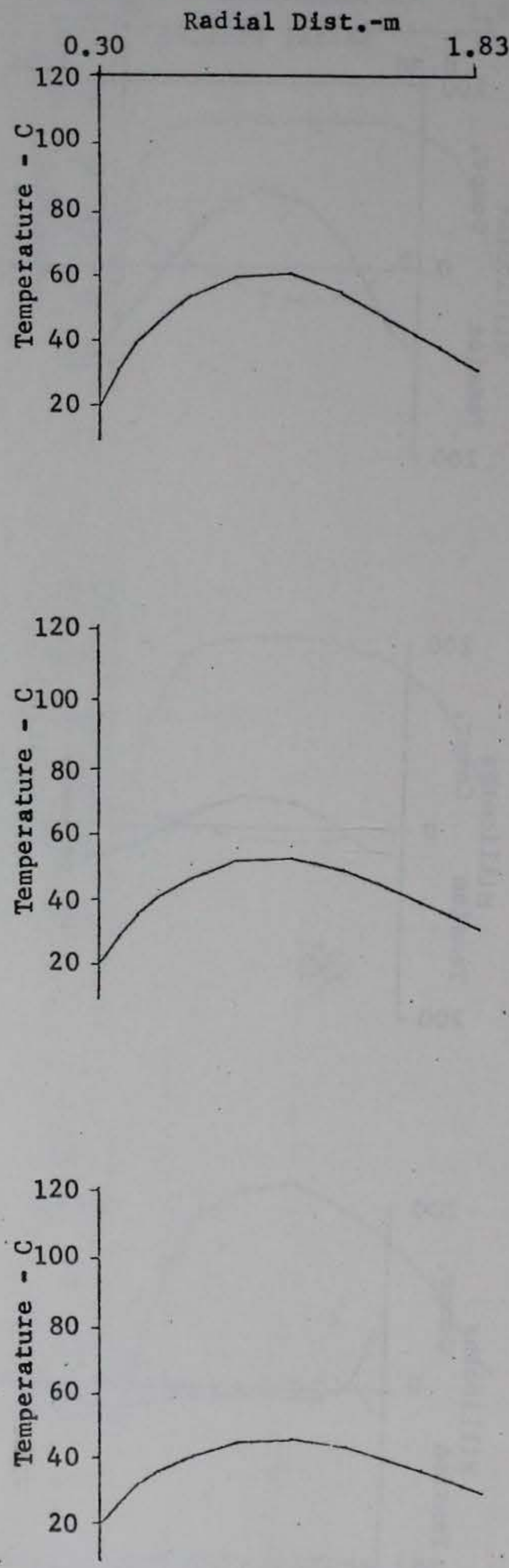

Figure 21. (Sheet 3 of 3 ) 
-Tangential, ---Radia1

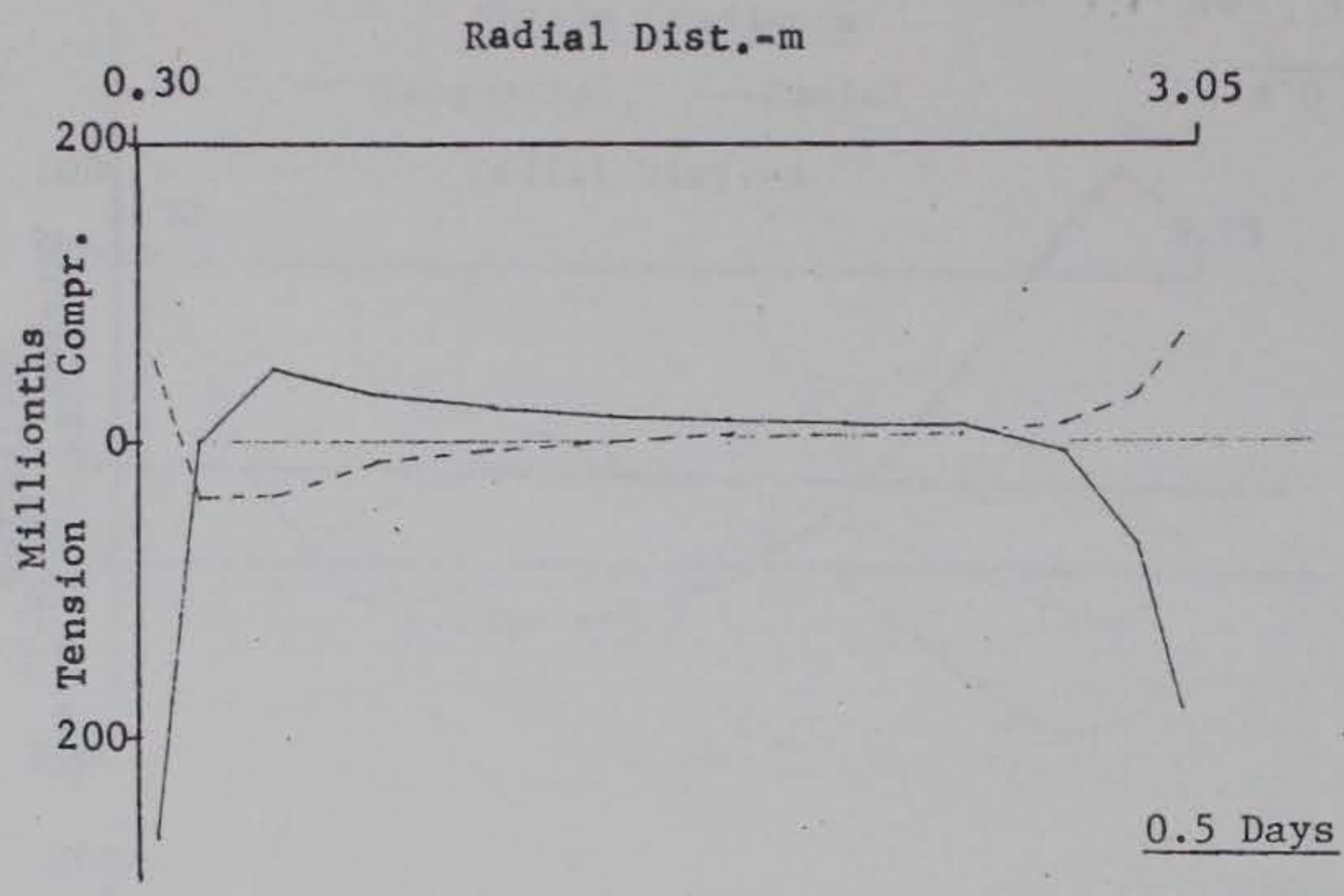

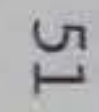

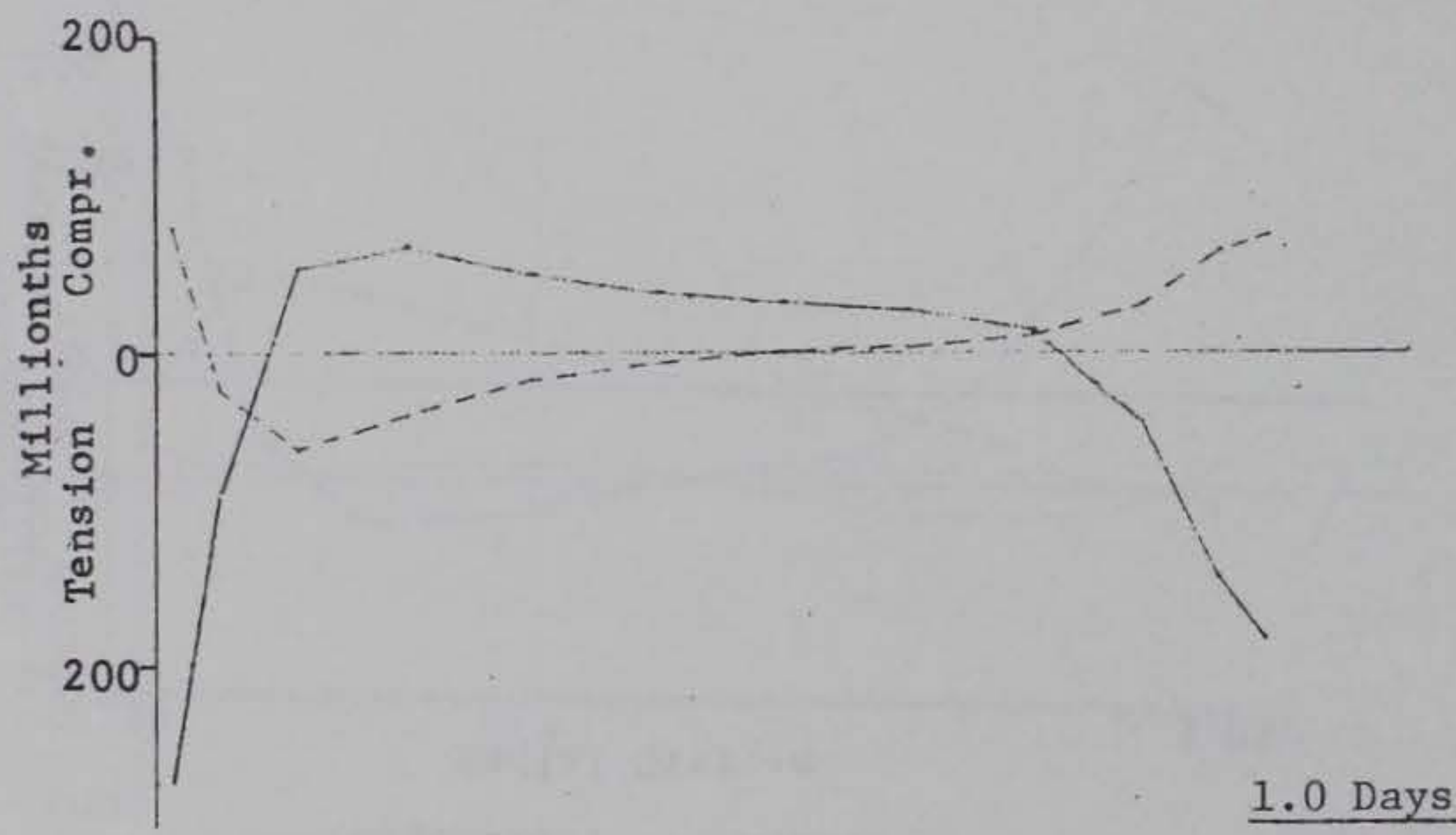

Figure 22. Computed strain and temperature gradients across the radius of $6.10-\mathrm{m}(20-\mathrm{ft})$ diameter cylinder at successive times after placement (Sheet 1 of 4)
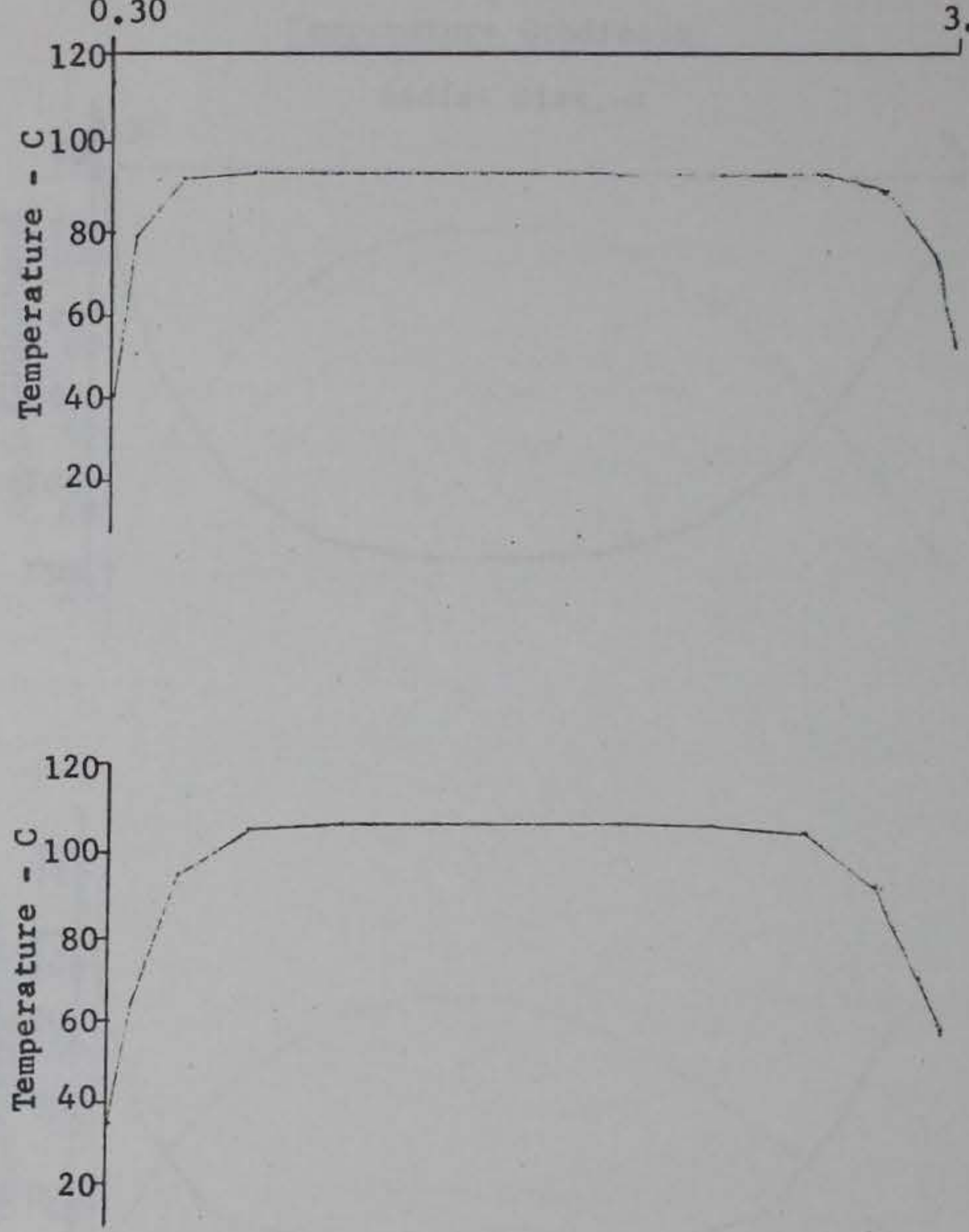

3.05

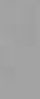




\section{$\underline{\text { Strain Gradients }}$}

- Tangential, ---Radial

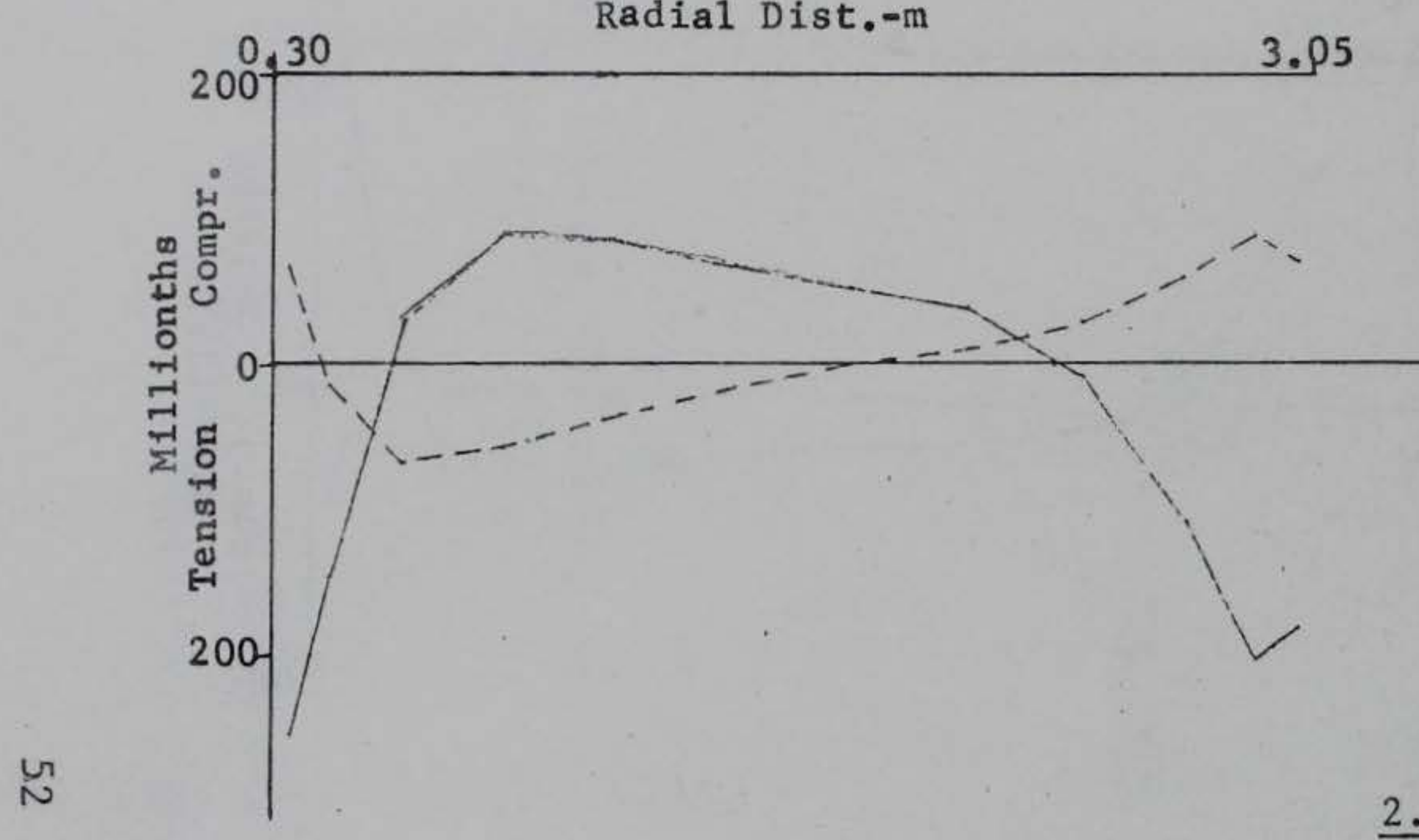

\subsection{Days}

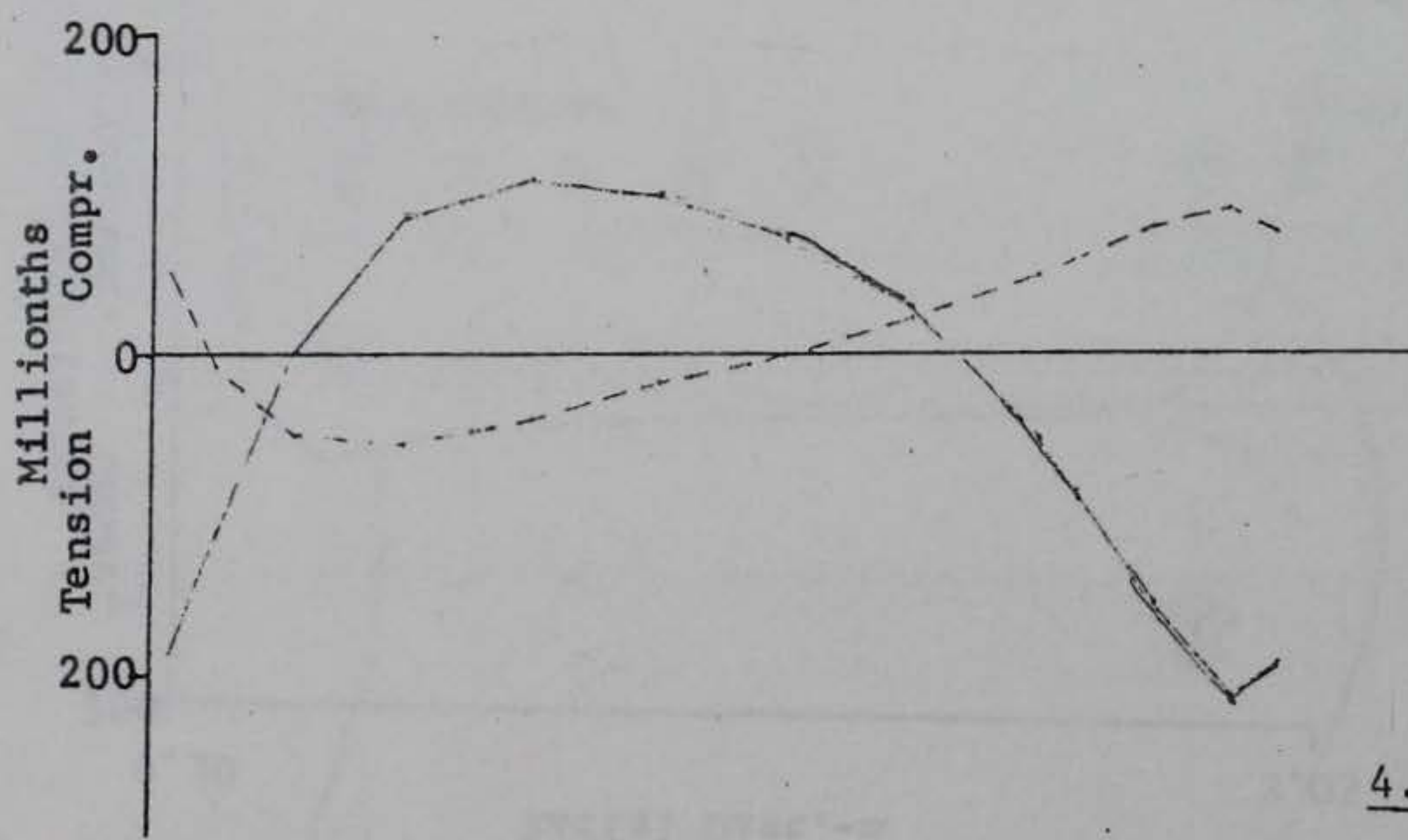

\section{Temperature Gradients}
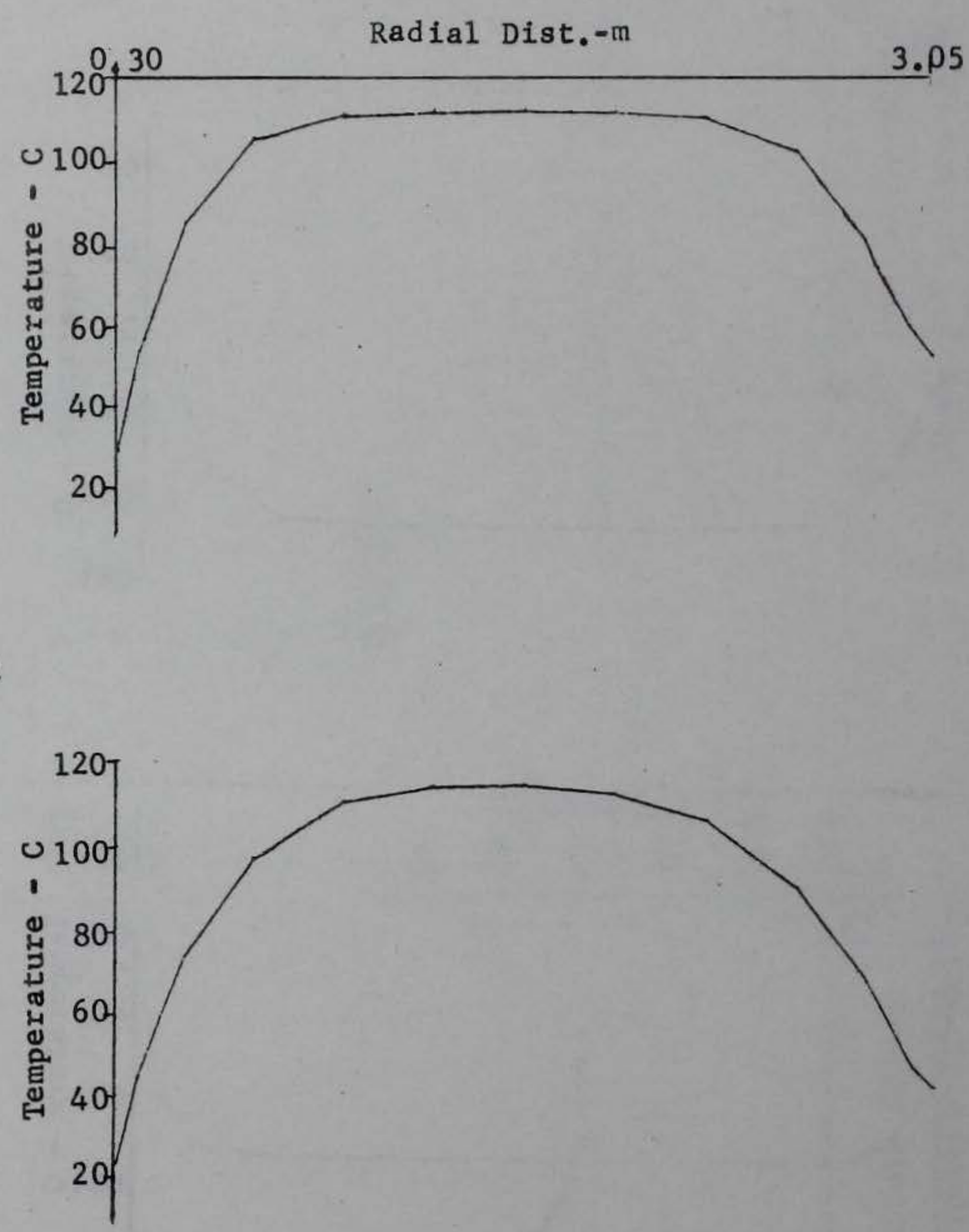

Figure 22. (Sheet 2 of 4 ) 
Strain Gradients

- Tangential, ---Radial

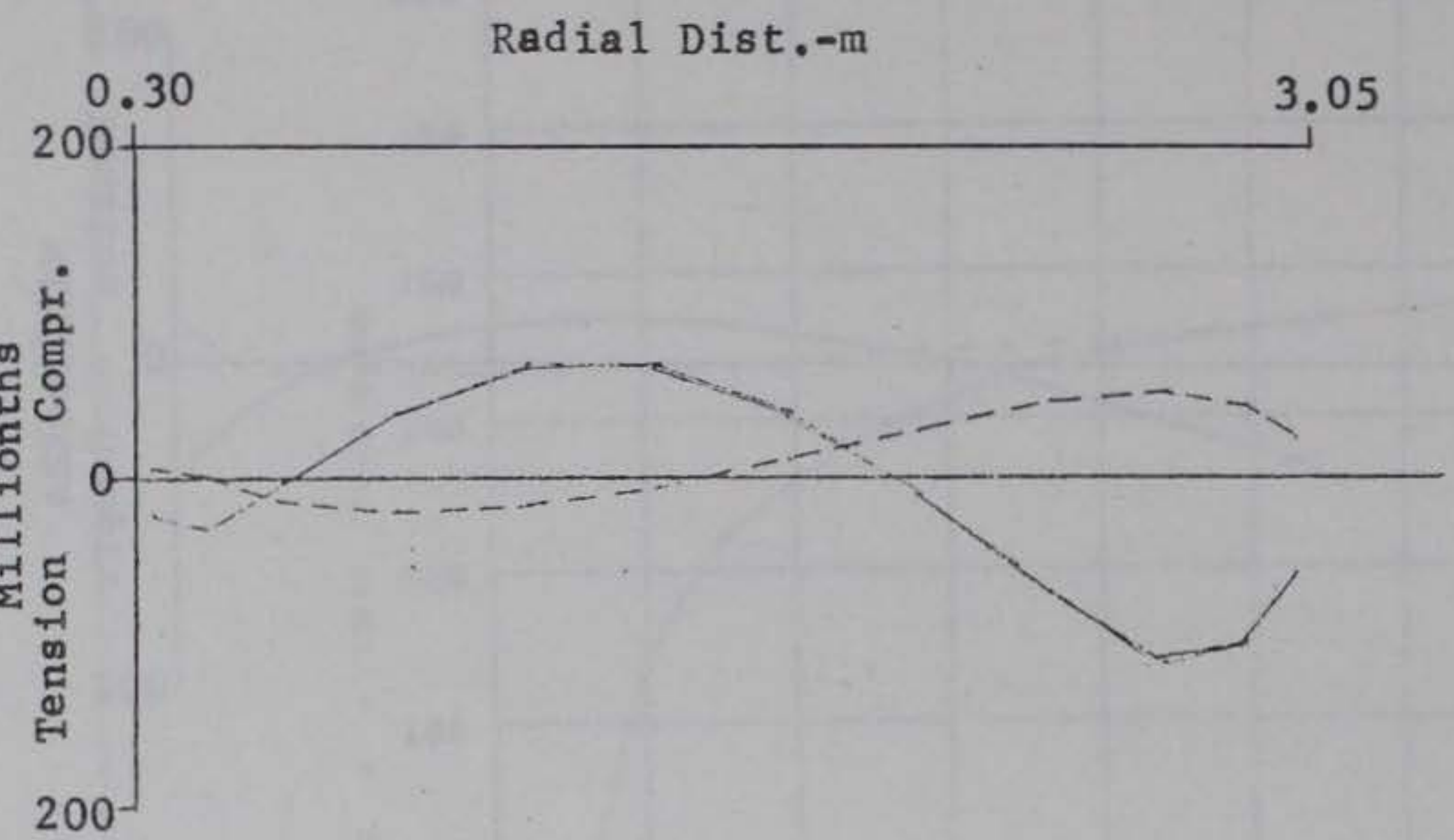

\section{Temperature Gradients}

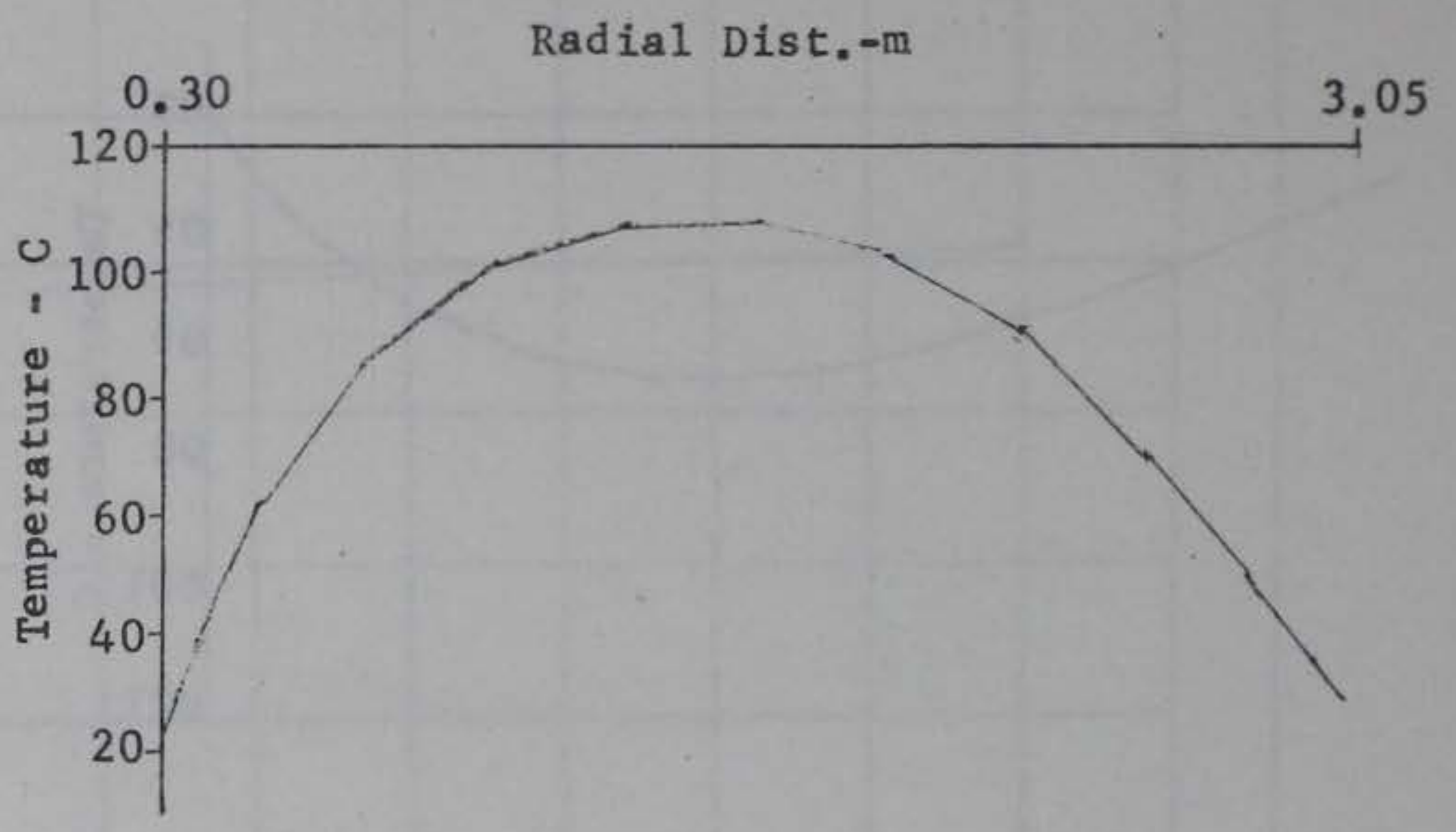

8.0 Days
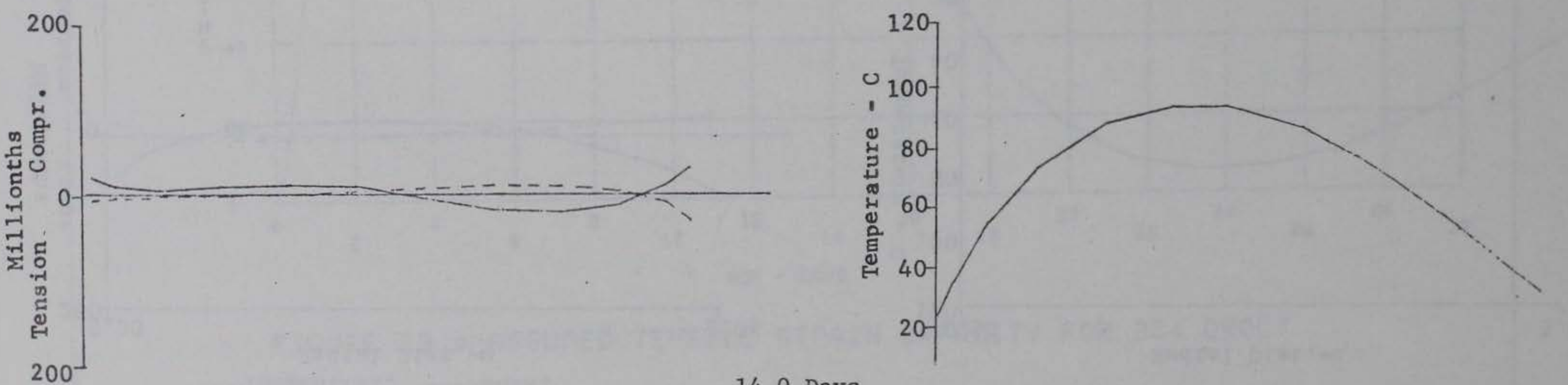

14.0 Days

Figure 22. (Sheet 3 of 4 ) 
Strain Gradients

-Tangential, ---Radial

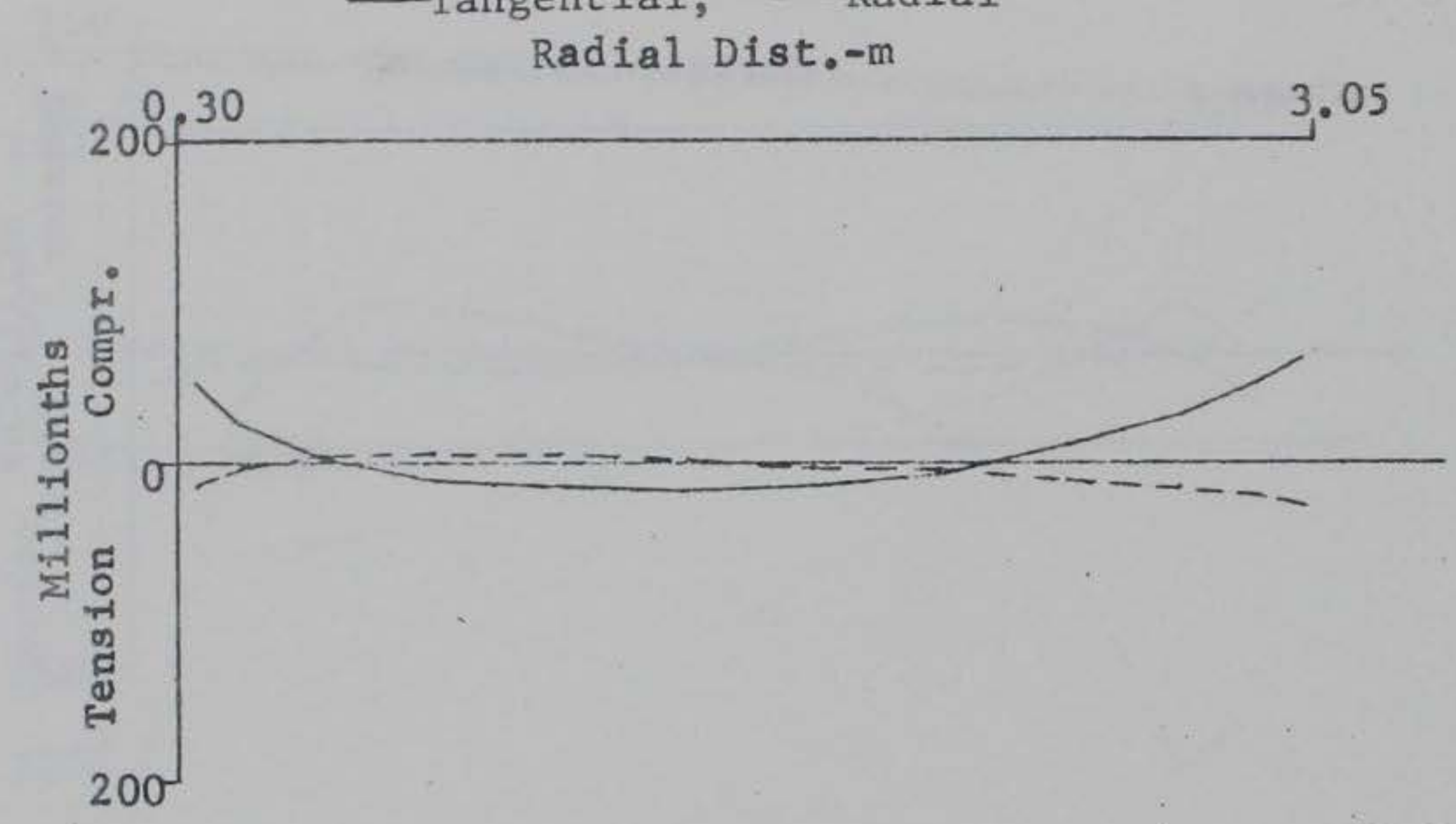

Temperature Gradients

Radial Dist. $-\mathrm{m}$

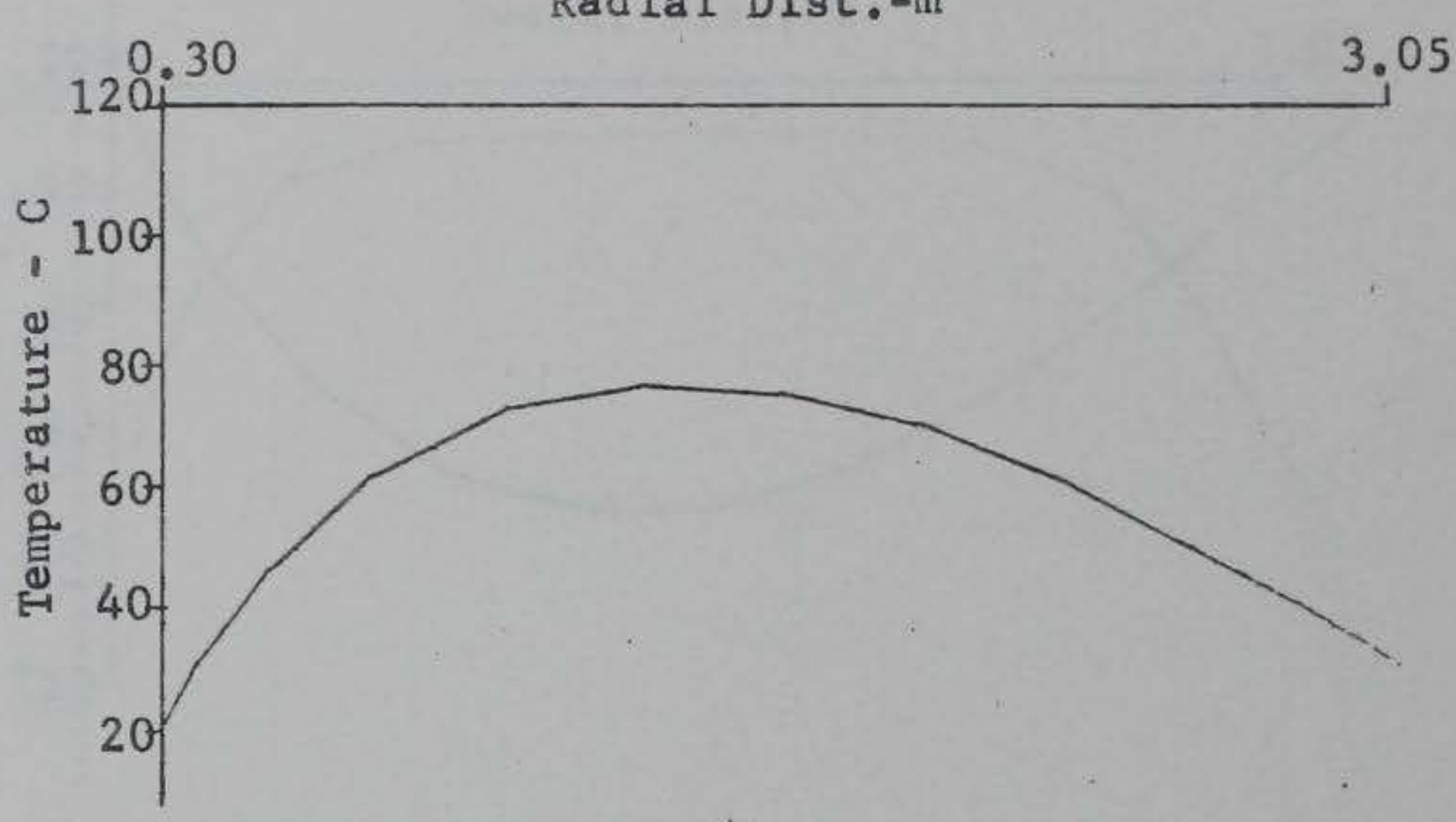

22.0 Days
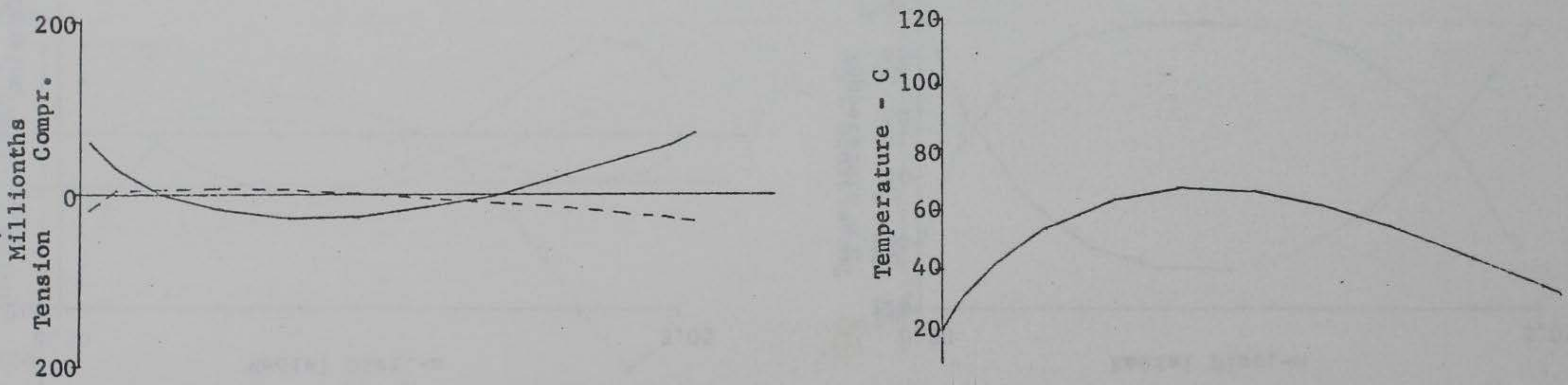

28.0 Days

Figure 22. (Sheet 4 of 4 ) 


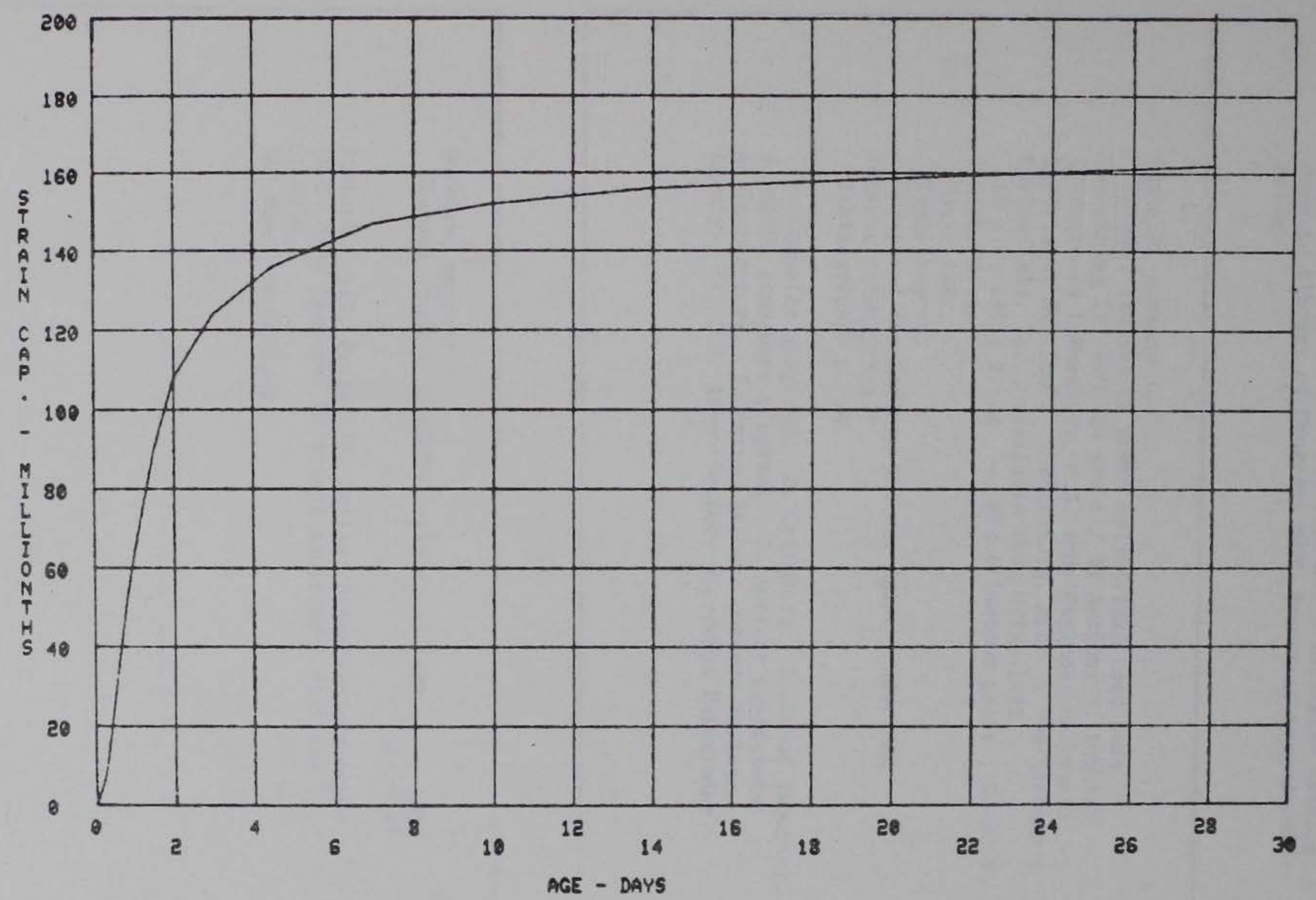

FIGURE 23 - ASSUMED TENSILE STRAIN CAPACITY FOR $2 C 4$ GROUT 